Universidade de São Paulo

Faculdade de Filosofia, Ciências e Letras de Ribeirão Preto

Departamento de Química

Programa de Pós-Graduação em Química

"Atividade peroxinitrito redutase de tiol peroxidases em células."

André Luís Condeles

Dissertação apresentada à Faculdade de Filosofia, Ciências e Letras de Ribeirão Preto da Universidade de São Paulo, como parte das exigências para a obtenção do título de Mestre em Ciências, Área: Química

RIBEIRÃO PRETO - SP 


\section{ANDRÉ LUÍS CONDELES}

\section{Versão corrigida}

"Atividade peroxinitrito redutase de tiol peroxidases em células"

Dissertação apresentada à Faculdade de Filosofia, Ciências e Letras de Ribeirão Preto da Universidade de São Paulo, como parte das exigências para a obtenção do título de Mestre em Ciências.

Área: Química

Orientador: Prof. Dr. José Carlos Toledo Junior

RIBEIRÃO PRETO - SP 
Autorizo a reprodução e divulgação total ou parcial deste trabalho, por qualquer meio convencional ou eletrônico, para fins de estudo e pesquisa, desde que citada a fonte.

FICHA CATALOGRÁFICA

Condeles, André Luís

Atividade peroxinitrito redutase de tiol peroxidases em células. Ribeirão Preto, 2017.

80 p. : il. ; $30 \mathrm{~cm}$

Dissertação de Mestrado, apresentada à Faculdade de Filosofia, Ciências e Letras de Ribeirão Preto/USP - Área de concentração: Química. 
Nome: Condeles, André Luís

Título: "Atividade peroxinitrito redutase de tiol peroxidases em células"

Dissertação apresentada à Faculdade de Filosofia, Ciências e Letras de Ribeirão Preto da USP, como parte das exigências para obtenção do título de Mestre em Ciências.

Aprovado em:

Banca Examinadora

Prof. Dr. Instituição:

Julgamento:

Assinatura:

Prof. Dr. Instituição:

Julgamento:

Assinatura:

Prof. Dr. Instituição:

Julgamento: Assinatura:

Prof. Dr. Instituição:

Julgamento: Assinatura: 
Dedicatória

Dedico este trabalho à minha família e amigos que sempre me incentivaram a persistir. 


\section{AGRADECIMENTOS}

Ao meu orientador Prof. Dr. José Carlos Toledo Junior, pela oportunidade, orientação, por tudo que me ensinou, e pela conversa jogada fora nos momentos do cafezinho.

À minha Família, pelo apoio psicossocial e financeiro nos momentos difíceis. Aos colegas, Angélica, Fernando Damasceno, Fernando Aranha, Gisdélia, Jesimiel e Laura.

Às colegas de laboratório que me suportaram, Caroline, Cristina, Dayane, Fernanda, Giuliana e Roberta.

À professora Maria Lúcia Arruda Moura Campos.

Às pessoas que contribuíram diretamente com o projeto, ao Prof. Dr. Luis Eduardo

Soares Netto por fornecer as cepas para o estudo, e aos integrantes do grupo CEPID-REDOXOMA pelas discussões e ideias.

Ao Prof. Dr. João Atílio Jorge, por disponibilizar o laboratório durante este período e também pelo o que me ensinou de microbiologia.

Aos colegas, funcionários, técnicos e afins dos Departamentos de Química e de Biologia.

Ao programa de Pós-graduação em Química. À Fapesp pelo financiamento do projeto. À CAPES pela bolsa concedida. 


\section{RESUMO}

CONDELES, A. L. Atividade peroxinitrito redutase de tiol peroxidases em células. 2017. 74 f. Dissertação (Mestrado) - Faculdade de Filosofia, Ciências e Letras de Ribeirão Preto, Universidade de São Paulo, São Paulo, 2017

A família Tiol Peroxidases (TPxs - Peroxirredoxinas e Glutationa peroxidases) purificadas definitivamente reduzem peróxidos rapidamente (peroxinitrito, $\mathrm{ONOOH} / \mathrm{ONOO}^{-}$; peróxido de hidrogênio, $\mathrm{H}_{2} \mathrm{O}_{2}$ ), mas nenhuma evidência direta desta atividade foi demonstrada em células vivas. Isto é particularmente importante pois o ciclo catalítico da atividade peróxido redutase de TPxs depende de sucessivas reações de trocas de tióis que podem limitar a velocidade de redução do peróxido. Neste trabalho, esta questão foi investigada em Saccharomyces cerevisiae (Sc) por meio de cinética de competição com um indicador fluorescente que é específico para $\mathrm{ONOO}^{-}$(ácido borônico de cumarina; CBA), com a expectativa de que quanto maior a atividade peroxinitrito redutase, menor a oxidação do indicador. Também foi investigado o papel de duas peroxirredoxinas (Prxs) específicas na remoção deste peróxido. O estudo mostrou que a oxidação do indicador CBA dependente de $\mathrm{ONOO}^{-}$ foi sempre significativamente maior em células de Saccharomyces cerevisiae deficientes em TPxs (cepa $\Delta 8$ ) relativo a cepa nativa (WT). Além disso, a transfecção do gene que codifica a Prx mais abundante em Saccharomyces cerevisiae (Tsa1) na cepa $\Delta 8$ diminui parcialmente a oxidação de CBA. Além disso, a oxidação de CBA foi maior na cepa deficiente apenas da peroxirredoxina Tsa1 (a mais abundante da família) relativo à cepa WT, mostrando a relevância desta isoforma especificamente. De forma adversa, a oxidação de CBA na cepa deficiente da peroxirredoxina Tsa2 foi semelhante à cepa WT. Também, foi constatado que o processo de remoção de $\mathrm{ONOO}^{-}$é catalítico (e não estequiométrico) para crescentes fluxos de peroxinitrito em todas as cepas e condições utilizadas no estudo. Finalmente, o estudo sugere que células possuem sistemas catalíticos peroxinitrito redutase redundantes, já que a própria cepa $\Delta 8$ apresenta e pode modular esta atividade. Estes resultados confirmam a expectativa da relevância de TPxs na remoção de $\mathrm{ONOO}^{-}$e por extensão de outros peróxidos biologicamente relevantes e são a primeira evidência direta e em tempo real da atividade peroxinitrito redutase de TPxs em células. 
Palavras-chave: Peroxirredoxinas (Prxs), peroxinitrito, Saccharomyces cerevisiae $(S c)$, tiol peroxidases, boronatos 


\section{ABSTRACT \\ CONDELES, A. L. Peroxynitrite reductase activity of thiol peroxidases in cells.}

2017. 74 f. Dissertação (Mestrado) - Faculdade de Filosofia, Ciências e Letras de Ribeirão Preto, Universidade de São Paulo, São Paulo, 2017

The purified Thiol Peroxidases family (TPxs - Peroxiredoxins and Glutathione peroxidases) rapidly reduces peroxides (peroxynitrite, $\mathrm{ONOOH} / \mathrm{ONOO}^{-}$, hydrogen peroxide, $\mathrm{H}_{2} \mathrm{O}_{2}$ ), but no direct evidence of this activity has been demonstrated in living cells. This is particularly important since the catalytic cycle of the TPxs peroxide reductase activity depends on successive thiol exchange reactions, which may limit the rate of peroxide reduction. In this work, this question was investigated in Saccharomyces cerevisiae (Sc) by competition kinetics using a fluorescent indicator that is specific for ONOO- (coumarin boronic acid; CBA). It is expected that the higher the peroxynitrite reductase activity, the lower the oxidation of the indicator. The role of two specific peroxiredoxins (Prxs) in the removal of this peroxide has also been investigated. The study showed that the oxidation of ONOO- dependent CBA indicator was always significantly higher in TPxs-deficient Saccharomyces cerevisiae cells (strain $\Delta 8$ ) compared to the native strain (WT). In addition, the transfection of the gene encoding the most abundant Prx into Saccharomyces cerevisiae (Tsa1) in the $\Delta 8$ strain partially diminishes CBA oxidation. Besides that, CBA oxidation was greater in the deficient strain only of the peroxiredoxin Tsa1 (the most abundant in the family) compared to the WT strain, showing the relevance of this isoform specifically. On the other hand, CBA oxidation in the deficient strain of the Tsa2 peroxiredoxin was similar to the WT strain. Also, it was found that the ONOO- removal process is catalytic (and not stoichiometric) for increasing peroxynitrite fluxes in all strains and conditions used in the study. Finally, the study suggests that cells have redundant peroxynitrite reductase catalytic systems, since the $\Delta 8$ strain itself presents and can modulate this activity. These results confirm the expectation of the relevance of TPxs in the removal of $\mathrm{ONOO}^{-}$and by extension of other biologically relevant peroxides and are the first direct and real-time evidence of peroxynitrite reductase activity of TPxs in cells.

Keywords: Peroxiredoxins (Prxs), peroxynitrite, Saccharomyces cerevisiae (Sc), thiol peroxidases, boronates. 


\section{LISTA DE FIGURAS}

Figura 1 -Representação genérica dos sistemas redutores tioredoxina (Trx) e

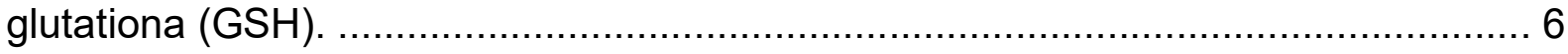

Figura 2 - Representação genérica do ciclo catalítico de Peroxirredoxinas. ........... 10

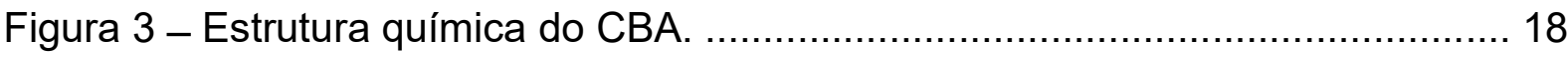

Figura 4 -Mecanismo de reação entre boronatos e peroxinitrito. .......................... 19

Figura 5 -Modelo de competição entre os principais alvos endógenos por peroxinitrito.

Figura 6 - Construção do plasmídeo e expressão da enzima Tsa1 na cepa $\Delta 8+$ Tsa1

Figura 7 - Curva de crescimento das cepas WT e $\Delta 8$.

Figura 8 - Produção de ONOO- por SIN-1. 28

Figura 9 - Esquema do ciclo redox do Paraquat. 29

Figura 10 - Oxidação do indicador CBA em células utilizando a combinação paraquat/doador de $\mathrm{NO} \bullet$ ou SIN-1.

Figura 11 - Oxidação e taxa de oxidação de CBA em função de parâmetros importantes. 35

Figura 12 - Oxidação de CBA na presença do competidor APBE. 38

Figura 13 - Oxidação do CBA em cepas Sc-WT e Sc- $\Delta 8$ adaptadas em meio suplementado com glicerol. 40

Figura 14 - Atividade peroxinitrito redutase de peroxirredoxinas específicas. 42

Figura 15 - Oxidação do CBA em cepa com transfecção da Tsa1 na cepa $\Delta 8(\Delta 8+T s a 1)$. 44

Figura 16 - Curvas de crescimento das cepas na presença de oxidantes. 46 


\section{LISTA DE ABREVIAÇÕES}

6PG $6 \mathrm{~L}$ 6-fosfoglicono-lactona (6-Phosphoglucono-delta-lactone)

Ahp1 Alquil-hidroperóxido redutase 1 (Alkyl-hydroperoxide redutase 1)

AhpC Alquil-hidroperóxido redutase subunidade C ( Alkyl Hydroperoxide reductase C)

AhpF Flavoproteína Alquil-hidroperóxido redutase subunidade $\mathrm{F}$ (Alkyl hydroperoxide reductase $F$ )

APBE Éster pinacol do ácido 4-acetil-fenil-borónico (4-acetylphenyl boronic acid, pinacol ester)

CBA Ácido borônico de cumarina (coumarin boronic acid)

Ccp1 Citocromo c peroxidase 1 (cytochromo c peroxidase 1)

cGMP Monofosfato de guanosina cíclico (cyclic guanosine monophosphate)

cNOS Óxido nítrico sintase constitutiva (constitutive nitric oxide synthase)

$\mathrm{COH}$ 7-hidroxi-cumarina

$\mathrm{CuOOH}$ hidroperóxido de cumeno

DO600 Densidade Ótica em 600 nm

deta/NO Aduto dietilienotriamina/óxido nítrico (dietilenetriamine/nitric oxide adduct)

eNOS Óxido nítrico sintase endotelial (endothelial nitric oxide synthase)

G6P Glicose-6-Fosfato

G6PD Glicose-6-Fosfato Desidrogenase

GCs Guanilato Ciclase solúvel

GAPDH Gliceraldeído-3-fosfato desidrogenase

GPx Glutationa Peroxidase

GPxs Glutationa Peroxidases

GPX2 Glutationa Peroxidase 2 (Glutathione peroxidase 2)

GSH Glutationa

GR Glutationa redutase

IL-1 1 Interleucina 1 beta

iNOS Óxido nítrico sintase induzível (inducible nitric oxide synthase)

DMSO Dimetilsulfóxido 
DTPA Ácido pentacético de dietilenotriamina (dietilenetriamine pentaacetic acid)

LOO• Radical peroxila lipídico

$\mathrm{LOOH} \quad$ Hidroperóxido de lipídios

LPS Lipopolissacarídios

NADPH Fosfato de nicotinamida adenina dinucleótido

nNOS Óxido nítrico sintase neuronal (neuronal nitric oxide synthase)

NO• Radical óxido nítrico (Nitric oxide radical)

$\mathrm{O}_{2}^{-\bullet} \quad$ Ânion radical superóxido (superoxide radical anion)

PPP Via da pentose fosfato (Pentose Phosphate Pathway)

Prx Peroxirredoxina

Prxs Peroxirredoxinas

RNS Espécies reativas de nitrogênio (Reactive nitrogen species)

ROS Espécies reativas de oxigênio (Reactive oxygen species)

Sc Saccharomyces cerevisiae

$\mathrm{SIN}-1 \quad 3-m o r p h o l i n o s y d n o n i m i n e$

SNP Sistema nervoso periférico

SNC Sistema nervoso central

SOD Superóxido dismutase (Superoxide dismutase)

Sper/NO Spermine/NONOate

Srx1 Sulfiredoxina 1 (Sulfiredoxin 1)

t-BOOH Hidroperóxido de terc-butila (terc-butyl hydroperoxide)

TNF- $\alpha \quad$ Fator de necrose tumoral alfa

TPxs Tiol Peroxidases

Trx Tioredoxina

TR Tioredoxina Redutase

Tsa1 Enzima antioxidante tiol-específica 1 citosólica (citosolic thiol-specific antioxidant enzyme 1)

Tsa2 Enzima antioxidante tiol-específica 1 citosólica (citosolic thiol-specific antioxidant enzyme 2)

YPD Extrato de leveduras, peptone e dextrose (Yeast, Peptone and Dextrose)

WT Linhagem nativa (Wild Type) 
6-AN 6-aminonicotinamida (6-aminonicotinamide) 


\section{SUMÁRIO}

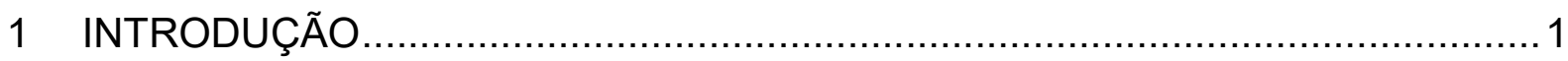

1.1 Fundamentos da Química e Bioquímica de óxido nítrico ........................... 2

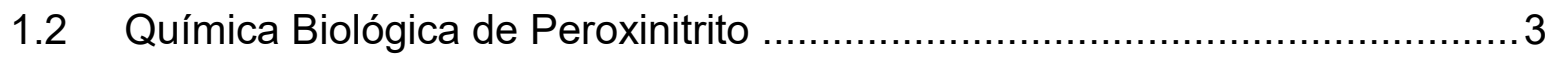

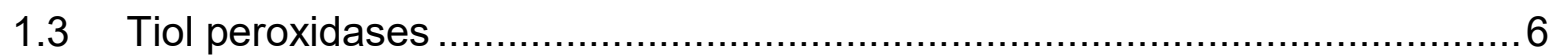

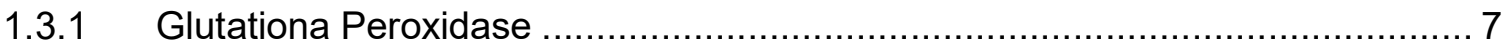

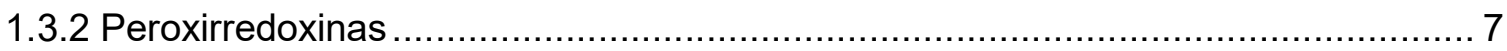

1.3.3 Peroxirredoxinas: estrutura, atividade e funções ......................................... 9

1.4 Atividade peróxido redutase de peroxirredoxinas .................................... 12

1.4.1 A atividade peroxinitrito redutase de Peroxirredoxinas. ............................... 16

1.5 Detecção seletiva de peroxinitrito usando Boronatos. .............................. 18

1.6 Modelo de cinética de competição .....................................................19

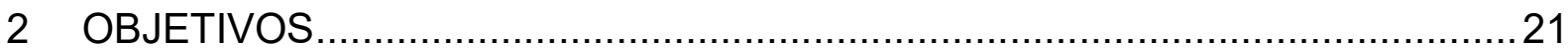

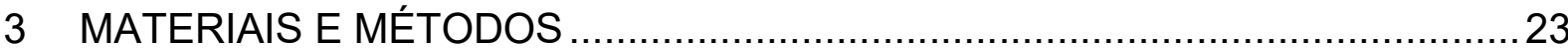

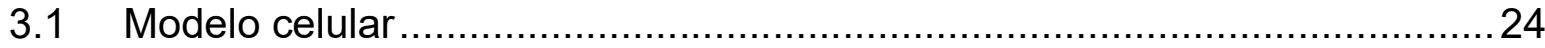

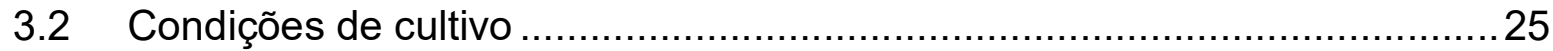

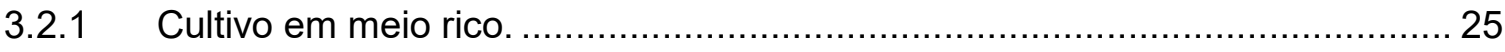

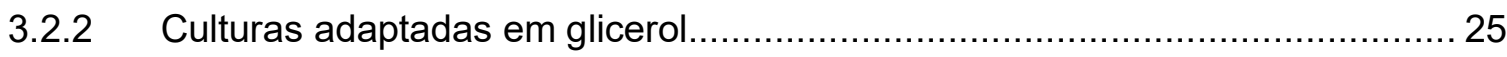

3.2.3 Curvas de crescimento na presença de oxidantes...................................... 26

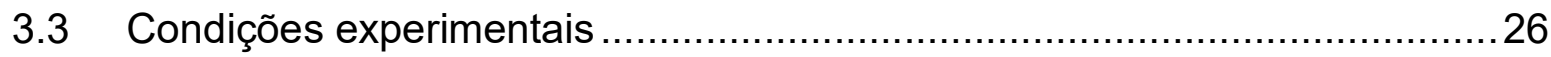

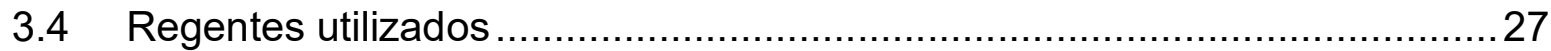

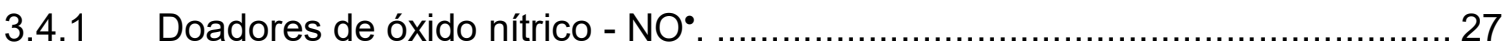

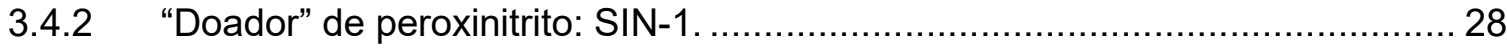

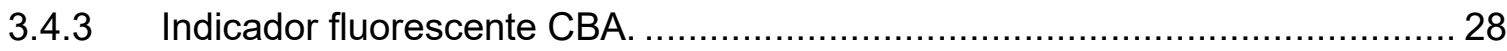

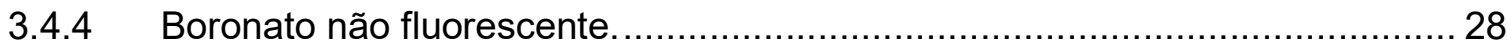

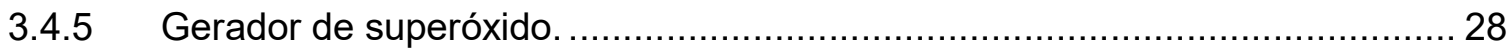

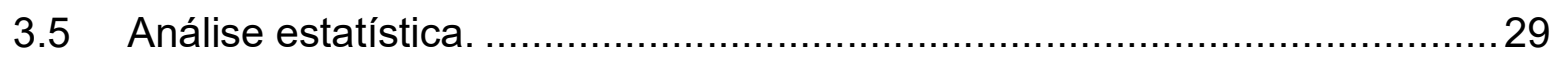

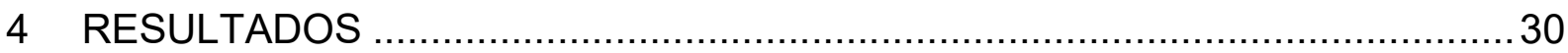

4.1 Oxidação do ácido borônico de cumarina (CBA) nas cepas WT e $\Delta 8$ desafiadas com fluxo de peroxinitrito. 
4.2 Oxidação de CBA em função da densidade celular, concentração do doador

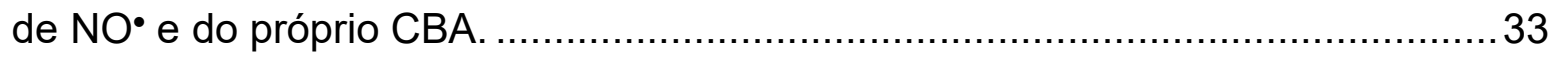

4.3 Oxidação do ácido borônico de cumarina (CBA) depende de peroxinitrito. . 36

4.4 Oxidação de CBA em condições respiratórias. 38

4.5 Avaliação da atividade peroxinitrito redutase de peroxirredoxinas específicas. 40

4.6 Oxidação do CBA na cepa $\Delta 8+$ Tsa1 42

4.7 Curvas de crescimento das cepas mediante exposição a oxidantes.

5 DISCUSSÃO 46

6 CONCLUSÕES 52 
1 INTRODUÇÃO 
1.1 Fundamentos da Química e Bioquímica de óxido nítrico

Monóxido de nitrogênio (óxido nítrico, NO•) é um importante mediador na sinalização e controle de processos biológicos. ${ }^{1 ; 2}$ Essencialmente, estas funções são dependentes da sua interação com metais de transição, principalmente ferro-heme proteínas, mas também cluster de ferro-enxofre e talvez até ferro lábil. ${ }^{3} \mathrm{~A}$ origem celular do $\mathrm{NO}^{\bullet}$, quando se fala em células de mamíferos/eucariontes, é por meio da oxidação do aminoácido L-arginina, produzindo L-citrulina e NO• (Equação 1). ${ }^{4}$

$$
\mathrm{L}-\text { arginina }+\mathrm{O}_{2} \stackrel{\text { NO Sintase }}{\longrightarrow} \mathrm{L}-\text { citrulina }+\mathrm{NO} \cdot
$$

Esse processo oxidativo é complexo e enzimaticamente controlado. Requer vários cofatores enzimáticos, oxigênio $\left(\mathrm{O}_{2}\right)$ e é conduzido por enzimas específicas, óxido nítrico sintases (do inglês, Nitric Oxide Synthase - NOS). ${ }^{4}$ Essas enzimas são divididas em duas classes, constitutiva (cNOS) e induzível (iNOS). Duas isoformas fazem parte da classe cNOS, uma endotelial (eNOS) e outra neuronal (nNOS). Sob estímulo físico (cisalhamento) ou químico (hormônios), NOS endotelial (eNOS) e neuronal (nNOS) de mamíferos, ativadas pelo complexo $\mathrm{Ca}^{2+} /$ Calmodulina (CaM) sintetizam NO•, que por sua vez difunde-se livremente através de tecidos próximos. Em células da musculatura lisa arterial, NO• ativa seu clássico receptor guanilato ciclase solúvel (GCs) pela nitrosilação rápida e reversível de seu grupo ferro-heme.5; 6; 7 Este processo desencadeia transdução de sinais que finalmente resulta no relaxamento muscular e vasodilatação ${ }^{8 ;}{ }^{9}$, inibição da agregação de plaquetas $^{10 ; 11}$ e em miócitos, controla a contração cardíaca ${ }^{12 ;} 13$ além de controlar a demanda de força na musculatura esquelética. ${ }^{14}$ Este processo é fundamental para o funcionamento do sistema cardiovascular e regula a distribuição de oxigênio tecidual por demanda. $A$ isoforma nNOS é normalmente encontrada no cérebro humano (neurônios) e musculatura esquelética, associada a membranas ou estruturas do citoesqueleto. ${ }^{14} \mathrm{O}$ NO• produzido por essa enzima atua como neurotransmissor no sistema nervoso central (SNC) e periférico (SNP) e está associado aos processos de aprendizado e memória. ${ }^{14 ;} 15$ A expressão da isoforma iNOS em células glia e leucócitos é ativada por citocinas como Lipopolissacarídeos (LPS) ou outros agentes como o fator de necrose tumoral alfa (TNF- $\alpha$ ), Interferon gamma (IFN- $\gamma$ ) e Interleucina 1 beta (IL-1 $\beta$ ) em condições patofisiológicas inflamatórias, isquêmicas, e de reposta imunológica. Esta classe de enzimas é naturalmente associada a calmodulina e atua 
independentemente de $\mathrm{Ca}^{2+} .{ }^{14 ;} 15$ Kanadia et. al. ${ }^{16}$ utilizando um anticorpo monoclonal anti-neuronal-NOS de rato, identificaram uma isoforma de NOS constitutiva em Saccharomyces cerevisiae $(S c)$, cuja atividade pode ser inibida ou estimulada da mesma forma que a de mamíferos.

A despeito da noção que sua natureza radicalar possa sugerir, NO• apresenta reatividade limitada a espécies químicas contendo elétrons desemparelhados, como metais de transição e outros radicais livres. Por outro lado, $\mathrm{NO} \bullet$ reage rapidamente e reversivelmente (no caso de metais) com estas classes de compostos. Estas propriedades conferem a rapidez, a reversibilidade e sobretudo a seletividade exigida em sinalização biológica. Isto explica a evolução de receptores específicos de NO• como GCs, que é responsável pelo controle de várias funções biológicas atribuídas a NO*

As reações de $\mathrm{NO}^{\bullet}$ com outros radicais são rápidas, mas não oferecem oportunidades óbvias para transdução de sinais. Dependendo da situação estas recombinações radicalares podem até ser benéficas quando resultam na terminação de processos radicalares oxidativos, como tem sido sugerido para recombinação de NO• e radicais lipídicos. ${ }^{17 ;} 18$ Esta terminação poderia interromper processo de degradação oxidativa de membranas biológicas, que pode levar ao desenvolvimento de arteriosclerose. Contudo, reações com radicais geralmente são maléficas. Nesta última categoria a recombinação com o ânion radical superóxido $\left(\mathrm{O}_{2}{ }^{\bullet-}\right)$ é inquestionavelmente a mais importante no contexto biológico. Nenhum dos radicais é perigoso individualmente, mas esta recombinação (Equação 2) ocorre com velocidade próxima ao limite difusional $\left(\mathrm{k}=1,9 \times 10^{9} \mathrm{M}^{-1} \mathrm{~s}^{-1}\right)^{19}$ e produz o forte e reativo oxidante peroxinitrito $\left(\mathrm{ONOOH} / \mathrm{ONOO}^{-}, \mathrm{pKa}=6,9\right.$ a $\left.37^{\circ} \mathrm{C}\right) .{ }^{20}$

$$
\mathrm{NO}+\mathrm{O}_{2}^{\cdot-} \rightarrow \mathrm{ONOO}^{-}
$$

\subsection{Química Biológica de Peroxinitrito}

Peroxinitrito reage diretamente com alvos biológicos e sofre decomposição homolítica promovida pela protonação ou por reação com dióxido de carbono $\left(\mathrm{CO}_{2}\right)$. Estequiometricamente, estas reações resultam na produção fenomenológica de 1/3 de radicais livres ainda mais reativos, como dióxido de nitrogênio $\left(\mathrm{NO}_{2}{ }^{\circ}\right)$, ânion radical carbonato $\left(\mathrm{CO}_{3}{ }^{\bullet-}\right)$ e radical hidroxila $\left(\mathrm{OH}^{\bullet}\right)^{21}$ (Equações 3 e 4). 
Peroxinitrito possivelmente se engaja em múltiplas reações químicas que causam danos diretos e indiretos a biomoléculas. Cineticamente, os alvos preferenciais de peroxinitrito em ambiente biológico são metais de transição, especialmente ferro, tiolatos (RS-), inclusive resíduos de cisteína em proteínas, e a já citada reação com $\mathrm{CO}_{2}{ }^{22}$ As equações abaixo ilustram o destino de peroxinitrito. Todas as reações são rápidas. Por exemplo, a constante de velocidade da reação de oximioglobina $\left(\mathrm{HbFeO}_{2}\right)$ com peroxinitrito (Equação 5$)$ se encontra na faixa entre $10^{4}$ $10^{5} \mathrm{M}^{-1} \mathrm{~s}^{-1} 23$; 24 , enquanto que a reação deste oxidante com $\mathrm{CO}_{2}$ (Equação 4) tem $\mathrm{k}=$ $3 \times 10^{4} \mathrm{M}^{-1} \mathrm{~s}^{-1} .{ }^{25 ;} 26$ Apesar da constante ser relativamente menor do que com metaloproteinas, acredita-se que $\mathrm{CO}_{2}$ é um dos principais alvos de peroxinitrito devido sua elevada concentração in vivo. ${ }^{27}$ Os oxidantes radicalares derivados de peroxinitrito aumentam a diversidade de biomoléculas nas quais peroxinitrito pode causar danos por oxidação, nitração e nitrosação. ${ }^{22 ;}$ 28; 29

$$
\begin{aligned}
& \mathrm{ONOO}^{-}+\mathrm{H}^{+} \rightarrow \mathrm{ONO}-\mathrm{OH} \rightarrow \\
& 2 / 3\left(\mathrm{H}^{+}+\mathrm{NO}_{3}^{-}\right) \text {e } 1 / 3\left(\mathrm{NO}_{2}{ }^{-} \cdot \mathrm{OH}\right) \\
& \mathrm{ONOO}^{-}(\mathrm{H})+\mathrm{CO}_{2} \rightarrow \mathrm{ONOO}_{-} \mathrm{CO}_{2}^{-} \rightarrow \\
& 2 / 3\left(\mathrm{CO}_{2}+\mathrm{NO}_{3}^{-}\right) \text {e } 1 / 3\left(\mathrm{NO}_{2}{ }^{-}+\mathrm{CO}_{3}^{\bullet-}\right) \\
& \mathrm{ONOO}^{-}+\mathrm{HbFeO}_{2} \rightarrow \mathrm{HbFe}^{-} \mathrm{O}^{++}+\mathrm{NO}_{2}{ }^{-} \\
& \mathrm{ONOO}^{-}+\mathrm{PS}^{-} \rightarrow \mathrm{PSOH}+\mathrm{NO}_{2}^{-}
\end{aligned}
$$

A oxidação de resíduos catalíticos de cisteínas à ácido sulfênico (RSOH) em proteínas (Equação 6) pode desencadear formação de pontes de enxofre em proteínas, ambos intra e/ou intermolecular. ${ }^{30}$ Estas modificações podem inibir proteínas irreversivelmente ou mesmo alterar atividade. Por exemplo, a gliceraldeído3-fosfato desidrogenase (GAPDH) apresenta função de fator de transcrição quando seu resíduo de cisteína é oxidado a ácido sulfênico. ${ }^{31}$ Sugere-se inclusive que oxidação de resíduos de cisteína pode ser mecanismo de sinalização celular, como por exemplo o fator de transcrição bacterial OxyR, a oxidação dos resíduos de cisteína desta proteína resulta em modificações estruturais que permitem sua associação ao DNA, ${ }^{32 ;} 33$ ativando a transcrição da enzima antioxidante Alquil-hidroperóxido redutase subunidade C (do inglês, Alkyl Hydroperoxide reductase $C, A h p C$ ) e seu redutor catalítico mais eficiente, a flavoproteína Alquil-hidroperóxido redutase subunidade $F$ 
(do inglês, Alkyl hydroperoxide reductase $F$, AhpF). ${ }^{34}$ Entretanto, exceto por peroxirredoxinas (Prxs) e glutationa peroxidases (GPxs), a cinética da oxidação de tiolato por peroxinitrito não costuma ser elevada, por exemplo, tiolados de albumina e glutationa $\left(\mathrm{k}=2,8 \times 10^{3} \mathrm{M}^{-1} \mathrm{~s}^{-1}\right.$ e $\mathrm{k}=281 \mathrm{M}^{-1} \mathrm{~s}^{-1}$, respectivamente). ${ }^{35 ;} 36 \mathrm{~A}$ cinética da reação de peroxinitrito com vários membros das Prxs de diferentes organismos tem sido estudada extensivamente com proteínas purificadas. Estas proteínas apresentam um resíduo de cisteína que é particularmente reativo com peróxidos em geral, reagindo com peroxinitrito com constantes de velocidade entre $10^{5}-10^{8} \mathrm{M}^{-1} \mathrm{~s}^{-1}$ dependendo do membro da família. ${ }^{37 ;} 38$

Desta forma, considerando a conservação de $\mathrm{NO}^{\bullet}$ como mensageiro secundário em comunicação celular, é possível especular que a natureza foi pressionada a produzir condições ou estratégias para evitar ou minimizar a produção de oxidantes derivados de $\mathrm{NO}^{\bullet}$ como peroxinitrito. Realmente, há evidência de ações complementares neste sentido: i) Elevada sensibilidade de receptores a NO•; Estimase que $\mathrm{NO}$ ' seja fisiologicamente ativo numa faixa impressionantemente baixa, entre 10 pM - 100 nM. Talvez esta propriedade seja devido a elevada sensibilidade e elevada concentração em células $(\mu \mathrm{M})$ do seu clássico receptor sGC e amplificação da sinalização promovida por GCs, produzindo grandes quantidades do mensageiro secundário monofosfato cíclico de guanosina (do inglês, cyclic guanosine monophosphate, cGMP) sob ativação por NO•. ${ }^{39} 40$ ii) Superóxido dismutases; A existência e conservação de enzimas chamadas superóxido dismutases (mamífero têm duas classes; Cu,Zn-SOD e Mn-SOD) sempre foi interpretada como a necessidade de remover o radical $\mathrm{O}_{2}{ }^{\bullet-}$, cuja produção é indissociável do processo de respiração mitocondrial. ${ }^{41}$ Este radical não é um oxidante forte, na verdade é um redutor leve. O produto de seu desproporcionamento natural ou catalisado por SODs, peróxido de hidrogênio, é ainda menos reativo e hoje especula-se que seja na verdade um importante mensageiro secundário. ${ }^{42}$ Com a descoberta da síntese endógena de $\mathrm{NO}{ }^{\bullet}$ e da rápida reação com $\mathrm{O}_{2}{ }^{\bullet-}$ (Equação 2), talvez seja mais plausível que SODs são conservadas para prevenir a formação de peroxinitrito. iii) Existência de Tiol Peroxidases; Quando, apesar de SODs, peroxinitrito é formado, células ainda dispõem de peroxirredoxinas e outras peroxidases como glutationa peroxidases. ${ }^{30}$ Portanto, células possuem mecanismos múltiplos de ação que visam minimizar a produção e remover peroxinitrito. 


\subsection{Tiol peroxidases}

Tiol peroxidases (TPxs) são proteínas que possuem atividade peróxido redutase. São divididas em duas famílias, peroxirredoxinas (Prx) e glutationa peroxidases (GPx). Prx e GPx são conservadas, sendo encontradas em espécies de todos os reinos. Diferentemente de peroxidases dependente de grupos prostéticos de ferro-heme (como catalase e mieloperoxidase), a atividade peroxidase de TPxs é baseada na oxidação do tiolato de um resíduo de cisteína (PS-) a ácido sulfênico (PSOH). ${ }^{34} \mathrm{~A}$ redução do $\mathrm{PSOH}$ para tiolato, que completa o ciclo catalítico, depende de parceiros redutores. Em Saccharomyces cerevisiae, Prx e GPx compartilham o mesmo sistema redutor, sendo restauradas à forma reduzida por tioredoxina (Trx), que por vez é reduzida por tioredoxina redutase (TR) de forma dependente do redutor celular (NADPH). Esta sequência de reações é denominada sistema tiorredoxina (Trx/TR/NADPH) (Figura 1A). ${ }^{43}$ Contudo, há exceções, GPx de leveduras (ScGPx) podem ser reduzidas por glutationa (GSH), porém com menor atividade catalítica comparado ao sistema Trx. GSH oxidada é reduzida por glutationa redutase (GR) também de forma dependente de $\mathrm{NADPH}$, sendo denominado como sistema glutationa (GSH/GR/NADPH) (Figura 1B). Em mamíferos, diferentemente, as isoformas de GPx contém uma seleno-cisteína (SecGPx) ao invés de duas cisteínas e a atividade catalítica é conduzida preferencialmente pelo sistema GSH. ${ }^{44}$

Figura 1 - Representação genérica dos sistemas redutores tioredoxina (Trx) e glutationa (GSH).

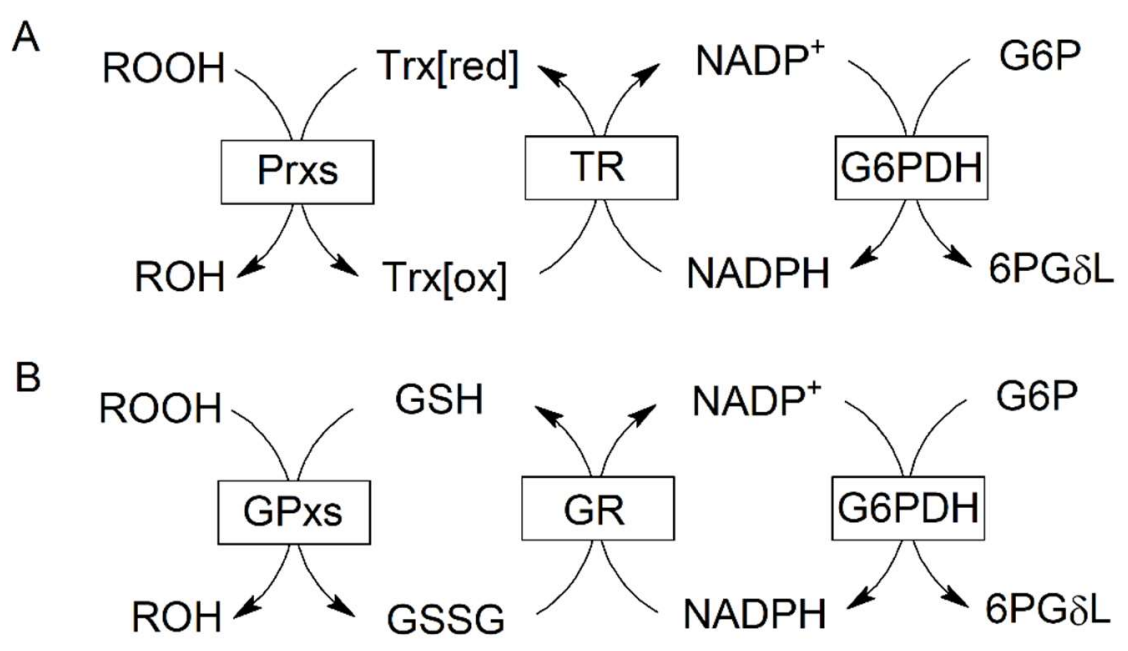

Fonte: adaptado da referência ${ }^{45}$. 


\subsubsection{Glutationa Peroxidase}

Glutationa peroxidase é uma superfamília de enzimas com cerca de 700 membros distribuídos em praticamente todas as espécies. Em mamíferos são tetrâmeros, e cada subunidade tem aproximadamente 22 kDa. GPx apresenta atividade peróxido redutase, mais notadamente para $\mathrm{H}_{2} \mathrm{O}_{2}$, mas algumas isoformas também reduzem peróxidos orgânicos e lipídicos, entre outros. ${ }^{46}$

Em Saccharomyces cerevisiae são expressas três (3) isoformas de GPx: glutationa peroxidase 1 (GPx1), glutationa peroxidase 2 (GPx2); glutationa peroxidase 3 (GPX3). ${ }^{38 ;} 45$ GPx3 é também conhecida por Orp1 (do inglês, oxidant receptor peroxidase 1) e atua como sensor de $\mathrm{H}_{2} \mathrm{O}_{2}$ e na transdução de sinal, ativando cascatas de sinalização que culminam na ativação do regulador transcricional Yap1 (do inglês, yes-associated protein 1). ${ }^{47}$ GPxs de Saccharomyces cerevisiae e de outros organismos, apresentam uma cisteína no sítio catalítico em substituição à selenocisteína encontrada no homólogo de mamífero. ${ }^{46} \mathrm{~A}$ região próxima ao sítio catalítico é altamente conservada nos dois homólogos, porém, a sequência de aminoácidos apresenta apenas $36 \%$ de identidade. Entre as isoformas presentes em Saccharomyces cerevisiae, a identidade na sequência de aminoácidos é maior que $53 \% .45$

\subsubsection{Peroxirredoxinas}

A existência de peroxirredoxinas foi documentada pela primeira vez como uma proteína antioxidante no final da década de 80 do século passado. ${ }^{48} \mathrm{Kim}$ et. al. ${ }^{49}$ observaram que glutamina sintetase purificada de um extrato de Sacchomyces cerevisiae era oxidada por oxigênio molecular $\left(\mathrm{O}_{2}\right)$ na presença de íons $\mathrm{Fe}^{3+}$ e um redutor, incluindo tióis (por exemplo ditiotreitol, DTT). No entanto, o mesmo sistema $\mathrm{Fe}^{3+} / \mathrm{O}_{2} / \mathrm{DTT}$ não oxidava glutamina sintetase não purificada no extrato bruto. Esta observação levou a conclusão de que o extrato continha enzimas resistentes ao sistema $\mathrm{Fe}^{3+} / \mathrm{O}_{2} / \mathrm{DTT}$ e que protegia glutamina sintetase. Baseado nesta propriedade, uma proteína da levedura de $27 \mathrm{kDa}$ (valores aproximados) foi purificada. Esta proteína era distinta de antioxidantes proteicos clássicos como catalase, SOD e GPx. Também descobriu-se que a atividade antioxidante desta proteína dependia de tióis, propriedade a qual the deu o primeiro nome, thiol specific antioxidant (TSA). 
Motivados por esta descoberta, pesquisadores identificaram homólogos da TSA em organismos de todos os táxons até a primeira metade da década de 90. Também, os genes que as codificam em leveduras e mamíferos tinham sido sequenciados e clonados. Contemporaneamente aos estudo de TSA em Saccharomyces cereviasiae, uma enzima que reduz hidroperóxidos orgânicos cataliticamente e de forma dependente de NADPH em Salmonella typhimurium (St) e Escherichia coli (E.coli) foi identificada. Essa enzima, do inglês, alkyl hydroperoxide reductase é composta de duas subunidades: uma de $21 \mathrm{kDa}(\mathrm{AhpC})$ e outra $57 \mathrm{kDa}$ $(\mathrm{AhpF})$, a qual apresenta um cofator FAD associado. Após sequenciamento destes genes foi verificado que a AhpF é homologa à tioredoxina redutase (TR) de E. coli, a qual foi posteriormente identificada como o redutor secundário de scTSA. AhpC protegia glutamina sintetase de inativação por hidropéroxidos, o que indicou corretamente que scTSA também apresentava atividade peróxido redutase. Posteriormente, foram identificadas duas proteínas cuja presença simultânea era necessária para a atividade peróxido redutase de scTSA, tioredoxina (Trx) e TR. Neste sistema o redutor primário de TSA era Trx que, por sua vez, era reduzida por TR de forma dependente de NADPH. Esse sistema (Trx/TR/NADPH) deu origem a denominação tioredoxina peroxidase (TPxs) para TSA e seus homólogos. Entretanto, a descoberta de isoformas com atividade peróxido redutase independentes do sistema tioredoxina levaram à nomeação de Peroxirredoxinas.

Ao longo das últimas décadas, vários estudos mostraram que a atividade de peroxirredoxinas é inespecífica em relação a natureza do oxidante. Inicialmente foi verificada a atividade "catalase" de $\mathrm{Prxs},{ }^{50}$ reduzindo $\mathrm{H}_{2} \mathrm{O}_{2}$ à $\mathrm{H}_{2} \mathrm{O}$. Posteriormente descobriu-se que oxidantes como $\mathrm{ONOO}^{-}$42; 51; 52 e hidroperóxidos orgânicos ${ }^{51}$ também são reduzidos com elevada eficiência para $\mathrm{NO}_{2}^{-}$e o respectivo álcool, correspondentemente. Mais intrigante é a redução de hidroperóxidos, que podem ser pequenas moléculas exógenas, como o hidroperóxido de terc-butil (do inglês, tertbutyl hydroperoxide, $t-\mathrm{BOOH})^{51}$ e hidroperóxido de cumeno $(\mathrm{CuOOH})^{53}$ ou endógeno, como peróxidos de lipídios (LOOH). ${ }^{54}$ Uma consequência da formação de ROS e RNS em células são os danos a constituintes celulares vitais como proteínas, lipídios de membrana e DNA. ${ }^{55}{ }^{56}$ A formação de radicais lipídicos ( $\left(\mathrm{LO}^{\circ}\right)$ e hidroperóxido de lipídios ( $\mathrm{LOOH}$ ) são reportadas como uma das causas de doenças crônicas. ${ }^{57}$ Estudos mostram que Prx6 de mamífero, além de evitar danos a esses constituintes celulares 
removendo peróxidos em geral, agem na redução de hidroperóxido de lipídios ${ }^{58}$ cataliticamente e com altas constantes cinéticas, possivelmente impedindo que o dano seja propagado.

\subsubsection{Peroxirredoxinas: estrutura, atividade e funções}

Peroxirredoxinas constituem uma família de proteínas taxonalmente distribuídos. ${ }^{30 ;}$ 34; 59 São conhecidos atualmente seis (6) isoformas de Prxs em humanos (Prx I-VI). Inicialmente Prxs foram identificadas em leveduras e posteriormente encontradas em células de mamíferos pela sua atividade de redução de peróxidos, especialmente peróxido de hidrogênio. ${ }^{34}$ Detalhes do mecanismo da reação de redução ainda não foram totalmente esclarecidos, mas todas as Prx apresentam três aminoácidos conservados no sítio catalítico: Cisteína (Cys), Arginina (Arg) e Treonina (Thr). ${ }^{34 ;}$ 37; 60 O ciclo catalítico de uma peroxirredoxina envolve basicamente três etapas reacionais, que estão simplificadamente ilustradas na figura 2A: Primeiramente, (1) o grupo tiol $(\mathrm{SH})$ da cisteína peroxidásica conservada $\left(\mathrm{C}_{\mathrm{pH}}\right.$ ou $\mathrm{S}_{\mathrm{PH}} \mathrm{H}$ ) reage rapidamente reduzindo o peróxido com formação de água (ou o respectivo álcool) e produzindo ácido sulfênico ( $\mathrm{R}-\mathrm{SOH})$; (2) Esta etapa é seguida da condensação do ácido sulfênico com uma segunda cisteína conservada, chamada cisteína de resolução $\left(\mathrm{C}_{\mathrm{R}} \mathrm{H}\right.$ ou $\left.\mathrm{S}_{\mathrm{R}} \mathrm{H}\right)$, resultando na formação de uma ligação dissulfeto $\left(S_{P}-S_{R}\right)$. Esta etapa distingue as Peroxirredoxinas em três classes principais que serão discutidas brevemente abaixo. (3) O ciclo catalítico é completado pela redução da ligação dissulfeto por tioredoxina (Trx), exceto para Prx VI, cujo redutor ainda é desconhecido, podendo ser inclusive ascorbato (Figura 2B). ${ }^{61}$ 
Figura 2 - Representação genérica do ciclo catalítico de Peroxirredoxinas.

A

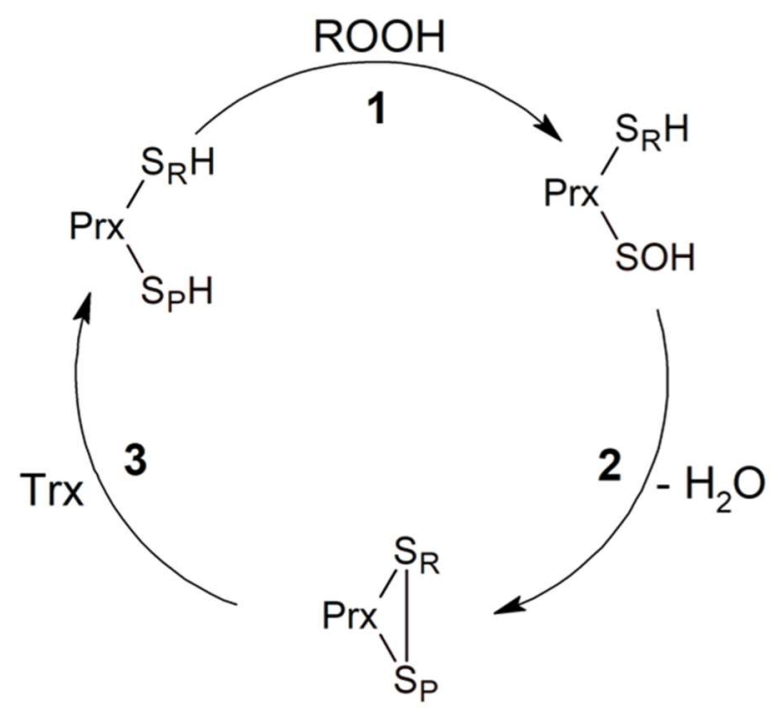

B

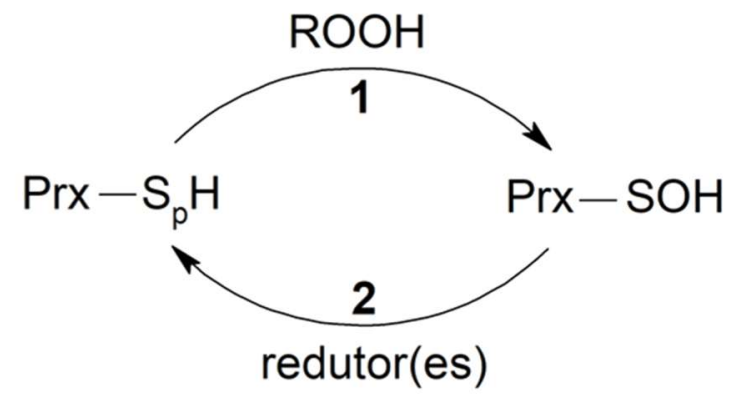

Fonte: adaptada da referência ${ }^{34}$. A.(1) Redução do peróxido na cisteína peroxidática $\left(\mathrm{S}_{\mathrm{P}} \mathrm{H}\right) \mathrm{com}$ formação de ácido sulfênico ( $R$ - SOH) e respectivo álcool ou água. (2) condensação do ácido sulfênico com a cisteína de resolução $\left(S_{R} H\right)$ formando a ligação de enxofre $\left(S_{P}-S_{R}\right)$. (3) Redução da ligação de enxofre por Trx e reconstituição da Prx reduzida. B. (1) 1-Cys Prxs são oxidadas a ácido sulfênico, posteriormente (2) redutores celulares reconstituem a enzima.

As várias isoformas de Prxs conhecidas são classificadas em três (3) subgrupos: Prx de duas cisteínas (2-Cys) típica [2-Cys (Prx I-IV)], atípica (Prx V) e Prx de uma cisteína (1-Cys) (Prx-VI). Apesar de serem isoformas diferentes, os sítios catalíticos são similares. As maiores diferenças estão nos seus estados oligoméricos, os subgrupos 2-Cys típica e 1-Cys são homodímeros e o subgrupo 2-Cys atípica é monomérica. O subgrupo de Prxs 2-Cys típicas normalmente estão na forma de pentâmeros de dímeros, ou seja, um decâmero. A oxidação da cisteína peroxidásica por um peróxido resulta na formação de uma ligação disulfeto entre duas subunidades do dímero, com subsequente desestabilização do decâmero em dímeros. ${ }^{62}$ As Prxs pertencentes ao subgrupo 2-Cys atípica, como são monoméricas, a ponte de enxofre $\left(S_{P}-S_{R}\right)$ é intramolecular. Finalmente, Prxs 1-Cys não tem a cisteína de resolução. ${ }^{30}$; ${ }^{59} \mathrm{~A}$ cisteína peroxidásica uma vez oxidada a ácido sulfênico pode ser reduzida por ascorbato (Figura 2B). ${ }^{61}$ Também, especula-se que os sistemas, glutaredoxina 2/glutationa (Grx2/GSH) ${ }^{63}$ e tioredoxina redutase 2/glutationa (Trr2/GSH) ${ }^{64}$, podem ser possíveis mecanismos de redução de Prxs do subgrupo 1-Cys em células. 
Os resíduos da $\mathrm{S}_{\mathrm{pH}}$ e $\mathrm{S}_{\mathrm{R}} \mathrm{H}$ estão separados por mais de $10 \AA$ em direções opostas nas isoformas 2-Cys. Portanto, para que a ligação dissulfeto ocorra, a Prx sofre rearranjos estruturais da alça-hélice no qual esses resíduos estão localizados. Os rearranjos estruturais das Prx 2-Cys típicas são associados ao estado redox da $\mathrm{SpH}$. Na forma de ácido sulfênico (Prx - SOH) a estrutura em hélice sofre rearranjo local, permitindo a aproximação do sítio da $\mathrm{S}_{\mathrm{PH}}$ ao da $\mathrm{S}_{\mathrm{R}} \mathrm{H}$ e formação da ligação dissulfeto ${ }^{30 ;} 59$. Essas diferenças entre isoformas podem garantir especificidade e outras funções, além da conhecida redução de peróxidos. Em trabalho recente, Flohe $^{34}$ sugere que tiol peroxidases, devido sua versatilidade, exerçam importante papel, uma vez que sua forma oxidada pode interagir com diversas vias regulatórias, incluindo regulação redox de resposta imunológica, inibição apoptótica e supressão tumoral, entre outras.

No entanto, peroxirredoxinas não são enzimas na definição mais rigorosa. 0 ciclo catalítico depende de redução por tiorredoxina, que por sua vez, depende da redução por TR/NADPH em duas trocas de tióis sequenciais (Figura 1). Portanto, a redução de peróxidos em geral por Prxs pode ser limitada pelas etapas de troca de tióis entre Prx e Trx ou Trx e TR. Concordantemente, as cinéticas de estado estacionário envolvendo todo o sistema catalítico revelam constantes de velocidade sempre menores que a constante de velocidade de redução de peróxidos por Prxs. Esta é uma indicação que pode ser a situação in vivo. Constantes cinéticas das várias etapas do sistema já foram determinadas para alguns poucos casos. De forma geral, a etapa de redução de Prx por Trx de diferentes origens taxonômicas apresentam valores de constantes cinéticas da ordem de $\left.1-3 \times 10^{6} \mathrm{M}^{-1} \mathrm{~S}^{-1}\right)^{53 ; 65 ; 66 ; 67 ; 68 ; 69 ; 70 ; 71 ; 72 .}$ Dentre eles podemos destacar o trabalho de Trujillo et. al. ${ }^{53}$ Usando $h$ PRDX5 (como Prx) e hTXN2 (como Trx) estes autores determinaram uma constante cinética de redução da PRDX5 de $2 \pm 0,5 \times 10^{6} \mathrm{M}^{-1} \mathrm{~s}^{-1}$ a $\mathrm{pH} 7,4$ e $25^{\circ} \mathrm{C}$. Piñeyro et. al. ${ }^{65}$ determinaram constante velocidade da mesma ordem de magnitude $\left(1,3 \pm 0,1 \times 10^{6}\right.$ $\mathrm{M}^{-1} \mathrm{~s}^{-1}, \mathrm{pH} 7,4$ e $25^{\circ} \mathrm{C}$ ) para a redução de Tryparedoxina peroxidase citosólica (cTXNPx) e mitocondrial (m-TXNPx) de Trypanosoma cruzi (T. cruzi) por Tryparedoxina de Trypanosoma brucei (TbTXNI). Manta et. al. ${ }^{72}$ determinaram constante de velocidade de redução de HsPrx2 purificada de eritrócito por HsTrx-1 uma ordem de magnitude menor $\left(2,1 \pm 0,3 \times 10^{5} \mathrm{M}^{-1} \mathrm{~s}^{-1}, \mathrm{pH} 7,4\right.$ e $\left.25^{\circ} \mathrm{C}\right)$. Similarmente, as constantes cinéticas de redução de $\operatorname{Trx} 1(H$. pylori e E. coli) por TR $(H$. pylori e E. coli) são 
próximas, 3,3 x $10^{6} \mathrm{M}^{-1} \mathrm{~s}^{-1}$ e $9,1 \times 10^{6} \mathrm{M}^{-1} \mathrm{~s}^{-1}$, respectivamente. Já a redução de TR por NADPH para ambas TR são idênticas e quase uma ordem de magnitude maior, $1,2 \times 10^{7} \mathrm{M}^{-1} \mathrm{~s}^{-1}$. Contudo, segundo os autores, esses valores independem da concentração da peroxidase (AhpC), sugerindo que as etapas de redução (Trx/AhpC) e (TR/Trx) limitam a redução catalítica de peróxidos. ${ }^{73}$ Além disso, a expressão dos redutores e a concentração de NADPH são fatores que não podem ser desprezados. De fato, os níveis de expressão de Trx e TR são relevantes para o ciclo catalítico de Prxs. Normalmente, estudos sugerem que Trx representa aproximadamente $0,3 \%$ da massa proteica em E. coli. ${ }^{74}$ Esse valor é comparável aos níveis de expressão de Prxs, na faixa de $\mu \mathrm{M}$. Por outro lado, TR apresenta níveis de expressão muito inferiores $(\mathrm{nM}-1 \mu \mathrm{M})$.

A limitação da atividade catalítica de Prxs e GPxs às sucessivas etapas de troca de tióis dos sistemas catalíticos (Prx/Trx/TrxR e GPx/GSH) deveria ser mais evidente em células, onde, além da cinética e expressão dos vários componentes do sistema enzimático de Prxs e GPxs, outros fatores como acessibilidade, difusão e encontro entre os vários componentes do sistema, bem como flutuações momentâneas nas suas disponibilidades, podem ocasionalmente limitar a atividade peroxidásica.

\subsection{Atividade peróxido redutase de peroxirredoxinas}

Naturalmente, as descobertas iniciais levaram a hipótese de que peroxirredoxinas são importantes agentes antioxidantes. O primeiro estudo avaliando a propriedade antioxidante de Prxs em Saccharomyces cerevisiae foi conduzido ainda antes da descoberta da natureza dos substratos oxidantes de Prxs. A exposição da levedura à atmosfera de $100 \% \mathrm{O}_{2}$ ou $\mathrm{Fe}^{3+}$, aumentava a expressão da proteína. ${ }^{48} \mathrm{~A}$ partir deste estudo, organismos de diferentes taxons foram utilizados para avaliar a capacidade protetiva de Prxs contra oxidantes. ${ }^{48 ;} 75$ Dados do sequenciamento das poucas proteínas identificadas até então, TSA e AhpC, revelaram a existência de outras proteínas com alta similaridade na sequência de aminoácidos (23 - $98 \%)$ e apresentando regiões do sítio catalítico conservados. ${ }^{76}$ Atualmente, as investigações da atividade peróxido redutase de Prxs em células são realizadas comparando, a capacidade de crescimento do modelo celular nativo (WT) com a de modelos com mutação na Prx de interesse, ambos expostos a diferentes (concentrações de) 
oxidantes por spot assay ou curva de crescimento. Wong et. al. ${ }^{51}$ demostrou o aumento da sensibilidade à $\mathrm{H}_{2} \mathrm{O}_{2}$, t-BOOH ou $\mathrm{ONOO}^{-}$de linhagens de Saccharomyces cerevisiae ( $\Delta$ Tsa1, $\Delta$ Tsa2 e o duplo mutante $\Delta$ Tsa1 $\Delta$ Tsa2) em relação a WT. Posteriormente, em um estudo mais amplo com mutações para todas as peroxiredoxinas, Wong et. al. ${ }^{77}$ concluiu que todas as cinco Prxs de Saccharomyces cerevisiae são importantes na remoção de oxidantes e que Prxs estas cooperam entre si e com outros sistemas antioxidantes na defesa contra ROS e RNS. Particularmente, a linhagem $\Delta 8$ apresentava aumento de expressão de outras enzimas antioxidantes (SOD, Catalase). Demasi et. al. mostraram que há aumento de sensibilidade de Saccharomyces cerevisiae exposta à $\mathrm{H}_{2} \mathrm{O}_{2}$ e com mitocôndrias não funcionais ( \pm Antimicina-A) e também aumento da expressão de proteínas de defesa e sinalização antioxidante com silenciamento do gene que codifica a isoforma Tsa1. ${ }^{78 ;} 79$ Munhoz et. al. ${ }^{80}$ mostraram que ambas as linhagens $\Delta$ Tsa1 e $\Delta$ Tsa2 são sensíveis a t-BOOH, mas somente a linhagem $\Delta$ Tsa1 apresenta sensibilidade $\mathrm{H}_{2} \mathrm{O}_{2}$ relevante.

Evidentemente, a relevância de Prxs e homólogos relativo a resistência de células a insultos oxidantes teria que ser reflexo da sua reatividade frente a peróxidos. Os primeiros estudos cinéticos foram conduzidos por abordagem de estado estacionário usando o sistema Prx/Trx/TR e NADPH, monitorando o consumo do redutor espectroscopicamente. Munhoz et al. determinaram constantes de velocidade na mesma ordem de magnitude $\left(\mathrm{k}=\mathrm{k}_{\mathrm{cat}} / \mathrm{km}_{\mathrm{m}}=10^{4} \mathrm{M}^{-1} \mathrm{~s}^{-1}\right)^{80}$ para redução de $\mathrm{H}_{2} \mathrm{O}_{2}$, $\mathrm{t}$ $\mathrm{BOOH}$ e $\mathrm{CuOOH}$ por scTsa1 e scTsa2. No entanto, estas constantes eram baixas para justificar a capacidade antioxidante de Prxs em geral. De fato, abordagens cinéticas mais diretas como de competição ou fluorescência intrínseca de várias Prxs (ScTSA1 e ScTSA2) revelaram posteriormente que a redução ocorre com constantes de velocidade consideravelmente mais elevadas, alcançando valores entre $10^{7} \mathrm{M}^{-1} \mathrm{~s}^{-1}$ para $\mathrm{H}_{2} \mathrm{O}_{2}$ e $10^{6} \mathrm{M}^{-1} \mathrm{~s}^{-1}$ para peroxinitrito. ${ }^{81}$ Estes métodos revelaram, portanto, constantes de velocidade mais consistentes com o papel peróxido redutase de Prxs em geral, à medida que constantes de velocidade para isoformas de outros organismos foram sendo determinadas (bactérias, protozoários, plantas e mamíferos). Por exemplo, Perkins et al. mostraram que a isoforma bacteriana AhpC e a Prxll humana apresentam valores de $\mathrm{kcat} / \mathrm{km}_{\mathrm{m}}\left(\mathrm{H}_{2} \mathrm{O}_{2}\right)$ da ordem de $10^{7}-10^{8} \mathrm{M}^{-1} \mathrm{~s}^{-1} 82$. Prx $\mathrm{V}$, uma 2-Cys atípica de mamífero, apresenta constante de velocidade da ordem $10^{7} \mathrm{M}^{-}$ ${ }^{1} \mathrm{~s}^{-1}$ para $\mathrm{ONOO}^{59}$. Horta et. al. ${ }^{83}$ caracterizaram a atividade peróxido redutase de 
PrxQ de Xylella fastidiosa (XfPrxQ), determinando valores de constante cinética desta isoforma próximos ao determinado para ScTsa1 e ScTsa2, $\mathrm{k}\left(\mathrm{H}_{2} \mathrm{O}_{2}\right)=10^{7} \mathrm{M}^{-1} \mathrm{~s}^{-1} \mathrm{e}$ konOo- $=10^{6} \mathrm{M}^{-1} \mathrm{~s}^{-1}$. Por meio de fluorescência intrínseca Meotti et. al. ${ }^{84}$ determinaram constantes de velocidades da redução de Hidroperóxido de urato (UOOH) por isoformas de Prxs humana ( $\mathrm{hPrx} 1, \mathrm{k}=4,90 \pm 0,47 \times 10^{5} \mathrm{M}^{-1} \mathrm{~s}^{-1}$ ) e $(\mathrm{hPrx} 2, \mathrm{k}=2,26 \pm$ $\left.0,13 \times 10^{6} \mathrm{M}^{-1} \mathrm{~s}^{-1}\right)$. Toledo et. al. ${ }^{37}$ por meio de cinética de competição com horse radish peroxidase (HRP), determinaram constantes cinéticas de redução de $\mathrm{H}_{2} \mathrm{O}_{2}(\mathrm{k}$ $\left.=3,4 \pm 0,2 \times 10^{7} \mathrm{M}^{-1} \mathrm{~s}^{-1}\right)$ e $\mathrm{ONOO}^{-}\left(\mathrm{k}=3,7 \pm 0,4 \times 10^{5} \mathrm{M}^{-1} \mathrm{~s}^{-1}\right)$ por Prx de rato ( $\left.\mathrm{rPr} 6\right)$. Estas e outras constantes de velocidade são selecionadas na tabela 1, onde também, são selecionadas algumas constantes cinéticas de ScGpx e SecGPx. Os valores de constantes cinéticas para GPx em geral, são comparáveis às de Prxs.

Tabela 1 - Constantes cinéticas da redução peróxidos por Prxs e GPxs.

\begin{tabular}{|c|c|c|c|c|}
\hline $\begin{array}{l}\text { Isoforma } \\
\text { (organismo) }\end{array}$ & Subfamília & Substrato & $k\left(M^{-1} s^{-1}\right)$ & $\begin{array}{c}\text { Abundância } \\
(\mu \mathrm{M})^{*}\end{array}$ \\
\hline Tsa1 (Sc) & AhpC-Prx1 & $\begin{array}{l}\mathrm{H}_{2} \mathrm{O}_{2}^{80 ; 81} \\
\mathrm{ONOOH}^{81} \\
\mathrm{t}-\mathrm{BOOH}^{80} \\
\mathrm{CuOOH}^{80}\end{array}$ & $\begin{array}{l}2,6 \times 10^{4} \mathrm{e} \\
2,2 \times 10^{7 \mathrm{a}} \\
7,4 \times 10^{5 \mathrm{a}} \\
3,6 \times 10^{4 \mathrm{e}} \\
1,5 \times 10^{4 \mathrm{e}}\end{array}$ & 48 \\
\hline Tsa2 $(S c)$ & AhpC-Prx1 & $\begin{array}{l}\mathrm{H}_{2} \mathrm{O}_{2}^{80 ; 81} \\
\mathrm{ONOOH}^{81} \\
\mathrm{t}-\mathrm{BOOH}^{80} \\
\mathrm{CuOOH}^{80}\end{array}$ & $\begin{array}{l}1,3 \times 10^{4} \mathrm{e} \\
1,3 \times 10^{7 \mathrm{a}} \\
5,1 \times 10^{5 \mathrm{a}} \\
2,7 \times 10^{4 \mathrm{e}} \\
3,0 \times 10^{4 \mathrm{e}}\end{array}$ & $2-3$ \\
\hline $\operatorname{Prx1}(H s)$ & AhpC-Prx1 & $\begin{array}{l}\mathrm{H}_{2} \mathrm{O}_{2} \\
\mathrm{HOOU}^{84}\end{array}$ & $\begin{array}{c}3,80 \pm 0,15 \times 10^{7 f} \\
4,9 \pm 0,47 \times 10^{5 f}\end{array}$ & - \\
\hline $\operatorname{Prx2}(H s)$ & AhpC-Prx1 & $\begin{array}{l}\mathrm{H}_{2} \mathrm{O}_{2}^{82} \\
\mathrm{ONOOH} \\
\mathrm{HOOU}^{84}\end{array}$ & $\begin{array}{c}1,0 \pm 0,1 \times 10^{8 a} \\
1,3 \times 10^{7 a} \\
1,4 \pm 0,4 \times 10^{7 a} \\
2,26 \pm 0,13 \times 10^{6 f}\end{array}$ & $240-410$ \\
\hline $\operatorname{Prx3}(H s)$ & AhpC-Prx1 & $\mathrm{H}_{2} \mathrm{O}_{2}$ & $2,0 \times 10^{7 a}$ & 60 \\
\hline $\operatorname{Prx} 5(H s)$ & Prx5 & $\begin{array}{l}\mathrm{H}_{2} \mathrm{O}_{2} \\
\mathrm{ONOOH}^{59} \\
\mathrm{t}-\mathrm{BOOH} \\
\mathrm{CuOOH}\end{array}$ & $\begin{array}{c}3,0 \times 10^{5 \mathrm{f}} \\
2,2 \pm 0,7 \times 10^{5 \mathrm{a}} \\
3,0 \times 10^{5 \mathrm{~b}} \\
6,7 \pm 1,0 \times 10^{7 \mathrm{f}} \\
1,2 \pm 0,6 \times 10^{8 \mathrm{a}} \\
7,0 \pm 3,0 \times 10^{7 \mathrm{~b}, \mathrm{~d}} \\
5,0 \pm 0,5 \times 10^{6 \mathrm{f}} \\
8,0 \pm 2,0 \times 10^{6} \\
8,5 \pm 2,0 \times 10^{7 \mathrm{f}}\end{array}$ & 20 \\
\hline
\end{tabular}


Continuação

\begin{tabular}{|c|c|c|c|c|}
\hline $\begin{array}{c}\text { Isoforma } \\
\text { (organismo) }\end{array}$ & Subfamília & Substrato & $k\left(M^{-1} s^{-1}\right)$ & $\begin{array}{c}\text { Abundância } \\
(\mu \mathrm{M})^{*}\end{array}$ \\
\hline Prx6 (rato) & Prx6 & $\begin{array}{l}\mathrm{H}_{2} \mathrm{O}_{2}{ }^{37} \\
\mathrm{ONOOH}^{37}\end{array}$ & $\begin{array}{l}3,4 \pm 0,210^{7 a} \\
3,7 \pm 0,410^{5 a}\end{array}$ & - \\
\hline AhpC (St) & AhpC-Prx1 & $\begin{array}{l}\mathrm{H}_{2} \mathrm{O}_{2}^{82} \\
\mathrm{ONOOH} \\
\mathrm{Et}-\mathrm{OOH} \\
\text { TBHP } \\
\mathrm{CHP} \\
\end{array}$ & $\begin{array}{l}3,9 \times 10^{7 c} \\
1,5 \times 10^{6 d} \\
1,2 \times 10^{7 c} \\
2,3 \times 10^{5 c} \\
4,9 \times 10^{5 c} \\
\end{array}$ & - \\
\hline AhpC (Hp/Mt) & AhpC-Prx1 & $\mathrm{ONOOH}$ & $\begin{array}{l}1,3 \times 10^{6 \mathrm{~d}}(\mathrm{Hp}) \\
1,2 \times 10^{6 \mathrm{~d}}(\mathrm{Mt})\end{array}$ & - \\
\hline c-TXNPx (Tc) & AhpC-Prx1 & $\begin{array}{l}\mathrm{H}_{2} \mathrm{O}_{2} \\
\mathrm{ONOOH} \\
\text { TBHP }\end{array}$ & $\begin{array}{c}3,0 \times 10^{7 a} \\
2,0 \times 10^{6 d} \\
7,2 \times 10^{5 d} \\
3,2 \times 10^{4}\end{array}$ & 2,75 \\
\hline m-TXNPX (Tc) & AhpC-Prx1 & $\begin{array}{l}\mathrm{H}_{2} \mathrm{O}_{2} \\
\mathrm{ONOOH}\end{array}$ & $\begin{array}{l}6,0 \times 10^{6 a} \\
1,8 \times 10^{7 d}\end{array}$ & 1,35 \\
\hline AhpE (Mt) & AhpE & $\begin{array}{l}\mathrm{H}_{2} \mathrm{O}_{2} \\
\mathrm{ONOOH}\end{array}$ & $\begin{array}{l}8,2 \times 10^{4 a} \\
1,9 \times 10^{7 a}\end{array}$ & - \\
\hline $\operatorname{Prx} Q(X f)$ & BCP-Prx Q & $\begin{array}{l}\mathrm{H}_{2} \mathrm{O}_{2}{ }^{83} \\
\mathrm{ONOOH}^{83}\end{array}$ & $\begin{array}{c}1,7 \times 10^{7 a} \\
1,02 \times 10^{6 a}\end{array}$ & - \\
\hline Gpx1 (Sc) & CysGPx & $\begin{array}{l}\mathrm{H}_{2} \mathrm{O}_{2}(\operatorname{trx})^{85} \\
\mathrm{H}_{2} \mathrm{O}_{2}(\mathrm{GSH})^{85} \\
\text { t-BOOH(Trx })^{85} \\
\text { t-BOOH(GSH) }\end{array}$ & $\begin{array}{l}1,19 \times 10^{6} \\
4,10 \times 10^{6} \\
1,49 \times 10^{6} \\
2,16 \times 10^{6}\end{array}$ & - \\
\hline Gpx2 (Sc) & CysGPx & $\begin{array}{l}\mathrm{H}_{2} \mathrm{O}_{2}(\operatorname{trx})^{43} \\
\mathrm{H}_{2} \mathrm{O}_{2}(\mathrm{GSH})^{43} \\
\text { t-BOOH}(\mathrm{Trx})^{43} \\
\text { t-BOOH }(\mathrm{GSH})^{43}\end{array}$ & $\begin{array}{l}4,79 \times 10^{7} \\
5,85 \times 10^{5} \\
5,89 \times 10^{6} \\
3,48 \times 10^{5} \\
\end{array}$ & - \\
\hline Gpx-1(bovino) & SecGPx & $\begin{array}{l}\mathrm{H}_{2} \mathrm{O}_{2}(\mathrm{GSH})^{86} \\
\mathrm{ONOOH}^{87} \\
\mathrm{t}-\mathrm{BOOH}(\mathrm{GSH})^{88}\end{array}$ & $\begin{array}{l}4,5 \times 10^{7} \\
8,0 \times 10^{6} \\
1,9 \times 10^{6}\end{array}$ & $2^{89}$ \\
\hline $\operatorname{GPx} 1(H s)$ & SecGPx & $\begin{array}{l}\mathrm{H}_{2} \mathrm{O}_{2}(\mathrm{GSH})^{38} \\
\mathrm{t}-\mathrm{BOOH}(\mathrm{GSH})^{38}\end{array}$ & $\begin{array}{l}4,1 \times 10^{7} \\
4,2 \times 10^{6}\end{array}$ & - \\
\hline
\end{tabular}

Fonte: Produção do autor. a, cinética de competição; b, determinação direta; c, oxidação de AhpF (stopped-flow); d, decomposição de peroxinitrito (stopped-flow); e, cinética de estado estacionário; f, fluorescência intrínseca; Sc - Saccharomyces cerevisiae; Hs - Homo sapiens; St - Salmonella tiphymurium; Hp - Helicobacter pylori; Mt - Mycobacterium tuberculosis; Tc - Trypanosoma cruzi; XfXylella fastidiosa; *, valores estimados a partir de dados relativo à fração do total de proteína solúvel, esses valores variam dependendo do tipo de célula ou organismo.

Portanto, resultados obtidos por diferentes métodos cinéticos mostram que a eficiência de Prxs na remoção de oxidantes é comparável a outros sistemas enzimáticos como catalases $\left(10^{6} \mathrm{M}^{-1} \mathrm{~s}^{-1}\right)$ e glutationa peroxidase $\left(10^{8} \mathrm{M}^{-1} \mathrm{~s}^{-1}\right),{ }^{90}$ e não enzimáticos como na redução de $\mathrm{ONOO}^{-}$por ebselen $\left(2,0 \times 10^{6} \mathrm{M}^{-1} \mathrm{~s}^{-1}\right)^{91}$, um 
reconhecido removedor intracelular de peroxinitrito, e GSH $\left(5,8 \times 10^{2} \mathrm{M}^{-1} \mathrm{~s}^{-1}\right)^{92}$. Um mecanismo eficiente de defesa contra peróxidos deve reunir as características de cinética favorável, sistema catalítico (enzimático) e altos níveis de expressão. Peroxiredoxinas apresentam estas três características de forma mais relevante que outras peroxidases (GPx e catalases), uma vez que os níveis de expressão de apenas uma de suas isoformas (Tsa1 em Saccharomyces cerevisiae) chega a ser 50 e 500 vezes superiores relativo às isoformas de maior expressão de GPx e catalase, respectivamente. ${ }^{95}$ Simulações cinéticas computacionais, levando em consideração o nível de expressão e a cinética de redução de $\mathrm{H}_{2} \mathrm{O}_{2}$ por alvos mitocondriais de células de mamíferos, estimam que $90 \%$ do $\mathrm{H}_{2} \mathrm{O}_{2}$ produzido na mitocôndria seria reduzido pela isoforma mitocondrial Prx3, em comparação a outros alvos mitocondriais que reduzem $\mathrm{H}_{2} \mathrm{O}_{2}$ enzimaticamente ou não. ${ }^{96}$ Impressionantemente, uma estimativa sugere que Prx2 de eritrócito humano remove cerca de $99 \%$ do $\mathrm{H}_{2} \mathrm{O}_{2}$ produzido no citosol. ${ }^{95}$ Contudo, resultados experimentais e simulados indicam que a Prx2 de eritrócito humano, especificamente devido à baixa concentração do redutor secundário TR, se acumula na forma dimerizada (sem atividade peroxidase), mesmo em baixas concentrações de $\mathrm{H}_{2} \mathrm{O}_{2}$, permitindo que outros alvos biológicos sejam afetados pela reação com $\mathrm{H}_{2} \mathrm{O}_{2} .{ }^{97 ;} 98$ Ainda assim, Prx2 elimina quase $50 \%$ do nível de $\mathrm{H}_{2} \mathrm{O}_{2}$ basal estimado para o eritrócito humano. ${ }^{98}$ Outro fato que pode justificar a importância da atividade peróxido redutase de Prxs, é que alguns patógenos humanos e outros microrganismos não expressam GPx e/ou catalases, mas expressam níveis elevados de Prxs. ${ }^{95}$

\subsubsection{A atividade peroxinitrito redutase de Peroxirredoxinas.}

Mais recentemente, vários grupos mostraram que Prx reduzem peroxinitrito a íons nitrito $\left(\mathrm{NO}_{2}{ }^{-}\right)$(Equação 6). As constantes de velocidade dependem da isoforma, ${ }^{37}$; 38; 93 mas são elevadas e nunca inferiores a $10^{6} \mathrm{M}^{-1} \mathrm{~s}^{-1}$. Além disso, como o produto da reação direta entre $\mathrm{S}_{\mathrm{PH}}$ e $\mathrm{ONOO}(\mathrm{H})$ é o ácido sulfênico, as etapas subsequentes do ciclo catalítico são as mesmas descritas para outros peróxidos. Portanto, Peroxirredoxinas podem reduzir peróxidos cataliticamente, atuando como espécies antioxidantes de espécies reativas de oxigênio (ROS) e nitrogênio (RNS).

$$
\mathrm{ONO}-\mathrm{O}(\mathrm{H})+\mathrm{Prx}-\mathrm{SH} \rightarrow \mathrm{Prx}-\mathrm{SOH}+\mathrm{NO}_{2}^{-}
$$


Algumas heme-proteínas como lacto/mieloperoxidases e certas catalases, apresentam atividade peroxinitrito redutase in vitro, assim como GPx de Saccharomyces cerevisiae e a seleno-proteína de mamífero Glutationa Peroxidase 1 (GPX-1). Glutationa (GSH) também reduz $\mathrm{ONOO}^{-}$em células, porém, com cinética lenta e de forma não enzimática. ${ }^{94}$

Os resultados da atividade peroxinitrito redutase de Prxs e GPxs, entre outros, conhecidos até o momento, foram determinados com proteínas purificadas utilizando diferentes métodos. Para esse propósito, células e/ou organismos unicelulares, nativos e com mutações enzimáticas específicas (restrita a aminoácidos ou deleções da proteína), são expostos a $\mathrm{ONOO}^{-}$(diretamente ou por estímulo da produção endógena). A consequência e extensão dos efeitos deste desafio são avaliados comparando os níveis de nitração de proteínas, mais precisamente de resíduos de tirosina (Tyr). Contudo, a nitração de resíduos de tirosina não é uma marcação específica da ação de $\mathrm{ONOO}^{-}$sobre proteínas, assim como, a resposta celular a altos níveis de peróxidos, exagerados, superam a atividade peroxinitrito redutase de peroxidases em geral e podem não revelar a relevância de tais enzimas como peróxido redutase celular.

Recentemente, uma classe de compostos derivadas de Boro foi desenvolvida para detectar peroxinitrito diretamente em células. Boronatos fluorescentes apresentam alta seletividade e sensibilidade na detecção de ONOO-.99; 100 Neste trabalho foi proposto usar boronatos para investigar a atividade peroxinitrito redutase de Prxs e GPxs 


\subsection{Detecção seletiva de peroxinitrito usando Boronatos.}

Recentemente, alguns ácidos ou ésteres borônicos fluorescentes foram desenvolvidos e pela primeira vez permitiram a detecção seletiva e sensível de peroxinitrito, em células. ${ }^{99 ;}$ 101; 102 Os boronatos usados para detecção de peroxinitrito são compostos contendo fragmentos de moléculas fluorescentes, cuja fluorescência é inibida pelo substituinte de boro $\mathrm{B}(\mathrm{OH})_{2}$. Um exemplo é o ácido borônico de cumarina (Coumarin Boronic Acid, CBA) (Figura 3).

Figura 3 - Estrutura química do CBA.

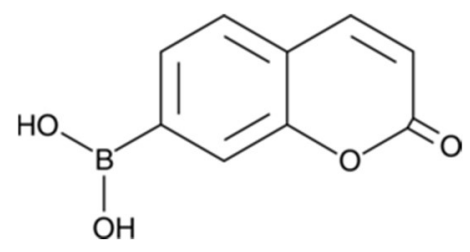

Fonte: Adaptado da referência ${ }^{103}$.

A elevada reatividade destes compostos de boro com peroxinitrito depende basicamente da eletrofilicidade e acidez de Lewis do boro. Seus três orbitais ligantes são híbridos do tipo $\mathrm{sp}^{2}$, restando um orbital $\mathrm{p}$ vazio ortogonal aos orbitais $\mathrm{sp}^{2}$. A etapa inicial da reação entre boronatos e peroxinitrito pode ser interpretada como uma simples conjugação do ácido de Lewis (boro) com a base de Lewis peroxinitrito $\left(\mathrm{ONOO}^{-}\right.$), formando o intermediário peroxiborato (1) (Figura 4). ${ }^{104}$ Esta etapa deve ser seguida do ataque do oxigênio terminal do substituinte peroxinitrito ao átomo de carbono ligado ao boro, produzindo íons nitrito e o intermediário arilborano (2). Finalmente, a hidrólise deste último resulta na formação de ácido bórico e o produto fenólico fluorescente (3). Estes boronatos reagem com peróxido de hidrogênio e hipoclorito mas com constantes de velocidade de 6 a 3 ordens de magnitude inferiores. ${ }^{100}$ Portanto, boronatos apresentam resolução cinética excelente para detecção de peroxinitrito, oferecendo medidas com elevada sensibilidade e seletividade em tempo real. Além disso, alguns boronatos como o ácido ou éster borônico de cumarina (CBA/CBE) $)^{102}$, fluoresceína (FIAMBE) $)^{102}$ e 1-pireno (PyBor) ${ }^{101}$ têm sido usados com sucesso na deteç̧ão de peroxinitrito em células em diferentes condições, sejam elas em condições normais ou simulando estresse nitrosativo. 
Figura 4 - Mecanismo de reação entre boronatos e peroxinitrito.

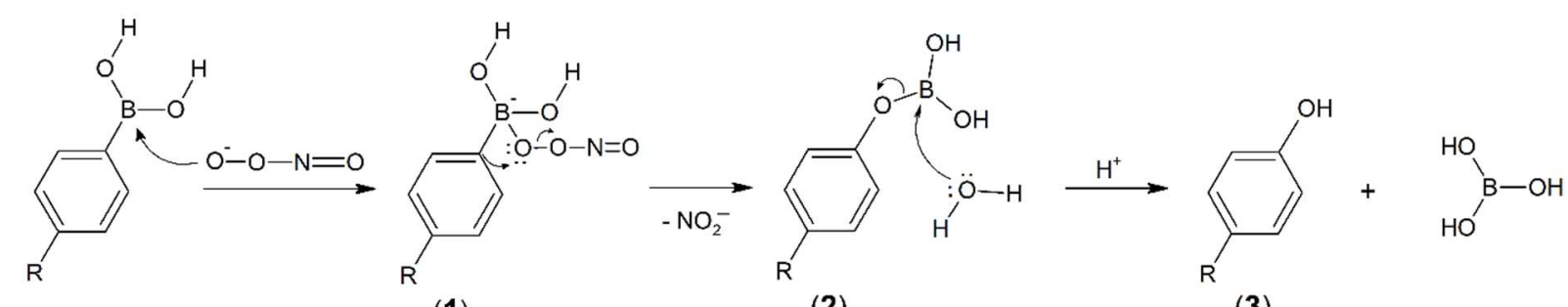

(1)

(2)

(3)

Fonte: Adaptado da referência ${ }^{101}$. Ilustração genérica do mecanismo proposto na literatura para a reação entre boronatos e peroxinitrito. i) primeiramente, há o ataque do oxigênio terminal da ligação peroxo do peróxido (nucleófilo) ao boro do indicador (eletrófilo) e formação do composto (1). ii) rearranjo estrutural do composto (1) com formação do arilborano (2) e eliminação de nitrito ( $\left.\mathrm{NO}_{2}^{-}\right)$, iii) hidrólise do composto (2) formando o derivado fenólico fluorescente (3) e ácido bórico.

\subsection{Modelo de cinética de competição}

Uma vez formado, peroxinitrito pode reagir com múltiplos alvos em células, notadamente metais, dióxido de carbono e tiol peroxidases (Prxs e Gpxs). Quando presentes, boronatos introduzem uma nova rota reacional e essencialmente competem com todos os alvos endógenos por peroxinitrito, como ilustra a Figura 5. Portanto, a detecção de peroxinitrito por boronatos depende de sua competitividade cinética com estes alvos. Evidentemente, concentrações elevadas do indicador garantem que teoricamente todo peroxinitrito formado reaja com o boronato em detrimento dos alvos biológicos naturais.

Figura 5 - Modelo de competição entre os principais alvos endógenos por peroxinitrito.

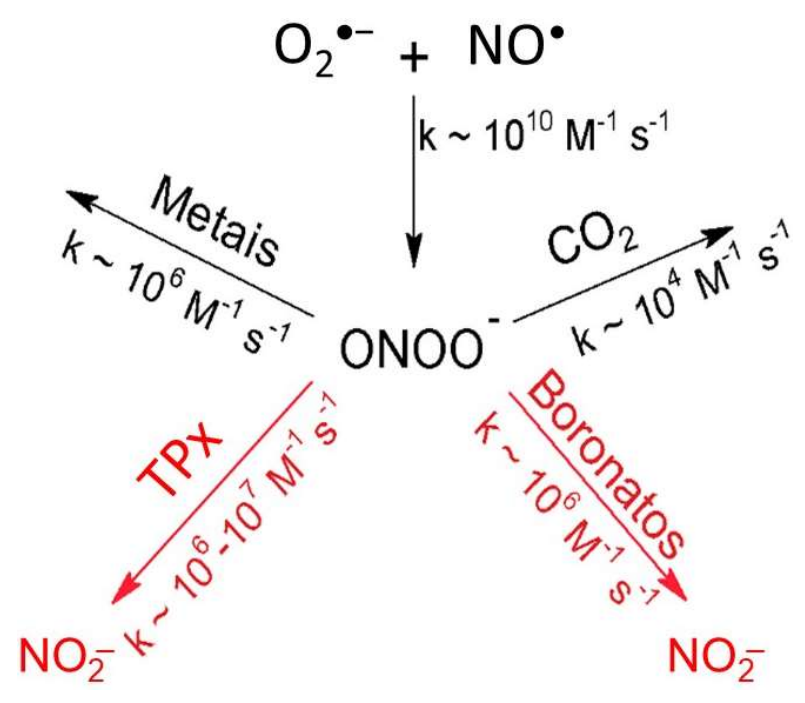


Fonte: produção do autor. Entre as constantes apresentadas destacam-se, a formação de peroxinitrito e sua reação com tiol peroxidases (TPxs) e boronatos. Metais e dióxido de carbono também reagem com peroxinitrito.

A estratégia do estudo para investigar a relevância da atividade peroxinitrito redutase de peroxidases é baseada no princípio de competição entre boronatos e estas peroxidases. A expectativa é que quanto maior o consumo de peroxinitrito por tiol peroxidases, menor a oxidação e a fluorescência do indicador boronato. Para investigar o papel peroxinitrito redutase a oxidação de boronato foi monitorada em células Saccharomyces cerevisiae (Sc) de linhagem nativa (WT) relativo a linhagens onde todas as TPxs ou peroxirredoxinas específicas, foram geneticamente removidas. Este modelo foi conveniente para este estudo pois Saccharomyces cerevisiae é eucariótico e principalmente devido a existência de linhagens que não expressam Prxs específicas ou todos os membros das famílias de Prxs e GPxs. Isto foi importante para comparar a oxidação do indicador boronato nestas linhagens com a linhagem nativa. Além disso, como supramencionado Prx foram identificadas inicialmente em leveduras e estas expressam NOS. Desta forma, os resultados obtidos na pesquisa podem ser extrapolados para outros modelos de células, como de mamíferos. Neste modelo de estudo peroxinitrito foi produzido preferencialmente utilizando a combinação de um doador de NO` e um gerador de superóxido ou com composto SIN-1. Ambos métodos de geração de peroxinitrito são melhor detalhados no item 3.4. 
2 OBJETIVOS 


\subsection{Objetivo Geral}

Investigar a atividade peroxinitrito redutase de tiol peroxidases (Peroxirredoxinas e Glutationa peroxidases) em células de Saccharomyces cerevisiae.

\subsection{Objetivos específicos}

Investigar a atividade peroxinitrito redutase de Peroxirredoxinas específicas (Tsa1 e Tsa2).

Averiguar se a atividade peroxinitrito redutase é catalítica nas condições experimentais utilizadas no estudo. 
3 MATERIAIS E MÉTODOS 


\subsection{Modelo celular}

Para este estudo as cepas de leveduras foram obtidas de um banco de linhagens do colaborador deste projeto, o Prof. Dr. Luis Eduardo Soares Netto do Departamento de Genética e Biologia Evolutiva do Instituto de Biociências da USP (IB - USP), sendo:

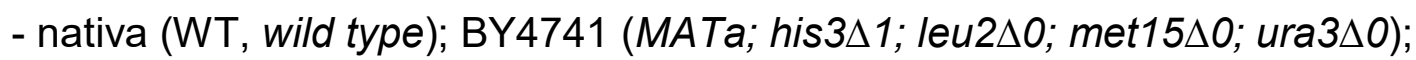

- mutante ( $\Delta 8$ ); nula para todas as cinco (5) Prx e três (3) GPx existentes no modelo celular, GY100 (MATa; his3; leu2; met15; ura3; $\triangle$ tsa1:KAN; $\Delta$ tsa2:LEU2;

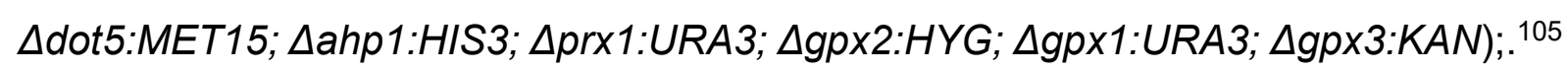

- mutantes para genes de Prx específicas;

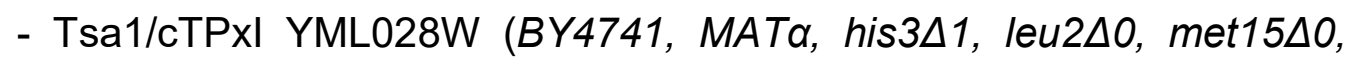
ura3 $\triangle 0$, YML028w::kanMX4); ${ }^{106}$ EUROSCARF - Y00545.

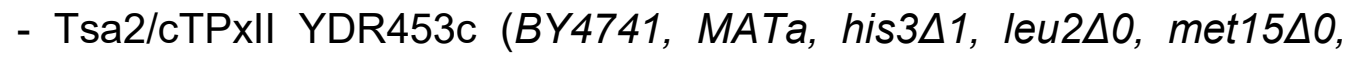
ura3 $\Delta 0$, YDR453c::kanMX4); ${ }^{51}$ EUROSCARF - Y04287

- $\Delta 8+T s a 1 ;$ transfecção da Prx mais abundante em leveduras (Tsa1) na сера $\Delta 8$.

A proteína Tsa1 foi expressa na cepa $\Delta 8$, cepa $\Delta 8+T s a 1$, utilizando 0 plasmídeo de expressão pCEV-G1-Ph construído sob controle do promotor constitutivo TEF1 (translation elongation factor EF-1 alpha) e com o gene marcador de seleção ble, que confere resistência à fleomicina, um antibiótico da classe de metalo-glicopeptídeos (Figura 6A), como descrito por Kaya et. al.. ${ }^{107}$ A expressão de Tsa1 nesta cepa foi confirmada por Western blotting (Figura 6B) e comparada com as cepas que não expressam a enzima, $\Delta 8$ e $\Delta$ Tsa1. 
Figura 6 - Construção do plasmídeo e expressão da enzima Tsa1 na cepa $\Delta 8+T s a 1$.

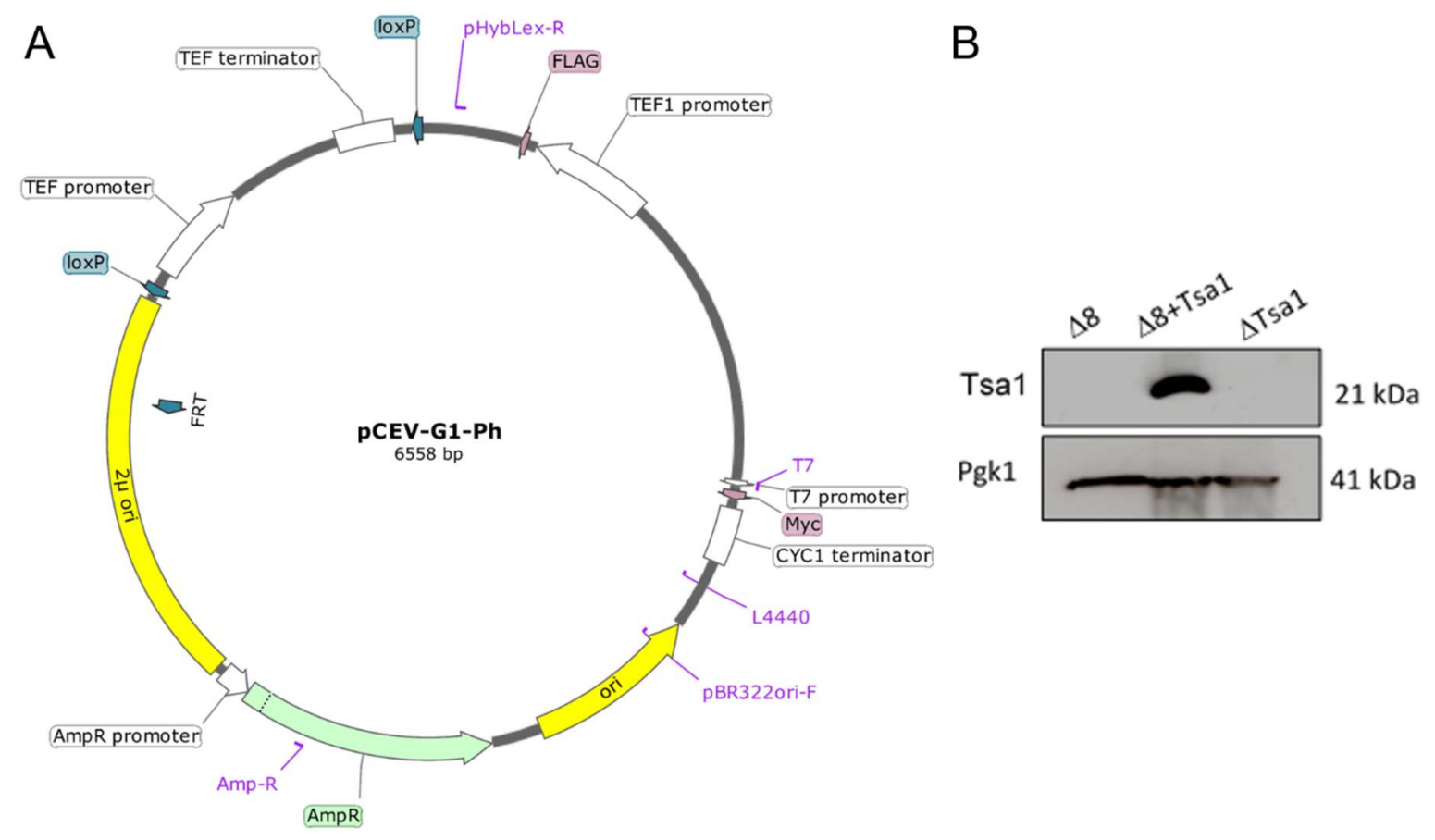

Fonte: Produção do autor. (A) Mapa circular do plasmídeo pCEV-G1-Ph utilizado na construção da linhagem $\Delta 8+T s a 1$. (B) Western blotting para a proteína Tsa1 (linha 1) nas cepas $\Delta 8, \Delta 8+T s a 1$ e $\Delta$ Tsa1. Promoter Pgk1 (linha 2). (A) visualizado com o software SnapGene Viewer 4.0.5 (SnapGene® software da GSL Biotech; disponível em snapgene.com) (B) Os dados foram fornecidos pelo colaborador Prof. Dr. Luis Eduardo Soares Netto.

\subsection{Condições de cultivo}

\subsubsection{Cultivo em meio rico.}

As cepas foram cultivadas em meio contendo extrato de leveduras, peptona e dextrose, YPD (yeast extract, peptone and dextrose) na proporção de 1:2:2 \% $/ \mathrm{v}$, por 12 horas e à $30^{\circ} \mathrm{C}$ em incubadora do tipo orbital (Shaker) à $150 \mathrm{rpm}$.

\subsubsection{Culturas adaptadas em glicerol.}

Para estimular atividade respiratória as linhagens foram cultivadas por 12 horas em meio YPD, como descrito no subitem acima, posteriormente, centrifugadas para completa remoção do meio YPD, re-suspensas e incubadas em meio de cultura contendo extrato de levedura, peptona e glicerol (YPG) na proporção de 1:2:3 \% $/ \mathrm{m}$ por 4 horas à $30^{\circ} \mathrm{C}$ e $150 \mathrm{rpm}$. 


\subsubsection{Curvas de crescimento na presença de oxidantes.}

Para as curvas de crescimento na presença de paraquat e doador de óxido nítrico, os pré-inóculos das cepas $\mathrm{WT}, \Delta 8, \Delta \mathrm{Tsa} 1$ e $\Delta \mathrm{Tsa} 2$ foram preparados e inoculadas em uma $\mathrm{DO}_{600}$ inicial de 0,05 em meio YPD e cultivadas por 24 horas à $150 \mathrm{rpm}$ e $30^{\circ} \mathrm{C}$. Periodicamente, amostras foram coletadas e as células contadas por $\mathrm{DO}_{600}$ para construção das curvas.

\subsection{Condições experimentais}

Todos os experimentos foram realizados com células coletadas no mesmo dia de análise com cerca de 12 horas do início do cultivo, que corresponde ao final da fase logarítmica da curva de crescimento para as cepas WT e $\Delta 8$ (Figura 7), lavadas por dois ciclos de centrifugação e re-suspensão em tampão fosfato salino PBS $10 \mathrm{mM}$ (do inglês, Phosphate-Buffered Salt) (composição: $\mathrm{NaCl} 137 \mathrm{mM}, \mathrm{KCl}$ 2,70 mM, $\mathrm{Na}_{2} \mathrm{HPO}_{4} \quad 8,10 \quad \mathrm{mM}, \quad \mathrm{KH}_{2} \mathrm{PO}_{4} \quad 1,76 \quad \mathrm{mM}$ complementado com o ácido dietilentriaminopentaacético, Dtpa $0,10 \mathrm{mM}$ ) de $\mathrm{pH} 7,4$ à $5^{\circ} \mathrm{C}$, para completa remoção do meio de cultura. O número de células nos experimentos foi determinado imediatamente antes dos experimentos pela densidade óptica em $600 \mathrm{~nm}\left(\mathrm{DO}_{600}\right)$, onde uma $\mathrm{DO}_{600}=0,1$ corresponde a 3,0 × $10^{6}$ células em $1 \mathrm{~mL}$ de suspensão em PBS, ${ }^{108}$ usando o espectrofotômetro Shimadzu UV-1800.

Figura 7 - Curva de crescimento das cepas WT e $\Delta 8$.

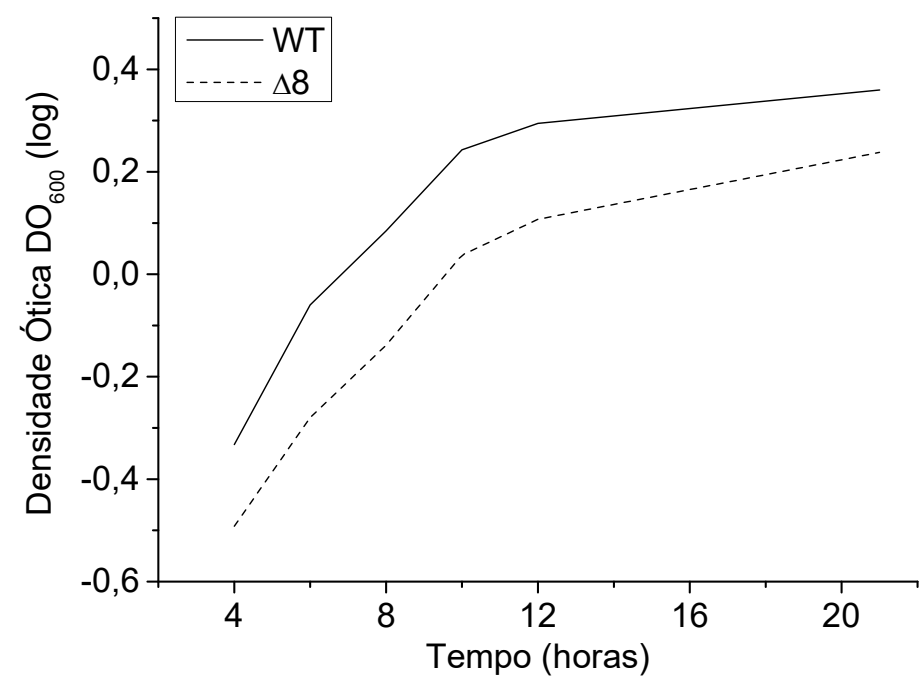

Fonte: Produção do autor. Curva de crescimento das cepas de Saccharomyces cerevisiae selvagem (WT) e mutante $(\Delta 8)$ no período de $4-20$ horas em meio YPD à $30^{\circ} \mathrm{C}$ e $150 \mathrm{rpm}$. 
Nos experimentos 20 milhões ou quantidades variáveis das células em tampão $\mathrm{PBS}$ pH 7,4 à $30^{\circ} \mathrm{C}$ foram adicionadas nos poços de microplacas, em seguida os reagentes, indicador fluorescente (CBA), ciclador redox (paraquat) e doador de NO• (sper/NO ou deta/NO) foram adicionados ordenadamente nas concentrações descritas na legenda das figuras para um volume final de $250 \mu \mathrm{L}$. Nos experimentos com SIN-1 este era adicionado após o CBA. Imediatamente após a adição dos reagentes as leituras eram iniciadas. As medidas de fluorescência com o indicador fluorescente CBA (ácido borônico de cumarina) foram conduzidas em placa de micropoços utilizando a leitora de placas spectraMax Gemini EM, spectraMax M3 ou spectraMax i3x (Molecular Devices) com fendas de excitação e emissão, 9 e 9 nm, 9 e $15 \mathrm{~nm}, 9$ e $15 \mathrm{~nm}$, respectivamente. Os comprimentos de onda de excitação e emissão para o CBA foram de 332 e $456 \mathrm{~nm}$, respectivamente. A aquisição de dados foi realizada em intervalos de 1 ou 5 minutos por no mínimo 60 minutos. Nos intervalos de aquisição, a janela de excitação foi mantida fechada para evitar o branqueamento (photobleaching) do composto fluorescente 7-hidroxi-cumarina $(\mathrm{COH})$. Ainda, a placa foi agitada pelo instrumento, em agitação média, a cada nova aquisição para evitar a sedimentação celular.

\subsection{Regentes utilizados}

Todos os reagentes foram adquiridos da Sigma-Aldrich, exceto o indicador CBA, adquirido da Boron Molecular. Os reagentes foram preparados seguindo determinação do fornecedor e protocolos experimentais.

\subsubsection{Doadores de óxido nítrico - NO•}

Foram utilizados dois doadores de NO• do tipo NONOate, SpermineNONOate (N-[4-[1-(3-aminopropil)-2-hidroxi-2-nitrosohidrazino]butil-1,3-propanodiamina, Sper/NO) e DietilenotriaminaNONOate (2,2'-(Hidroxinitrosohidrazona)bis-etanimina, Deta/NO). A característica principal desta família de compostos é a liberação de duas moléculas de $\mathrm{NO}^{\bullet}$ por molécula de doador com meias-vidas $\left(\mathrm{t}_{1 / 2}\right)$ de liberação de $\mathrm{NO} \bullet$ de 39 minutos e 19 horas $\left(\mathrm{pH} 7,25^{\circ} \mathrm{C}\right)$, respectivamente. Os doadores de NO foram pré-solubilizados em $\mathrm{NaOH} 0,01 \mathrm{M}$ e estocados à $-80^{\circ} \mathrm{C}$ até o uso e quando necessário as soluções foram calibradas através de ensaio com oxihemoglobina. ${ }^{109}$ 


\subsection{2 "Doador" de peroxinitrito: SIN-1.}

Como ilustrado na figura 8, o 3-(4-Morfolinil)sidnona imina hidrocloreto (SIN1) (A) produz o ânion radical superóxido por redução de oxigênio molecular $\left(\mathrm{O}_{2}\right)$ e o cátion radical SIN-1C (C) em um processo dependente do $\mathrm{pH}$, quanto mais alcalino mais rápida é formação do composto $\operatorname{SIN}-1 \mathrm{~A}(\mathrm{~B})$, contudo a etapa de redução é limitada pela disponibilidade de $\mathrm{O}_{2}$. Por vez, o composto (C) se decompõe produzindo NO• e o diazo composto (D). A eficiência na produção de ONOO- por SIN-1 pode ser melhorada fornecendo um doador de $\mathrm{NO}^{*}$. As soluções estoque foram preparadas em dimetilsulfóxido (DMSO) e armazenadas à $-20^{\circ} \mathrm{C}$.

Figura 8 - Produção de ONOO- por SIN-1.

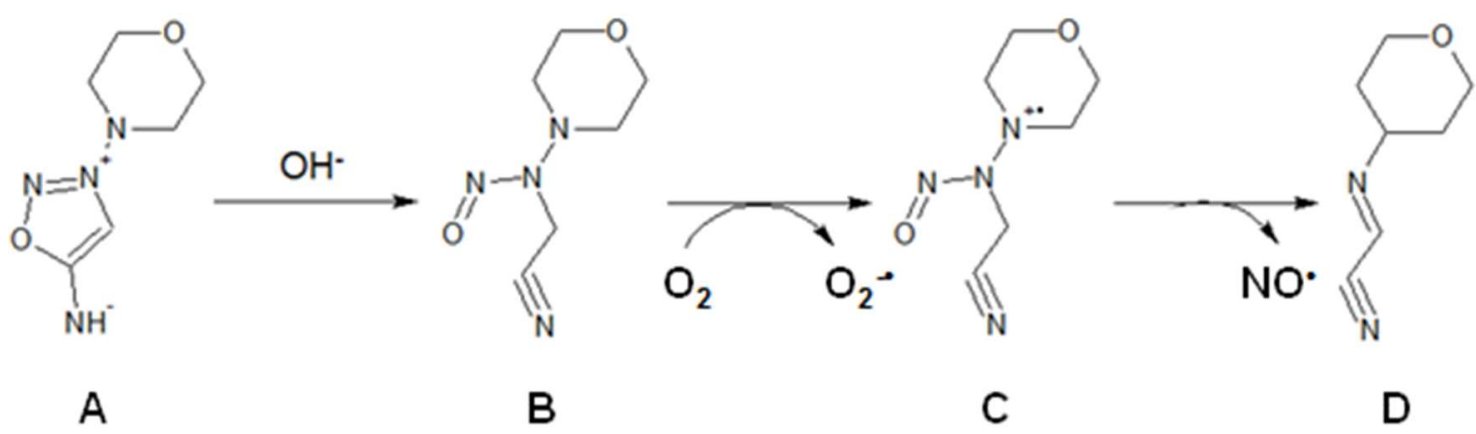

Fonte: Adaptado da referência ${ }^{93}$. SIN-1 produz o ânion radical superóxido por redução de oxigênio molecular e libera óxido nítrico, ambos precursores de ONOO.

\subsubsection{Indicador fluorescente CBA.}

$\mathrm{O}$ indicador CBA foi solubilizado em dimetilsulfóxido (DMSO) e armazenado em alíquotas à $-20^{\circ} \mathrm{C}$, a concentração dos estoques foram posteriormente ajustadas com DMSO para os experimentos em tampão PBS pH 7,4.

\subsubsection{Boronato não fluorescente.}

A forma éster pinacol do ácido 4-acetil-fenil-borónico (APBE), boronato não fluorescente utilizado como um removedor de peroxinitrito, foi preparado como descrito acima para o indicador CBA.

\subsubsection{Gerador de superóxido.}

Paraquat. Paraquat $\left(\mathrm{PQ}^{2+}\right)$ é um metil-viologeno usado como herbicida. Paraquat é reduzido por um elétron por vários redutores, produzindo o cátion radicalar correspondente $\left(\mathrm{PQ}^{+\bullet}\right)$ (Figura 9) que, por sua vez, reduz oxigênio $\left(\mathrm{O}_{2}\right)$ produzindo o ânion radical superóxido $\left(\mathrm{O}_{2}{ }^{-\bullet}\right) \cdot{ }^{110}$ Como requer um redutor, a produção de superóxido 
é dependente de redutores celulares (NADPH) no modelo do estudo. Esta é uma vantagem porque superóxido é produzido somente em ambiente intracelular. A solução do reagente foi preparada imediatamente antes dos experimentos no próprio tampão PBS pH 7,4.

Figura 9 - Esquema do ciclo redox do Paraquat

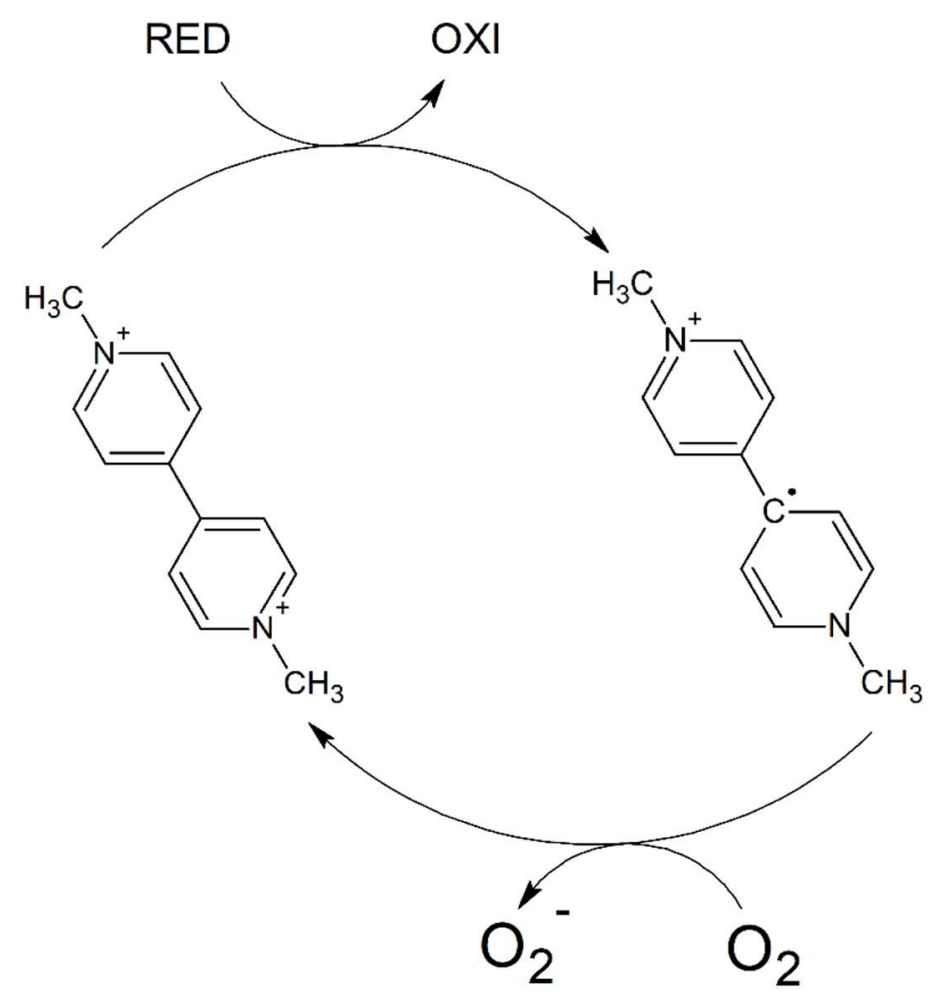

Fonte: Produção do autor. Ciclo redox do paraquat é iniciado por redução mono-eletrônica do dicátion paraquat $\left(\mathrm{PQ}^{2+}\right)$ formando o cátion radical $\left(\mathrm{PQ}^{+\bullet}\right)$, em seguida, há a redução do oxigênio $\left(\mathrm{O}_{2}\right)$ à superóxido $\left(\mathrm{O}_{2}^{-\bullet}\right)$ e reconstituição do di-cátion paraquat.

3.5 Análise estatística.

Os grupos principais foram comparados relativo usando análise de variância e o teste $t$-Students para o intervalo de confiança de $95 \%$ quando $p<0,05$ como descrito nas figuras. 
4 RESUltados 
4.1 Oxidação do ácido borônico de cumarina (CBA) nas cepas WT e $\Delta 8$ desafiadas com fluxo de peroxinitrito.

A oxidação do indicador CBA dependente de peroxinitrito via fluorescência em células das cepas WT e $\Delta 8$ foi avaliada utilizando duas estratégias diferentes de produção de peroxinitrito, combinação paraquat/doador de NO• ou SIN-1. Como mencionado anteriormente, a cepa $\Delta 8$ não expressa nenhum membro das famílias de Prxs e GPxs. Experimentalmente, $20 \times 10^{6}$ células de ambas as cepas suspensas em PBS/DTPA pré-aquecido a $30^{\circ} \mathrm{C}$ e contendo CBA $(50 \mu \mathrm{M})$, foram acondicionadas em placas de múltiplos poços. Em seguida, o fluxo de peroxinitrito foi induzido pela introdução sequencial da combinação de paraquat e do doador de NO• ou de SIN-1. A aquisição de dados de fluorescência do produto da oxidação, 7-hidroxi cumarina, foi iniciada imediatamente e conduzida em intervalos de cinco minutos por 90 minutos (Figuras 10A e 10B). Claramente, a taxa de oxidação do indicador fluorescente foi qualitativamente maior para a cepa mutante $\Delta 8$ (linha superior) relativo à cepa WT (linha inferior) para quaisquer estratégias de produção de peroxinitrito (Figuras $10 \mathrm{~A} \mathrm{e}$ 10B). A figura 10C mostra esta conclusão mais claramente, em termos das taxas de oxidação do CBA para ambas condições e cepas. 
Figura 10 - Oxidação do indicador CBA em células utilizando a combinação paraquat/doador de $\mathrm{NO}^{*}$ ou SIN-1.

A

B
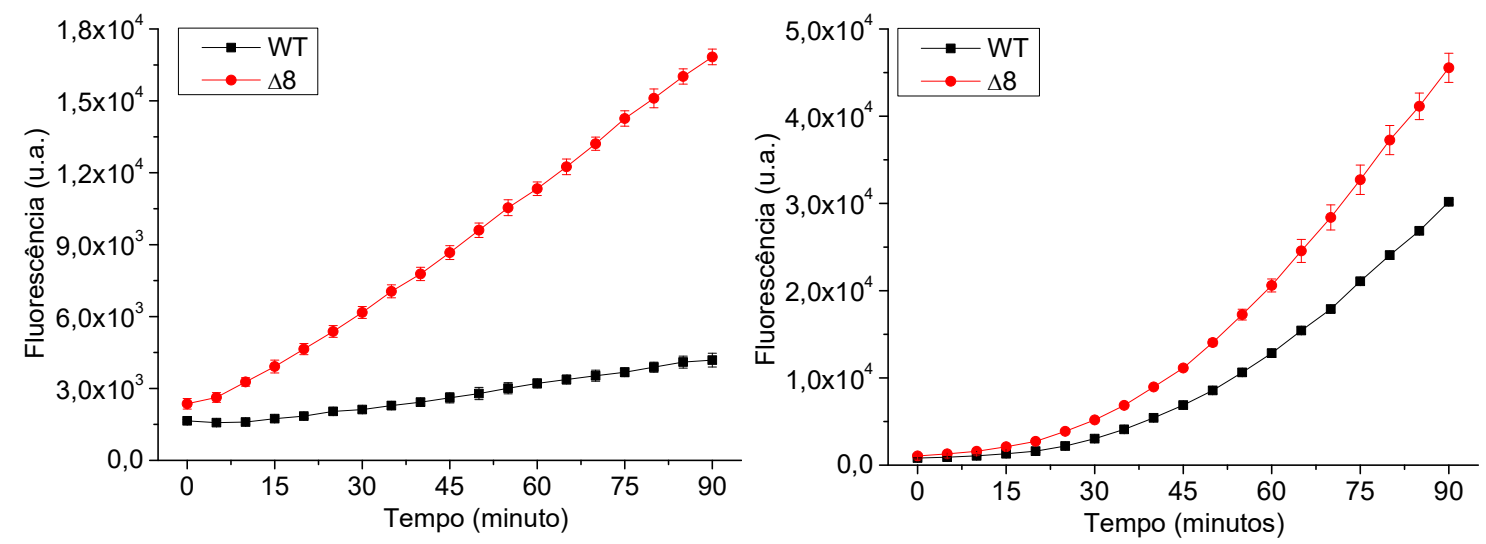

C

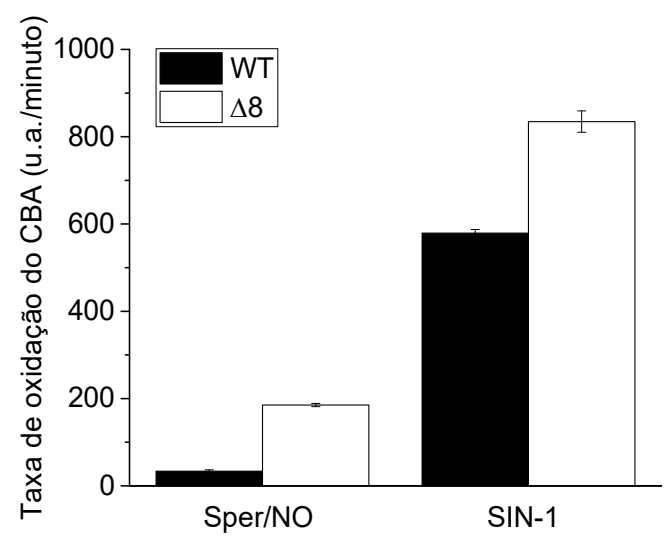

Fonte: produção do autor. $S c-W T$ (linha preta) e $S c-\Delta 8$ (linha vermelha). Condições Experimentais: CBA $(50 \mu \mathrm{M})$ e (A) paraquat $(10 \mu \mathrm{M})$ e sper/NO $(50 \mu \mathrm{M})$ ou (B) SIN-1 $(500 \mu \mathrm{M})$. (C) Taxa de oxidação do CBA. A taxa de oxidação do CBA foi determinada pela regressão linear entre 70 - 90 minutos nas curvas dos painéis A e B. Todos os ensaios foram conduzidos com 20 milhões de células em um volume final de $250 \mu \mathrm{L}$ de PBS pH 7,4 suplementado com DTPA $(100 \mu \mathrm{M})$ à $30^{\circ} \mathrm{C}$. Os dados são representativos de três (3) medidas independentes \pm D.P. e foram consideradas diferentes estatisticamente dentro do mesmo grupo e entre os grupos para $p<0,05$ usando o teste $t$-Student. Parâmetros de aquisição de fluorescência foram: $\lambda_{\mathrm{Ex}} 332 \mathrm{~nm} ; \lambda_{\mathrm{Em}}=456 \mathrm{~nm}$ durante 90 minutos na leitora de placas SpectraMax Gemini EM.

A taxa de oxidação do CBA foi maior para SIN-1, especialmente considerando que este composto produz $\mathrm{O}_{2}{ }^{--}$e $\mathrm{NO}^{\bullet}$ muito mais lentamente ${ }^{111}$ que sper/NO e paraquat. Mas este resultado pode simplesmente refletir as diferentes concentrações utilizadas. Mais importante, a diferença entre a taxas de oxidação do CBA entre WT e $\triangle 8$ para a combinação paraquat/doador de $\mathrm{NO}^{*}$ é claramente maior do que a para SIN-1 (Figura 10C). De fato, as taxas de oxidação de CBA entre WT e $\Delta 8$ para o caso 
do SIN-1 são semelhantes, sugerindo diferenças entre as duas estratégias de produção de fluxo de peroxinitrito utilizadas. A interpretação mais simples para esta observação experimental está relacionada às diferenças dos compostos utilizados no que concerne ao compartimento de produção de peroxinitrito. SIN-1 produz ambos $\mathrm{O}_{2}{ }^{--}$e $\mathrm{NO}^{\bullet}$ espontaneamente (e independentemente da presença de células), portanto, pode gerar peroxinitrito no meio extracelular. Por outro lado, paraquat produz $\mathrm{O}_{2}{ }^{--}$de forma dependente de redutores intracelulares. Considerando as cargas e a impermeabilidade ou limitada difusão de $\mathrm{O}_{2}{ }^{--}$e $\mathrm{ONOO}^{-}$por membranas celulares, esta estratégia produz peroxinitrito primariamente no meio intracelular. Desta forma, componentes celulares como TPxs competem com boronatos mais eficientemente por peroxinitrito gerado pela combinação paraquat/doador de NO• do que por SIN-1. Isto explica a resposta maior para SIN-1. Mas, mais importante, a observação de que as cepas WT e $\Delta 8$ comportam-se semelhantemente no caso do SIN-1 na verdade reforçam a noção de que tiol peroxidases são agentes com atividade peroxinitrito redutase importantes. Devido a estes resultados a maioria dos experimentos posteriores foram conduzidos com a combinação paraquat/doador de NO•.

4.2 Oxidação de CBA em função da densidade celular, concentração do doador de NO• e do próprio CBA.

Com o objetivo de analisar variáveis relevantes da oxidação intracelular de CBA, entre elas a densidade celular, concentração do doador de $\mathrm{NO} \bullet$ e do próprio indicador CBA. Primeiramente, a oxidação foi investigada em função da concentração do indicador CBA (Figuras 11A e 11B). Isso foi importante para definir uma concentração adequada de CBA que fornecesse simultaneamente, sensibilidade adequada e que permitisse competição entre o indicador e alvos celulares por peroxinitrito. Para isso, as cepas WT e $\Delta 8$ foram expostas a combinação (paraquat/doador de $\mathrm{NO}^{\bullet}$ ) na presença de crescentes concentrações do indicador CBA. A taxa de oxidação de CBA inicialmente aumenta com sua própria concentração, refletindo competição com outros alvos celulares de peroxinitrito. Como esperado, a taxa alcança um máximo acima de 10 e $20 \mu \mathrm{M}$ de CBA para as cepas WT e $\Delta 8$, respectivamente (Figura 11B), sugerindo que acima deste limite praticamente todo peroxinitrito formado reage com CBA. Novamente, a taxa de oxidação de CBA foi sempre significativamente maior para a cepa $\Delta 8$, independentemente da concentração 
do indicador. Interessante que esta diferença é mantida mesmo para concentrações limitantes de CBA. O significado desta diferença nesta faixa não é claro. Porém, este resultado pode indicar que WT possui agentes captadores de peroxinitrito em compartimentos inacessíveis ao CBA.

Figura 11 - Oxidação e taxa de oxidação de CBA em função de parâmetros importantes.
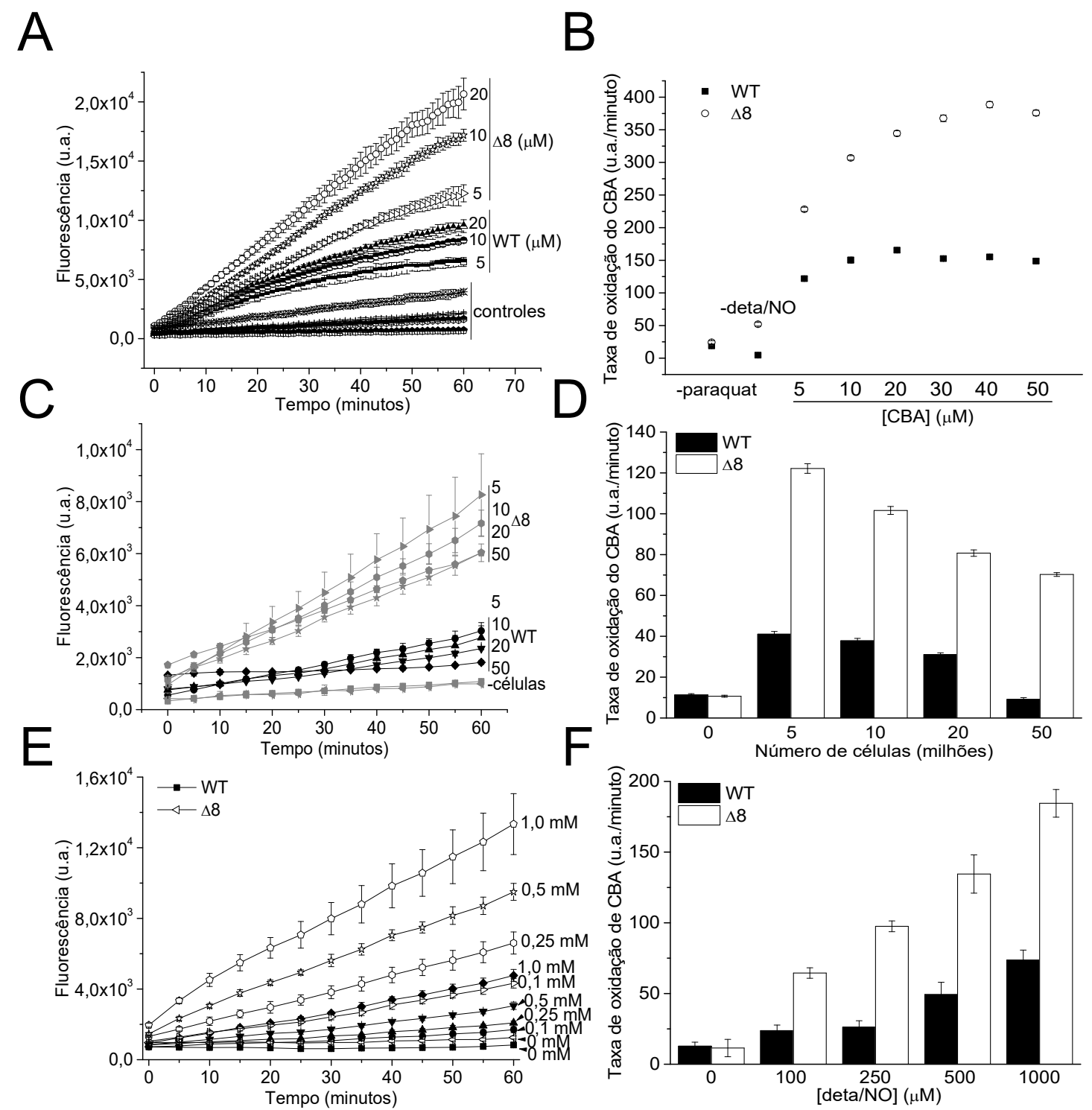

Fonte: Produção do autor. (A) Oxidação do CBA em função da concentração do próprio CBA (5, 10, 20, 30, 40 e $50 \mu \mathrm{M})$. (B) Taxas de oxidação do CBA relativas às curvas em $\underline{A}$ dadas em (u.a./minuto). (C) Oxidação do CBA em função da densidade celular (5, 10, 20 e 50 milhões). (D) Taxa de oxidação do $C B A$ relativas às curvas em $\underline{C}$ dadas em (u.a./minuto). (E) Oxidação do $C B A$ em função da variação da concentração de deta/NO $(0,0 ; 0,1 ; 0,25 ; 0,50$ e 1,0 mM). (F) Taxa de oxidação do CBA relativa às curvas em E dadas em (u.a./minuto). Os dados representam a média de três (3) medidas \pm D.P. As 
taxas de fluorescência obtidas pela regressão linear das curvas são paramétricas e são diferentes entre si no mesmo grupo, exceto controles (-paraquat, 0 e 0 ) em $\underline{B}, \underline{D}$ e $\underline{F}$ respectivamente, e entre os grupos a partir das concentrações de 10 e 20 em B para WT e $\Delta 8$ respectivamente, e WT (0 e 50), (100 e 250) em $D$ e $F$ respectivamente para $(p<0,05)$. Condições Experimentais: paraquat $10 \mu \mathrm{M}$, CBA $10 \mu \mathrm{M}$, deta/NO $500 \mu \mathrm{M}$ e 20 milhões de células, exceto quando especificado diferentemente acima. Os parâmetros de aquisição de fluorescência foram iguais a da figura 9 .

Para o restante do estudo, os experimentos foram conduzidos com $10 \mu \mathrm{M}$ de CBA. Esta concentração apresenta sensibilidade de fluorescência razoável e encontra-se numa faixa que permite competição entre CBA e componentes celulares para as duas cepas.

Nas figuras 11C e 11D são mostrados os resultados em função de crescentes densidades celulares na presença de paraquat e deta/NO. Não há oxidação significativa de CBA na ausência de células, simplesmente indicando que a produção de $\mathrm{O}_{2}{ }^{\bullet-}$ por paraquat depende de redutores celulares e que o processo é intracelular. Mais relevante, a oxidação do indicador diminui com a densidade celular, mostrando que células apresentam mecanismos de consumo de peroxinitrito e foi sempre menor para cepa WT relativo a $\Delta 8$, sugerindo novamente que TPxs são agentes importantes na remoção de peroxinitrito. Esta conclusão está mais evidente na figura 11D, que expressa a taxa de oxidação do CBA. Para a cepa $\Delta 8$ a taxa de oxidação do CBA diminuiu de aproximadamente 120 para 75 u.a./min entre 5 e 50 milhões de células respectivamente, uma diminuição de $38 \%$. Já para a WT, a diminuição foi de aproximadamente 40 para 10 u.a./min para as mesmas densidades celulares, uma diminuição de 75\%, e o nível de oxidação de CBA para 50 milhões de células WT é idêntico ao controle na ausência de células. Finalmente, a observação de que a taxa de oxidação também diminui para a cepa mutante $\Delta 8$ indica que estas células possuem mecanismos adicionais de remoção de peroxinitrito (além de TPxs), provavelmente envolvendo metalo-proteínas (Figura 5). A partir deste experimento ficou definido o uso de 20 milhões de células para os estudos.

Por fim, a taxa de oxidação do indicador foi investigada em função da concentração do doador de $\mathrm{NO}^{*}$. Como esperado para o aumento da produção de peroxinitrito, a oxidação de CBA aumenta proporcionalmente com a concentração de doador de $\mathrm{NO}^{\bullet}$ para as duas cepas e foi sempre significativamente maior para a cepa $\Delta 8$ relativo a cepa WT (Figuras 11E e 11F). Este resultado reforça que tiol peroxidases são agentes com atividade peroxinitrito redutase e são relevantes numa ampla faixa 
de concentração de $\mathrm{NO}^{\bullet}$, simulando condições normais e de estresse oxidativo. E isto foi mantido durante todo intervalo de tempo monitorado.

\subsection{Oxidação do ácido borônico de cumarina (CBA) depende de peroxinitrito.}

Para confirmar que a oxidação de CBA, nas condições experimentais do estudo, é depende de peroxinitrito, embora que teoricamente, o uso de CBA já garante esta prerrogativa, uma vez que boronatos respondem quase que seletivamente a peroxinitrito relativo a outros oxidantes potencialmente presentes, como peróxido de hidrogênio. foi utilizado um outro boronato não fluorescente APBE (do inglês, 4acetylphenylboronic acid pinacol ester). Desta forma, experimentos em condições similares aos descritos no item acima foram conduzidos na presença de crescentes concentrações de APBE. Os resultados mostram que houve redução considerável na oxidação do CBA, melhor observado quando comparamos as taxas de oxidação do CBA em função da concentração de $\operatorname{APBE}(0,10,25$ e $50 \mu \mathrm{M})$. Isto confirma que a oxidação do CBA é dependente de ONOO- nas condições experimentais do estudo (Figuras 12A e 12B). A diminuição na taxa de oxidação do CBA para ambas as cepas WT e $\Delta 8$ é proporcional a concentração de APBE utilizada (Figura 12B). Isto é, a relação de prevenção da oxidação de CBA entre $\Delta 8$ / WT para a menor concentração de APBE $(10 \mu \mathrm{M})$ é idêntica a situação controle (sem adição de APBE, razão $\triangle 8$ / WT = aproximadamente 2,67), indicando que há consumo de peroxinitrito por APBE, competindo extensivamente com CBA por peroxinitrito. Essa mesma concentração de APBE reduz em aproximadamente $50 \%$ a oxidação do CBA em ambas as cepas. $\mathrm{Na}$ concentração de $25 \mu \mathrm{M}$ de APBE, a taxa de oxidação retornou para valores próximos ao do controle sem adição de Paraquat (-Paraquat) para a cepa WT. 
Figura 12 - Oxidação de CBA na presença do competidor APBE.
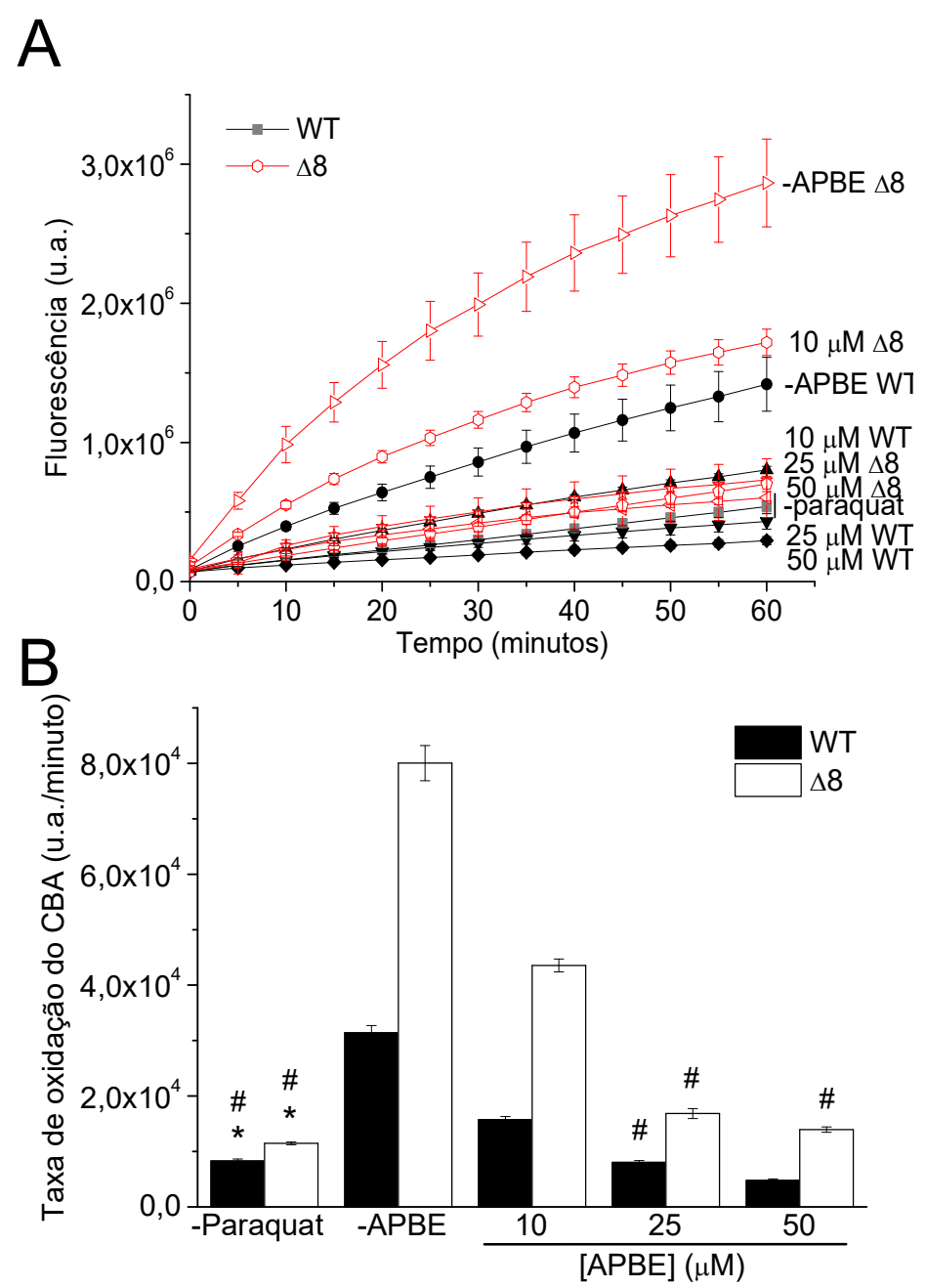

Fonte: Produção do autor. (A) Oxidação do CBA na presença de crescentes concentrações do competidor APBE. (B) taxa de oxidação do CBA das curvas em $\underline{A}$ (u.a./minuto). Os dados são representativos de três (3) análises \pm D.P. e foram considerados diferentes no grupo, exceto $\left({ }^{*}\right)$ e entre os grupos, exceto (\#) para $(p<0,05)$. Condições experimentais: Condições utilizadas; paraquat $10 \mu \mathrm{M}$, deta/NO $500 \mu \mathrm{M}$, CBA $10 \mu \mathrm{M}, 20$ milhões de células e APBE 10, 25 e $50 \mu \mathrm{M}$. Os parâmetros de aquisição de fluorescência foram $\lambda \mathrm{Ex} .332 \mathrm{~nm}$ e $\lambda \mathrm{Em}$. $456 \mathrm{~nm}$ à $\left(30^{\circ} \mathrm{C}\right.$, PBS $100 \mu \mathrm{M}$ DTPA, pH 7,4) usando o instrumento SpectraMax M3. 


\subsection{Oxidação de CBA em condições respiratórias.}

Organismos de uma forma geral produzem quantidades maiores de espécies reativas derivadas do oxigênio (ROS, particularmente superóxido) quando realizam respiração aeróbica. Isto é suportado pelo aumento do consumo de oxigênio e da expressão de transcritos envolvidos no metabolismo oxidativo (citocromo c oxidase 1, COX1 e citrato sintase 1,CIT1). ${ }^{112}$ Como consequência, há um aumento na expressão de enzimas antioxidantes que combatem tais espécies; superóxido dismutases (SOD), catalase (Ccat-1), glutationa peroxidases (GPxs) e também peroxirredoxinas (Prxs). ${ }^{113}$ Saccharomyces cerevisiae apresentam metabolismo facultativo, ou seja, podem realizar tanto respiração quanto fermentação, dependendo da quantidade, natureza dos nutrientes disponíveis e condições de oxigenação. Esta característica pode ser modulada em cultura celular pelo uso de diferentes fontes de carbono. Glicerol, etanol ou lactato ${ }^{108}$ são frequentemente utilizados para forçar metabolismo respiratório. Para explorar este aspecto, após o crescimento celular em YPD, as células foram lavadas por ciclos de centrifugação e ressuspensão. Em seguida, o meio contendo dextrose foi substituído por outro contendo glicerol (YPG) e mantidas neste meio por 4 horas. Posteriormente, as células foram coletadas para o estudo.

Células das cepas WT e $\Delta 8$ adaptadas a glicerol foram então submetidas a fluxos de peroxinitrito gerado pela combinação paraquat e crescentes concentrações de doador de $\mathrm{NO}^{\bullet}$ como descrito para o meio YPD. A figura 13A reúne a comparação das taxas de oxidação do CBA para cepas WT e $\Delta 8$ cultivadas apenas em dextrose, com células posteriormente adaptadas a glicerol. Para os dois casos a taxa de oxidação de CBA aumenta com crescentes concentrações do doador de NO• e é sempre maior para a cepa $\Delta 8$, como esperado, simplesmente reproduzindo resultados em cepas cultivadas em dextrose. Ainda, observamos que ambas as cepas WT e $\Delta 8$ adaptadas em glicerol apresentaram uma menor taxa de oxidação do CBA quando comparada às cultivadas em dextrose para todas as concentrações de deta/NO testadas (experimentos realizados concomitantemente). Calculou-se o percentual de aumento de resistência a oxidação de CBA das cepas adaptadas a glicerol pela razão das taxas de oxidação. Para isso, a taxa de oxidação em dextrose foi normalizada para $100 \%$ para cada concentração de doador de NO• empregada. A cepa WT adaptada em glicerol apresentou aumento de resistência a oxidação do CBA entre 62$70 \%$ com o aumento da concentração de doador de $N^{\bullet}$. A cepa $\Delta 8$ apresentou 
aumento variando entre 15 e 50\% (Figura 13B) com o aumento da concentração de doador.

Figura 13 - Oxidação do CBA em cepas Sc-WT e Sc- $\Delta 8$ adaptadas em meio suplementado com glicerol.

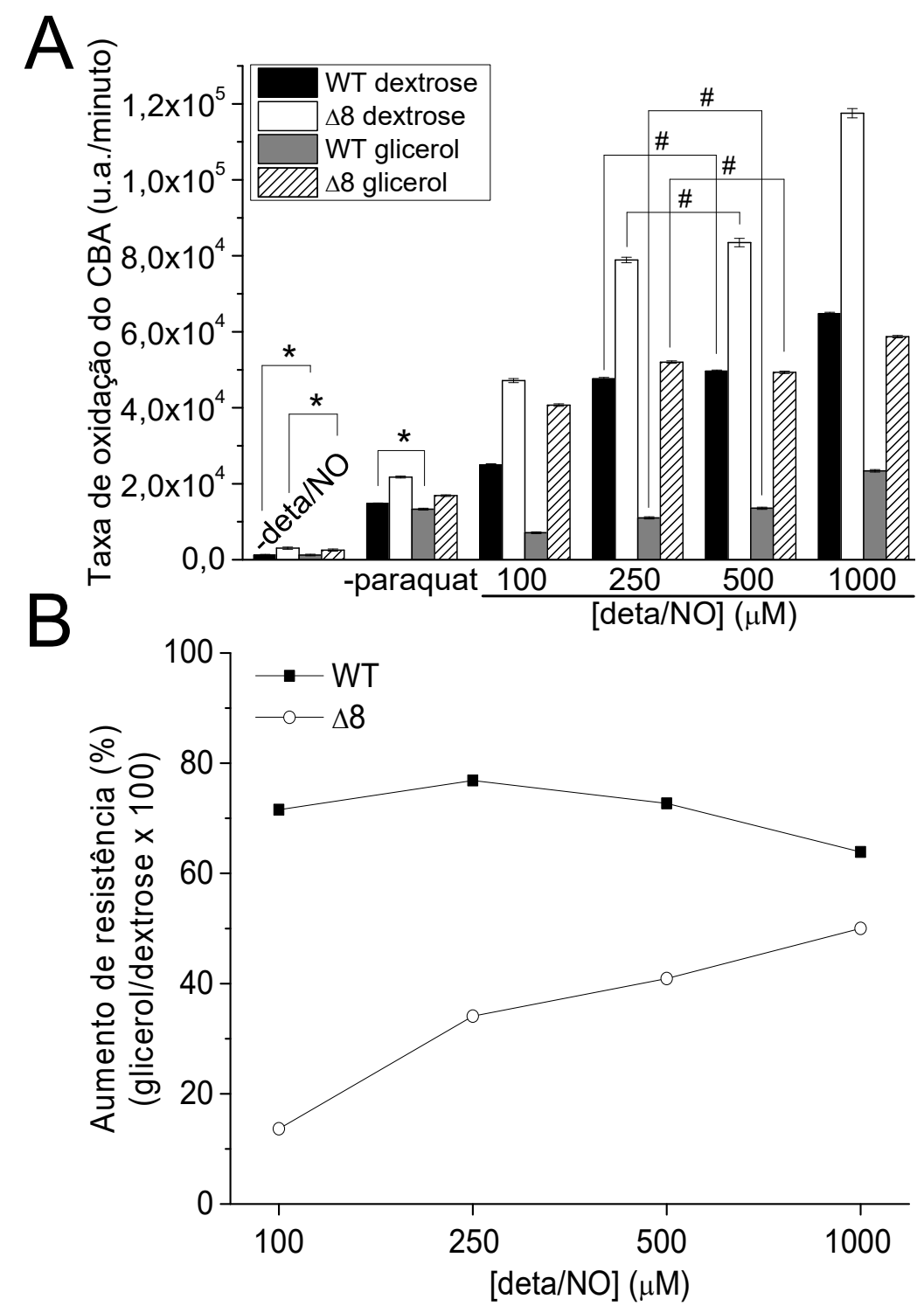

Fonte: Produção do autor. (A) gráfico da taxa de oxidação do indicador CBA em meio dextrose e adaptada em glicerol em crescentes concentrações do doador de $\mathrm{NO}^{\bullet}$ deta/NO. (B) percentual de aumento de resistência das cepas com base na diminuição da oxidação do indicador nas cepas adaptadas em glicerol em relação às cultivadas em dextrose (100\%). O experimento foi realizado como descrito na figura 4 com 20 milhões de células, $10 \mu \mathrm{M}$ de CBA, $10 \mu \mathrm{M}$ de paraquat por poço com crescentes concentrações de deta/NO. Os dados são representativos de três (3) medidas \pm D.P. Esses dados foram considerados diferentes dentro do grupo, exceto ${ }^{*}$ ) e entre grupos, exceto (\#) quando $p$ $<0,05$. Os parâmetros de aquisição de fluorescência foram os mesmos da figura 12

Portanto, os resultados claramente mostram que o ganho de resistência é muito maior para a cepa WT, em relação a $\Delta 8$, e sugerem que a adaptação da cultura 
em glicerol favorece o aumento da expressão de Prxs e GPxs na WT e que estas famílias de enzimas antioxidantes são agentes com relevante atividade peroxinitrito redutase. Contudo, os resultados mostram que a adaptação em glicerol aumenta a proteção celular relativo à peroxinitrito para ambas as cepas. Mesmo a cepa $\Delta 8$ dispõe de outros mecanismos de proteção contra peroxinitrito que também têm expressão aumentada em condições mais respiratórias. De fato, em trabalho recentemente publicado, Kaya et. al. identificaram alta expressão de genes associados ao cromossomo XI na cepa $\Delta 8$, dentre eles, da citocromo c peroxidase mitocondrial (Ccp1), ${ }^{114}$ que notadamente apresenta alta eficiência na remoção de $\mathrm{H}_{2} \mathrm{O}_{2}$ e peroxinitrito, com cinética da ordem de $10^{7}$ e $10^{6} \mathrm{M}^{-1} \mathrm{~s}^{-1}$, respectivamente. ${ }^{115}$

4.5 Avaliação da atividade peroxinitrito redutase de peroxirredoxinas específicas.

Com o objetivo de elucidar a atividade peroxinitrito redutase de peroxirredoxinas específicas em células, foram conduzidos experimentos com cepas de Saccharomyces cerevisiae contendo deleções dos genes TSA1 ou TSA2 ( $\Delta$ Tsa1 e $\Delta \mathrm{Tsa} 2)$. Os experimentos foram realizados por procedimentos idênticos aos realizados anteriormente, agora usando as cepas WT e $\Delta 8$ como controles. Primeiramente, as cepas $\Delta \mathrm{T}$ sa1 e $\Delta \mathrm{Tsa} 2$ foram expostas a crescentes concentrações do doador de $\mathrm{NO}^{\bullet}$. Os resultados mostram que a oxidação de CBA é dependente do fluxo de NO• para todas as cepas (Figura 14A). Mais relevantemente, ainda que levemente, exclusão do gene TSA1 aumenta a vulnerabilidade das células a ONOO', evidenciado pelo aumento da taxa de oxidação do CBA para a cepa $\Delta$ Tsa1 relativo a WT. Por outro lado, a cepa $\Delta T s a 2$ não apresenta mudanças significativas de sensibilidade a $\mathrm{ONOO}^{-}$em relação a WT, ou seja, a deleção do gene TSA2 não afeta a sensibilidade ou a capacidade da cepa em remover ONOO- Quando adaptadas em meio glicerol (Figura 14B), há um ganho de resistência para todas as cepas, sendo que a sensibilidade da cepa $\triangle \mathrm{Tsa}$ a $\mathrm{ONOO}^{-}$praticamente igualou-se a WT. Novamente, esse aumento de resistência das cepas é compreendido como uma adaptação do microrganismo a condições de maior estresse oxidativo e portanto contendo quantidades mais expressivas de enzimas antioxidantes. 
Figura 14 - Atividade peroxinitrito redutase de peroxirredoxinas específicas.

A

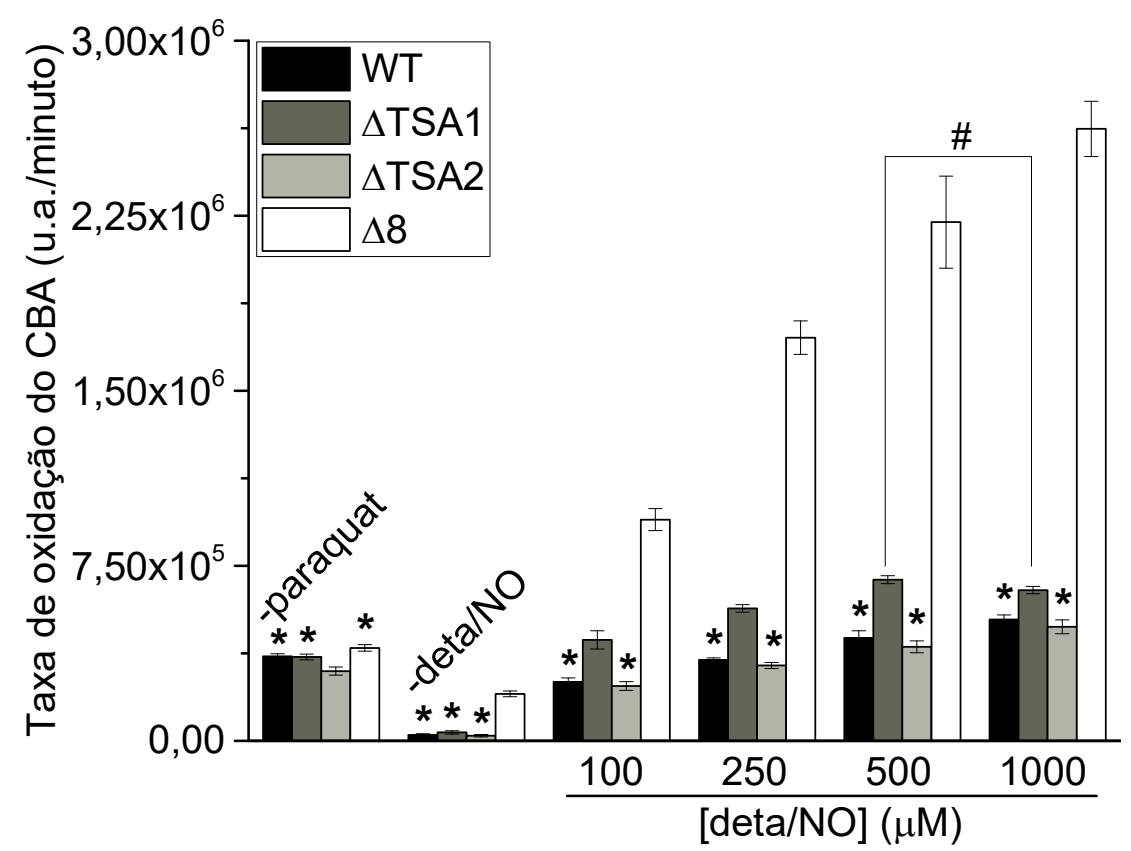

B

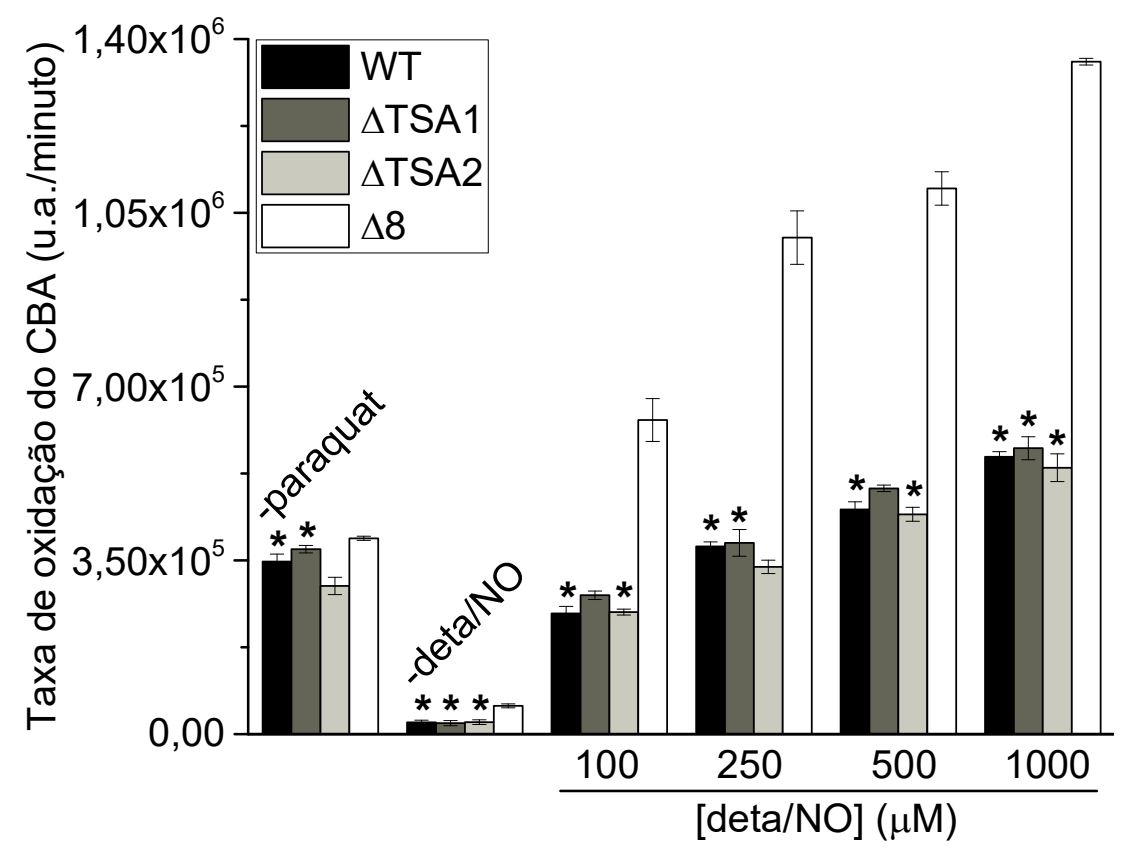

Fonte: Produção do autor. As cepas $\Delta T$ sa1 e $\Delta T$ sa2 (A) cultivadas em YPD e (B) adaptadas em meio glicerol, foram expostas a crescentes concentrações de deta/NO na presença de $10 \mu \mathrm{M}$ de paraquat e $10 \mu \mathrm{M}$ de CBA, exceto controles (-paraquat $=1 \mathrm{mM}$ deta/ $\mathrm{NO}$ ) e sem doador (-deta/ $\mathrm{NO}$ ) à $30^{\circ} \mathrm{C}$, PBS $100 \mu \mathrm{M}$ DTPA, pH 7,4. Os gráficos representam a taxa de oxidação do CBA por unidade de tempo. As cepas WT e $\triangle 8$ foram utilizadas como controles. Os dados são representativos de três (3) medidas \pm D.P. e foram considerados diferentes dentro do grupo, exceto (*) e entre grupos, exceto (\#), 
quando $(p<0,05)$. Os parâmetros de aquisição de fluorescência foram $\lambda E x .332 \mathrm{~nm}$ e $\lambda E m .456 \mathrm{~nm}$ à $\left(30^{\circ} \mathrm{C}\right.$, PBS $100 \mu \mathrm{M}$ DTPA, $\left.\mathrm{pH} 7,4\right)$ usando o instrumento SpectraMax i3X.

\subsection{Oxidação do CBA na cepa $\Delta 8+$ Tsa1}

Para confirmar a atividade peroxinitrito redutase, trabalhou-se com a cepa denominada $\Delta 8+T s a 1$, no qual foi utilizado um plasmídeo de expressão do gene TSA1 na cepa $\Delta 8$. Esta abordagem também permite avaliar o papel específico de Tsa1 no combate a peroxinitrito, ainda que limitadamente devido a diferenças de expressão entre a WT e esta cepa.

A investigação consistiu em comparar a taxa de oxidação do CBA nesta cepa relativo as cepas WT e $\Delta 8$ em células expostas a um fluxo de peroxinitrito gerado com paraquat e crescentes concentrações de doador de $\mathrm{NO}^{\bullet}$, como descrito em experimentos anteriores. Os dados de taxa de oxidação do CBA mostram que a reinserção do gene recupera parcialmente a atividade peroxinitrito redutase da cepa $\Delta 8$ (Figura $6 \mathrm{~A}$ ). A resistência da cepa a $\mathrm{ONOO}^{-}$, refletida pela diminuição da oxidação do CBA, aumentou no mínimo 60\% (concentração de $100 \mu \mathrm{M}$ de deta/NO), indicando que Tsa1 apresenta atividade peroxinitrito redutase relevante. A resistência aumentou em importância com crescentes concentrações de doador de $\mathrm{NO}^{\bullet}$, atingindo cerca de $75 \%$ para a maior concentração de doador utilizada. Notavelmente, o perfil de oxidação do CBA para a cepa $\Delta 8+T$ sa1 foi praticamente idêntico a WT quando as células foram adaptadas em meio YPG por 4 horas (Figura 15B). Esses resultados reforçam a ideia da importância de Prxs e de Tsa1 em particular na defesa celular contra peroxinitrito. 
Figura 15 - Oxidação do CBA em cepa com transfecção da Tsa1 na cepa $\Delta 8(\Delta 8+T s a 1)$.

A

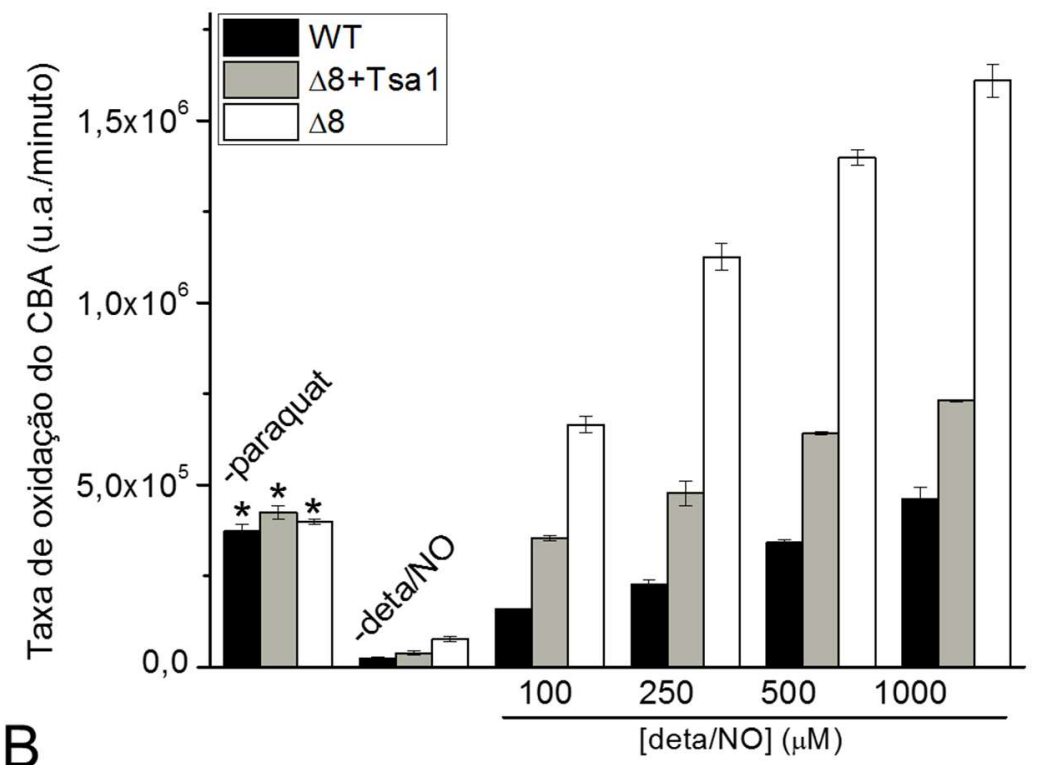

B

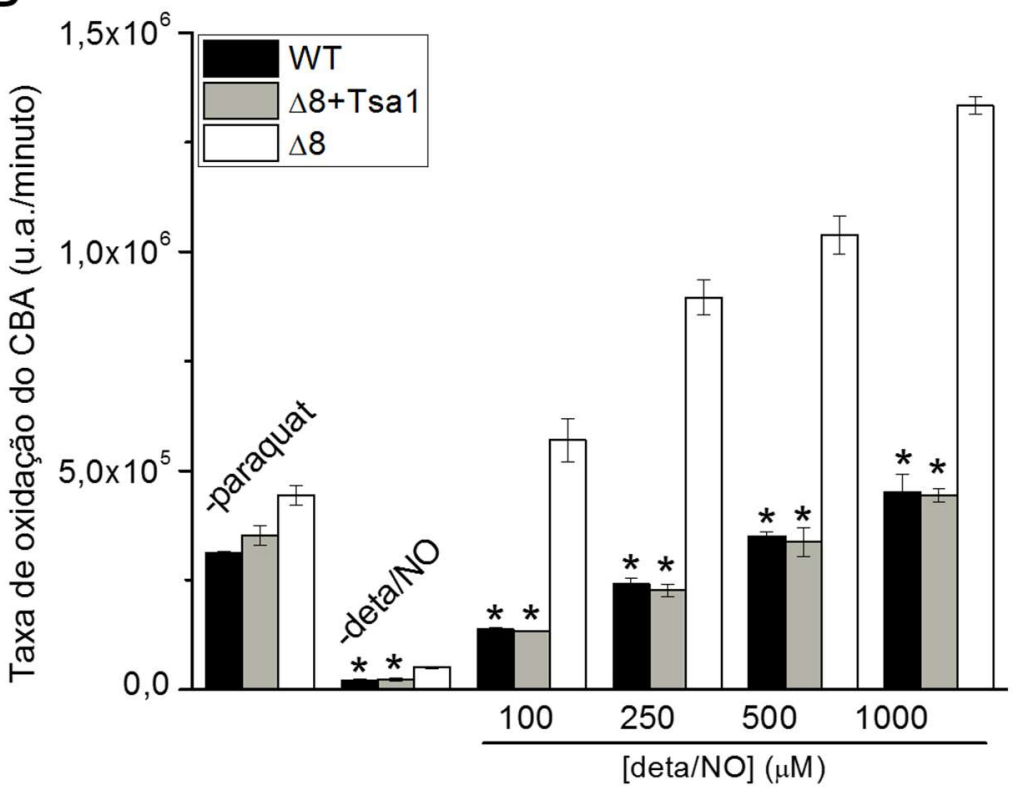

Fonte: Produção do autor. As cepas WT, $\Delta 8 \mathrm{~T}$ sa 1 e $\Delta 8$ foram expostas a crescentes concentrações do doador de $\mathrm{NO}^{\circ}$. (A) cepas cultivadas em meio YPD. (B) cepas adaptadas em meio contendo glicerol. Demais reagentes nas concentrações de $10 \mu \mathrm{M}$ de paraquat e $10 \mu \mathrm{M}$ de CBA. Controles sem deta/NO (-deta/NO) e sem paraquat (-paraquat) ao qual foi adicionado $1 \mathrm{mM}$ deta/NO à $30^{\circ} \mathrm{C}$, PBS $100 \mu \mathrm{M}$ DTPA, pH 7,4. O gráfico representa a taxa de oxidação do CBA por unidade de tempo. As cepas WT e $\Delta 8$ foram utilizadas como controles. Os dados são representativos de três (3) medidas \pm D.P. e foram considerados diferentes dentro do grupo, exceto $\left(^{*}\right)$ e entre grupos, exceto (\#), quando $(p<0,05)$. Os parâmetros de aquisição de fluorescência foram os mesmos da figura 14 . 
4.7 Curvas de crescimento das cepas mediante exposição a oxidantes.

Complementar aos experimentos de oxidação do CBA (fluorescência) foi realizado uma curva de crescimento em que as cepas WT, $\Delta 8, \Delta T$ sa1 e $\Delta$ Tsa2 foram expostas a condições oxidativas similares a dos experimentos anteriores, na presença ou não de paraquat/doador de $\mathrm{NO}^{\bullet}( \pm \mathrm{CBA})$. A cepa $\Delta \mathrm{Tsa} 2$ apresentou crescimento semelhante a cepa WT nas três condições testadas, sem oxidantes (Figura 16A), paraquat/doador de NO• (Figura 16B) e paraquat/doador de NO• + CBA (Figura 16C), demostrando ser viável e tolerante à condição de cultura imposta. Já a cepa $\Delta T s a 1$ apresenta bom crescimento, muito próximo ao das duas anteriores, mas com uma fase de latência maior, fato observado em todas as três condições testadas. Contudo, apesar de ser uma cepa viável na ausência de oxidantes (Figura 16A), as culturas de $\Delta 8$ são afetadas drasticamente na presença de oxidantes (Figura 16B), demonstrando serem altamente vulneráveis ao insulto com paraquat/doador de $\mathrm{NO}{ }^{\bullet}$, condição parcialmente revertida com a adição de CBA (Figura 16C). 
Figura 16 - Curvas de crescimento das cepas na presença de oxidantes.

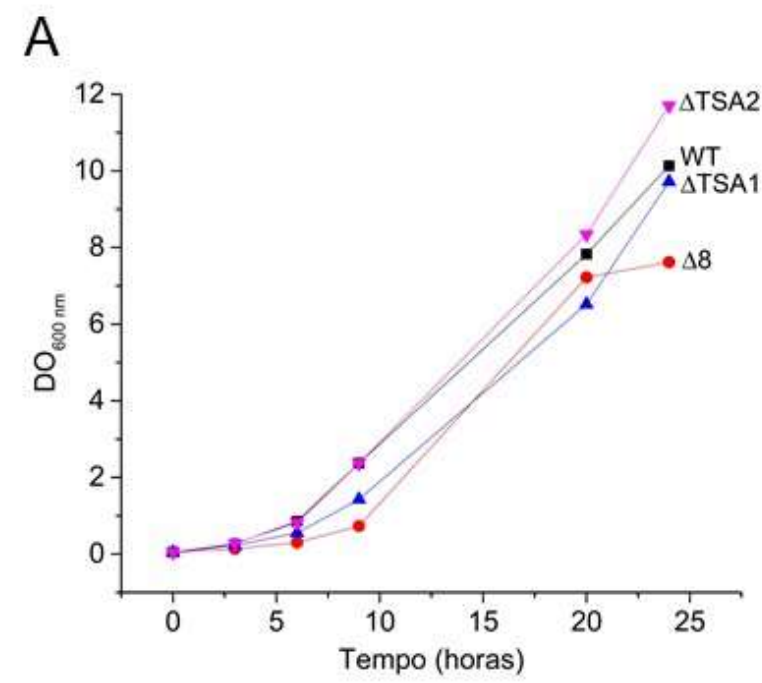

B

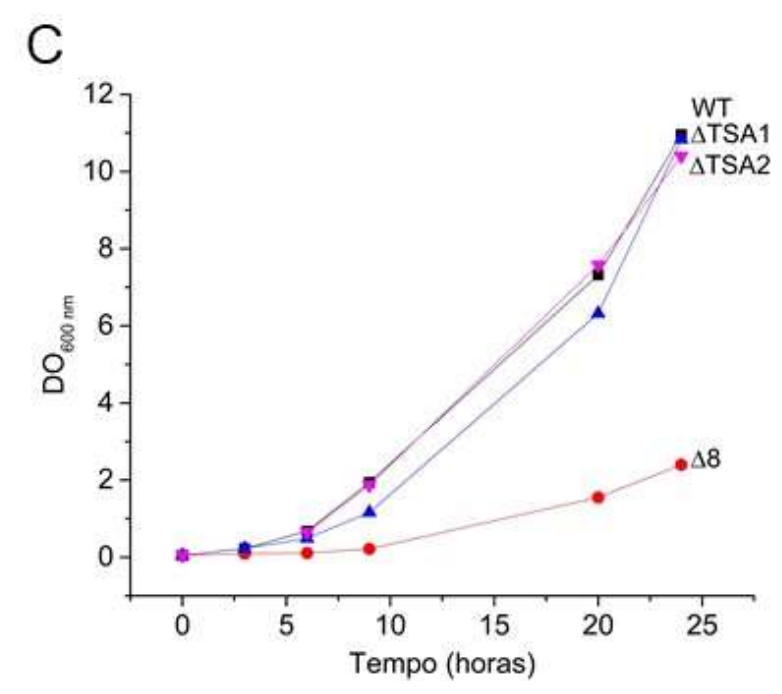

Fonte: Produção do autor. Curvas de crescimento para as cepas WT, $\Delta T$ sa1, $\Delta T$ sa2 e $\Delta 8$. (A) Curvas de crescimento sem adição de paraquat e doador de óxido nítrico ao meio de cultura. (B) Curvas de crescimento em meio de cultura suplementado com $10 \mu \mathrm{M}$ de paraquat e $500 \mu \mathrm{M}$ de deta/NO. (C) Curvas de crescimento nas condições de $\underline{B}$ e adição de $10 \mu \mathrm{M}$ de CBA. As cepas foram incubadas em shaker a $150 \mathrm{rpm}$ e $30^{\circ} \mathrm{C}$ por um período de 24 horas. 
5 DISCUSSÃO 
O presente estudo visou acessar a informação se tiol peroxidases são importantes peróxido redutase em células usando peroxinitrito como substrato e um boronato como indicador específico do oxidante em células e em tempo real. $O$ estudo foi baseado fundamentalmente na competição de tiol peroxidases com o indicador fluorescente por peroxinitrito em células nativas, relativo a células nas quais os genes de todas peroxirredoxinas e glutationa peroxidases foram removidos (cepa $\Delta 8$ ). A relevância de peroxirredoxinas específicas também foi avaliada. O uso de CBA como indicador, principalmente, e de controles apropriados garantem que o processo oxidativo foi dependente de peroxinitrito nas condições do estudo. A observação de que o processo foi inibido por um boronato não fluorescente também reforça esta noção.

Os resultados mostram que a oxidação do indicador CBA para a cepa $\Delta 8$ foi sempre maior do que para a cepa nativa (WT) em todas as condições testadas, indicando que Prxs e GPxs juntas representam sistemas catalíticos importantes na remoção de peróxidos e proporcionam resistência celular contra estes oxidantes. Esta conclusão é reforçada pelos resultados comparativos que mostrou recuperação da atividade peroxinitrito redutase da cepa $\Delta 8+$ Tsa1 relativo a $\Delta 8$.

No mesmo sentido, células adaptadas a glicerol também apresentaram maior resistência a fluxos de peroxinitrito, supostamente relacionado ao aumento da expressão de enzimas antioxidantes e de tiol peroxidases em particular. Em particular, Saccharomyces cerevisiae apresenta metabolismo facultativo, realizando fermentação ou respiração. ${ }^{116}$ Mesmo em condições que favorecem a respiração celular, a utilização de glicose não garante um metabolismo respiratório, levando desde a inativação de vias e processos associados a respiração (proteínas de defesa), até mesmo, disfunção mitocondrial, efeito conhecido como repressão por glicose. ${ }^{117}$; 118 Por outro lado, o uso de glicerol aumenta a atividade mitocondrial e há uma maior produção de ROS, consequentemente, levando a um aumento na expressão de proteínas de defesa antioxidante ${ }^{119}$, o que justificaria parte do aumento da resistência da linhagem nativa WT. Outros estudos mostraram que cepas de Saccharomyces cerevisiae respondem diferentemente a condições de estresse oxidativo quando cultivadas em glicose ou rafinose. ${ }^{78}$ Quando cultivados em glicerol, por exemplo, há aumento da viabilidade da linhagem nativa (WT) e de cepas com mutações enzimáticas ( $\Delta$ Tsa1 e $\Delta$ Tsa2) independente da presença de oxidantes. ${ }^{80}$ 
Juntos estes dados confirmam as expectativas de que estes sistemas são relevantes no combate a peroxinitrito e a outros peróxidos em geral em Saccharomyces cerevisiae, e por extensão, possivelmente em células de mamíferos, uma vez que os níveis de expressão e os componentes do sistema catalítico e cinéticas dos vários passos do ciclo catalítico são similares. A eficiência dos sistemas peroxinitrito redutase em células vem confirmar a expectativa baseada em estudos cinéticos fundamentais das várias etapas do mecanismo e sugerem que outros fatores como compartimentalização e dinâmica dos componentes são menos relevantes para atividade. Como supramencionado, a troca de tióis entre Prxe Trx apresenta a mesma eficiência cinética da redução de peroxinitrito por Prxs. Além disso, a expressão de Trx é comparável aos níveis de expressão de algumas Prxs. Por outro lado, GSH, o principal redutor de GPxs, reage muito mais lentamente, mas sua concentração elevada (podendo alcançar até $100 \mathrm{mM}$ ) ${ }^{120}$ pode compensar as baixas constantes de velocidade.

A diferença de oxidação do indicador entre as cepas nativa e $\Delta 8$ foi significativa para uma ampla faixa de concentração de doador $\mathrm{NO}^{\bullet}$, indicando que a atividade peroxinitrito redutase dos sistemas tiol peroxidases é relevante e efetivo, de condições que simulam a normalidade às que simulam estresse oxidativo. Ressaltase que esta diferença entre as cepas nativa e $\Delta 8$ é consequência de diferenças na atividade peroxinitrito redutase celular. De fato, em experimentos onde a oxidação de CBA é predominantemente extracelular (como no uso de SIN-1) as diferenças entre as taxas de oxidação de CBA para as duas cepas foram praticamente iguais.

Importante destacar que um dos objetivos do estudo foi investigar se peroxirredoxinas e glutationa peroxidases removem peróxidos efetivamente em células operando em condições catalíticas e não estequiometricamente. Assim, era necessário que o oxidante fosse produzido em excesso em relação a Prxs e GPxs no período de análise. Esta condição foi claramente alcançada nos experimentos considerando que a concentração total de Prxs e GPxs somadas era grosseiramente de $40 \mathrm{nM}$ no volume de trabalho, que reflete uma quantidade de 10 pico moles. Este cálculo foi feito considerando $20 \times 10^{6}$ células nos experimentos e que a concentração somada de Prxs e GPxs por célula é de $100 \mu \mathrm{M}$ (um valor propositadamente exagerado). O uso de cicladores redox (que produzem superóxido) e elevadas concentrações de doadores de $\mathrm{NO}^{\bullet}$ garantiram que a quantidade de oxidante 
produzida superasse a quantidade de Prxs e GPxs nos longos períodos de monitoramento. Cálculos mostram que o indicador boronato consumiu entre $0,1 \mu \mathrm{M}$ até 2,5 $\mu \mathrm{M}$ dependendo das condições do estudo, e isto despreza peroxinitrito consumido por constituintes celulares ou que sofreu degradação. Portanto, Prxs e GPxs foram os reagentes limitantes nas condições do estudo. A conclusão de que a atividade peroxinitrito redutase foi catalítica também é fundamentada pela manutenção da linearidade da oxidação de CBA durante todo o intervalo de tempo monitorado. Não foi observado em nenhum caso aceleração da oxidação de CBA, como seria esperado após o consumo estequiométrico de Prxs e GPxs.

Os resultados de crescimento celular reforçam a noção de que Prxs e GPxs são relevantes sistemas catalíticos peroxinitrito redutase. Coerentemente, células deficientes em Prxs e GPxs ( $\Delta 8$ ) (ainda que apresentem proliferação celular mais lenta relativo a linhagem nativa) são viáveis na ausência de insulto oxidativo, mas não proliferam na presença de fluxo de peroxinitrito proporcionado pela combinação paraquat e doador de $\mathrm{NO}^{\bullet}$. Este resultado está em concordância com relatado por Kaya et. al. anteriormente. ${ }^{114}$

A atividade peroxinitrito redutase em relação a peroxirredoxinas específicas (Tsa1 e Tsa2) também foi investigada. Os resultados são de difícil interpretação desde que a expressão de cada qual é influenciada pela ausência do gene da outra. Por exemplo, Wong ${ }^{51}$ et al. descrevem que a cepa $\Delta \mathrm{Tsa} 1$ apresenta níveis de expressão da Tsa2 superiores aos determinados na cepa WT, mesmo em condição normal (sem introdução de oxidantes) e que há efeito compensatório nas mutantes simples $\Delta$ Tsa1 e $\Delta$ Tsa2 em Saccharomyces cerevisiae. Além disso, Demasi et al. afirmam que há aumento de expressão de diversos outros genes associados a estresse oxidativo e nitrosativo, dentre eles, de uma Prx mitocondrial (PRX1) e outra citosólica/peroxissomal denominada alquil-hidroperóxido redutase ( $A H P 1)$ bem como de Glutationa peroxidase II (GPX2). ${ }^{78}$

Entretanto, é possível inferir que a isoforma Tsa1 é relevante na remoção de peroxinitrito em células. Essa conclusão foi baseada na observação de que, mesmo esperando os efeitos compensatórios relacionados logo acima, a linhagem de Saccharomyces cerevisiae deficiente em Tsa1 ( $\Delta$ Tsa1) é mais susceptível a condição oxidativa promovida por paraquat e doador de NO. Esta importância pode estar 
relacionada a elevada expressão de Tsa1. De fato, Tsa1 corresponde a cerca de 1\% da massa de proteínas solúveis em Saccharomyces cerevisiae. Na verdade, Tsa1 pode ser a enzima mais abundante em Saccharomyces cerevisiae. ${ }^{121}$ A segunda Prx mais abundante (Ahp1), apresenta expressão 20 vezes menor, e a isoforma Tsa2 é 3,5 vezes menor que Ahp1. ${ }^{95}$ Comparativamente, a subfamília de enzimas Prx1 em mamíferos, que compreendem as isoformas Prxl, PrxII, PrxIII e PrxIV, representam entre $0,1-1 \%$ do total de proteínas solúveis. ${ }^{82}$

Por outro lado, a deleção da proteína Tsa2, cepa $\Delta T s a 2$, não afeta a capacidade de remoção de $\mathrm{ONOO}^{-}$relativo a WT em Saccharomyces cerevisiae. Ao contrário, a linhagem apresenta atividade peroxinitrito redutase idêntica à da cepa WT, talvez simplesmente porque o nível basal de expressão de Tsa2 é muito baixo comparado à Tsa1. Em alguns casos a cepa $\Delta T$ sa2 demonstra ser até mais resistente a fluxos de peroxinitrito que a forma nativa WT (dados não apresentados). Munhoz ${ }^{80}$ et al. descrevem fato semelhante em que a cepa $\Delta T$ sa2 apresenta maior resistência (melhor crescimento celular) que a WT quando exposta a $\mathrm{H}_{2} \mathrm{O}_{2}$. Especulativamente, este aumento de resistência a peroxinitrito pode estar relacionado a aumento de expressão de Tsa1 e outras peroxinitrito redutases como a citocromo $\mathrm{C}$ peroxidase mitocondrial (Ccp1). Outros especulam que a Tsa2 tenha papel específico em células, possivelmente na sinalização de estresse oxidativo e regulação de outras enzimas antioxidantes, uma vez que apresenta níveis muito baixos de expressão, ${ }^{122}$ portanto, não sendo a principal linha de defesa contra peroxinitrito.

Mesmo a cepa $\Delta 8$ expressa enzimas com atividade peroxinitrito redutase diferentes de tiol peroxidases. Essa conclusão é suportada pelas observações experimentais de que esta cepa deficiente em Prxs e GPxs apresenta diminuição da oxidação do CBA com o aumento da densidade celular (número de células no experimento), virtualmente em consequência do aumento de enzimas que apresentam atividade peroxinitrito redutase. Concordantemente, a adaptação celular em meio contendo glicerol também aponta para esta noção, também apresenta diminuição da oxidação do CBA, entendido como aumento da atividade peroxinitrito redutase, porém em menor escala que a linhagem nativa (WT). De fato, células dispõe de outros sistemas enzimáticos capaz de reduzir peroxinitrito. Recentemente, Martins et. al. ${ }^{115}$ determinaram a constante cinética de redução de peroxinitrito por citocromo c peroxidase (Ccp1), uma enzima mitocondrial conhecida pela atividade catalase, 
obtendo valores de constantes superiores a $10^{6} \mathrm{M}^{-1} \mathrm{~s}^{-1}$. No entanto, é possível que este sistema encontra-se operante na linhagem $\Delta 8$ mesmo em cultivo com dextrose. Kaya et. al. ${ }^{114}$ afirmam que a linhagem $\Delta 8$ é inviável em condições anaeróbicas, onde sua capacidade de crescimento dependente exclusivamente de metabolismo respiratório e apresenta distribuição e aumento do conteúdo mitocondrial alterados. Ainda segundo os autores do estudo, foi detectada uma cópia extra do cromossomo $\mathrm{XI}$, resultando no aumento da expressão de genes codificados por esse cromossomo, dentre eles da Ccp1. 


\section{CONCLUSÕES}


De forma geral, os resultados indicam claramente que as duas classes de tiol peroxidases juntas (Peroxirredoxinas e Glutationa Peroxidases) são importantes agentes anti-oxidantes contra peroxinitrito, podendo representar a principal linha de defesa contra este oxidante.

Especificamente, a isoforma Tsa1 (peroxirredoxina) apresenta elevada capacidade de detoxificação de peroxinitrito em Saccharomyces cerevisiae.

Saccharomyces cerevisiae dispõe de outros mecanismos de remoção deste oxidante, diferentes de tiol peroxidases.

A atividade peroxinitrito redutase em Saccharomyces cerevisiae demonstra ser catalítica nas condições estudadas e não apenas estequiométrica. 


\section{REFERÊNCIAS}

IGNARRO, L. J. Nitric oxide: A unique endogenous signaling molecule in vascular biology. Bioscience Reports, v. 19, n. 2, p. 51-71, Apr 1999. ISSN 0144-8463. Disponível em: < <Go to |S|>://WOS:000081524800001 >.

MONCADA, S.; PALMER, R. M. J.; HIGGS, E. A. NITRIC-OXIDE - PHYSIOLOGY, PATHOPHYSIOLOGY, AND PHARMACOLOGY. Pharmacological Reviews, v. 43, n. 2, p. 109-142, Jun 1991. ISSN 0031-6997. Disponível em: <<Go to ISI>://WOS:A1991FU76700001 >.

TOLEDO, J. C.; AUGUSTO, O. Connecting the Chemical and Biological Properties of Nitric Oxide. Chemical Research in Toxicology, v. 25, n. 5, p. 975-989, May 2012. ISSN 0893-228X. Disponível em: < <Go to |SI : //WOS:000304235000001 >.

ALDERTON, W. K.; COOPER, C. E.; KNOWLES, R. G. Nitric oxide synthases: structure, function and inhibition. Biochemical Journal, v. 357, p. 593-615, Aug 2001. ISSN 0264-6021. Disponível em: $<<$ Go to $|S|>: / /$ WOS:000170405800001 >.

WINGER, J. A.; DERBYSHIRE, E. R.; MARLETTA, M. A. Dissociation of nitric oxide from soluble guanylate cyclase and heme-nitric oxide/oxygen binding domain constructs. J Biol Chem, v. 282, n. 2, p. 897-907, Jan 2007. ISSN 0021-9258. Disponível em: < http://www.ncbi.nlm.nih.gov/pubmed/17098738 >.

RODRIGUEZ-JUAREZ, F.; AGUIRRE, E.; CADENAS, S. Relative sensitivity of soluble guanylate cyclase and mitochondrial respiration to endogenous nitric oxide at physiological oxygen concentration. Biochemical Journal, v. 405, p. 223-231, Jul 15 2007. ISSN 0264-6021. Disponível em: <<Go to IS|>://WOS:000248158600002 >.

CARY, S. P.; WINGER, J. A.; MARLETTA, M. A. Tonic and acute nitric oxide signaling through soluble guanylate cyclase is mediated by nonheme nitric oxide, ATP, and GTP. Proc Natl Acad Sci U S A, v. 102, n. 37, p. 13064-9, Sep 2005. ISSN 0027-8424. Disponível em: < http://www.ncbi.nlm.nih.gov/pubmed/16131543 >.

IGNARRO, L. J. et al. ENDOTHELIUM-DERIVED RELAXING FACTOR FROM PULMONARY-ARTERY AND VEIN POSSESSES PHARMACOLOGICAL AND CHEMICAL-PROPERTIES IDENTICAL TO THOSE OF NITRIC-OXIDE RADICAL. Circulation Research, v. 61, n. 6, p. 866-879, Dec 1987. ISSN 00097330. Disponível em: <<Go to ISI>://WOS:A1987L149600014 >.

Endothelium-derived relaxing factor produced and released from artery and vein is nitric oxide. Proc Natl Acad Sci U S A, v. 84, n. 24, p. 9265-9, Dec 1987. ISSN 0027-8424. Disponível em: < http://www.ncbi.nlm.nih.gov/pubmed/2827174 >.

WINK, D. A.; MITCHELL, J. B. Chemical biology of nitric oxide: Insights into regulatory, cytotoxic, and cytoprotective mechanisms of nitric oxide. Free Radical Biology and Medicine, v. 25, n. 45, p. 434-456, Sep 1998. ISSN 0891-5849. Disponível em: < <Go to $|S|>: / /$ WOS:000075538000006 >. 
KOPPENOL, W. H. et al. Peroxynitrous acid: controversy and consensus surrounding an enigmatic oxidant. Dalton Trans, v. 41, n. 45, p. 13779-87, Dec 2012. ISSN 1477-9234. Disponível em: < http://www.ncbi.nlm.nih.gov/pubmed/23007920 >.

SCHULZ, R.; TRIGGLE, C. R. ROLE OF NO IN VASCULAR SMOOTH-MUSCLE AND CARDIACMUSCLE FUNCTION. Trends in Pharmacological Sciences, v. 15, n. 7, p. 255-259, Jul 1994. ISSN 0165-6147. Disponível em:<<Go to ISI>://WOS:A1994NW80000012 >.

SHAH, A. M.; LEWIS, M. J. MODULATION OF MYOCARDIAL-CONTRACTION BY ENDOCARDIAL AND CORONARY VASCULAR ENDOTHELIUM. Trends in Cardiovascular Medicine, v. 3, n. 3, p. 98-103, May-Jun 1993. ISSN 1050-1738. Disponível em: < <Go to ISI>://WOS:A1993LE30600005 >.

SUHR, F. et al. Skeletal Muscle Function during Exercise-Fine-Tuning of Diverse Subsystems by Nitric Oxide. International Journal of Molecular Sciences, v. 14, n. 4, p. 7109-7139, Apr 2013. ISSN 1422-0067. Disponível em: <<Go to ISI>://WOS:000318017100028 >.

ESPLUGUES, J. V. NO as a signalling molecule in the nervous system. British Journal of Pharmacology, v. 135, n. 5, p. 1079-1095, Mar 2002. ISSN 0007-1188. Disponível em: <<Go to |SI>://WOS:000174384400001 >.

KANADIA, R. N. et al. Constitutive nitric oxide synthase in Saccharomyces cerevisiae. Biochemistry and Molecular Biology International, v. 45, n. 6, p. 1081-1087, Sep 1998. ISSN 1039-9712. Disponível em: <<Go to ISI>://WOS:000075831300002 >.

O'DONNELL, V. B. et al. Nitric oxide inhibition of lipid peroxidation: kinetics of reaction with lipid peroxyl radicals and comparison with alpha-tocopherol. Biochemistry, v. 36, n. 49, p. 15216-23, Dec 1997. ISSN 0006-2960. Disponível em: < http://www.ncbi.nlm.nih.gov/pubmed/9398249 >.

RUBBO, $\mathrm{H}$. et al. Nitric oxide reaction with lipid peroxyl radicals spares alpha-tocopherol during lipid peroxidation. Greater oxidant protection from the pair nitric oxide/alpha-tocopherol than alpha-tocopherol/ascorbate. J Biol Chem, v. 275, n. 15, p. 10812-8, Apr 2000. ISSN 0021-9258. Disponível em: < http://www.ncbi.nlm.nih.gov/pubmed/10753874 >.

KISSNER, R. et al. Formation and properties of peroxynitrite as studied by laser flash photolysis, high-pressure stopped-flow technique, and pulse radiolysis volume 10, number 11 , november 1997, pp 1285-1292. Chem Res Toxicol, v. 11, n. 5, p. 557, May 1998. ISSN 15205010. Disponível em: < http://www.ncbi.nlm.nih.gov/pubmed/9585488 >.

DERBYSHIRE, E. R.; MARLETTA, M. A. Structure and Regulation of Soluble Guanylate Cyclase. In: KORNBERG, R. D. (Ed.). Annual Review of Biochemistry, Vol 81. Palo Alto: Annual Reviews, v.81, 2012. p.533-559. (Annual Review of Biochemistry). ISBN 978-0-8243-0881-0. 
BONINI, M. G. et al. Direct EPR detection of the carbonate radical anion produced from peroxynitrite and carbon dioxide. J Biol Chem, v. 274, n. 16, p. 10802-6, Apr 1999. ISSN 00219258. Disponível em: < http://www.ncbi.nlm.nih.gov/pubmed/10196155 >.

CARBALLAL, S.; BARTESAGHI, S.; RADI, R. Kinetic and mechanistic considerations to assess the biological fate of peroxynitrite. Biochimica Et Biophysica Acta-General Subjects, v. 1840, n. 2, p. 768-780, Feb 2014. ISSN 0304-4165; 1872-8006. Disponível em: < <Go to ISI>://WOS:000330818700008 >.

HEROLD, S.; EXNER, M.; BOCCINI, F. The mechanism of the peroxynitrite-mediated oxidation of myoglobin in the absence and presence of carbon dioxide. Chem Res Toxicol, v. 16, n. 3, p. 390-402, Mar 2003. ISSN 0893-228X. Disponível em: < http://www.ncbi.nlm.nih.gov/pubmed/12641440 >.

BOCCINI, F.; HEROLD, S. Mechanistic studies of the oxidation of oxyhemoglobin by peroxynitrite. Biochemistry, v. 43, n. 51, p. 16393-404, Dec 2004. ISSN 0006-2960. Disponível em: < http://www.ncbi.nlm.nih.gov/pubmed/15610034 >.

DENICOLA, A. et al. Peroxynitrite reaction with carbon dioxide/bicarbonate: kinetics and influence on peroxynitrite-mediated oxidations. Arch Biochem Biophys, v. 333, n. 1, p. 49-58, Sep 1996. ISSN 0003-9861. Disponível em: < http://www.ncbi.nlm.nih.gov/pubmed/8806753 $>$.

RADI, R.; DENICOLA, A.; FREEMAN, B. A. Peroxynitrite reactions with carbon dioxidebicarbonate. Methods Enzymol, v. 301, p. 353-67, 1999. ISSN 0076-6879. Disponível em: < http://www.ncbi.nlm.nih.gov/pubmed/9919584 >.

RADI, R. et al. Unraveling peroxynitrite formation in biological systems. Free Radical Biology and Medicine, v. 30, n. 5, p. 463-488, Mar 2001. ISSN 0891-5849. Disponível em: <<Go to |SI>://WOS:000167208600003 >.

AUGUSTO, O. et al. Nitrogen dioxide and carbonate radical anion: Two emerging radicals in biology. Free Radical Biology and Medicine, v. 32, n. 9, p. 841-859, May 2002. ISSN 0891-5849. Disponível em: < <Go to ISI>://WOS:000175291200008 >.

FERRER-SUETA, G.; RADI, R. Chemical Biology of Peroxynitrite: Kinetics, Diffusion, and Radicals. Acs Chemical Biology, v. 4, n. 3, p. 161-177, Mar 2009. ISSN 1554-8929. Disponível em: <<Go to $|S|>: / /$ WOS:000264535100004 >.

WOOD, Z. A. et al. Structure, mechanism and regulation of peroxiredoxins. Trends in Biochemical Sciences, v. 28, n. 1, p. 32-40, Jan 2003. ISSN 0968-0004.

HILDEBRANDT, T. et al. Cytosolic thiol switches regulating basic cellular functions: GAPDH as an information hub? Biological Chemistry, v. 396, n. 5, p. 523-537, May 2015. ISSN 1431-6730. Disponível em: <<Go to ISI>://WOS:000352810300010 >. 
ZHENG, M.; ASLUND, F.; STORZ, G. Activation of the OxyR transcription factor by reversible disulfide bond formation. Science, v. 279, n. 5357, p. 1718-1721, Mar 1998. ISSN 0036-8075. Disponível em: <<Go to ISI ://WOS:000072490000055 >.

$\mathrm{CHOI}, \mathrm{H}$. J. et al. Structural basis of the redox switch in the OxyR transcription factor. Cell, v. 105, n. 1, p. 103-113, Apr 2001. ISSN 0092-8674. Disponível em: < <Go to |SI>://WOS:000168063300011 >.

FLOHE, L. The impact of thiol peroxidases on redox regulation. Free Radical Research, v. 50, n. 2, p. 126-142, Feb 2016. ISSN 1071-5762.

RADI, R. et al. PEROXYNITRITE OXIDATION OF SULFHYDRYLS - THE CYTOTOXIC POTENTIAL OF SUPEROXIDE AND NITRIC-OXIDE. Journal of Biological Chemistry, v. 266, n. 7, p. 4244-4250, Mar 1991. ISSN 0021-9258. Disponível em: <<Go to ISI>://WOS:A1991FA69400037 >.

QUIJANO, C. et al. Pathways of peroxynitrite oxidation of thiol groups. Biochemical Journal, v. 322, p. 167-173, Feb 1997. ISSN 0264-6021. Disponível em: < <Go to |S|>://WOS:A1997WL28200023 >.

TOLEDO, J. C. et al. Horseradish peroxidase compound I as a tool to investigate reactive protein-cysteine residues: from quantification to kinetics. Free Radic Biol Med, v. 50, n. 9, p. 1032-8, May 2011. ISSN 1873-4596. Disponível em: < http://www.ncbi.nlm.nih.gov/pubmed/21354305 >.

AVERY, A. M.; AVERY, S. V. Saccharomyces cerevisiae expresses three phospholipid hydroperoxide glutathione peroxidases. Journal of Biological Chemistry, v. 276, n. 36, p. 33730-33735, Sep 2001. ISSN 0021-9258. Disponível em: $<<$ Go to $\mid$ ISI $>/ / /$ WOS:000170910200060 >.

ROY, B.; HALVEY, E. J.; GARTHWAITE, J. An enzyme-linked receptor mechanism for nitric oxideactivated guanylyl cyclase. J Biol Chem, v. 283, n. 27, p. 18841-51, Jul 2008. ISSN 0021-9258. Disponível em: < http://www.ncbi.nlm.nih.gov/pubmed/18463095 >.

BATCHELOR, A. M. et al. Exquisite sensitivity to subsecond, picomolar nitric oxide transients conferred on cells by guanylyl cyclase-coupled receptors. Proc Natl Acad Sci U S A, v. 107, n. 51, p. 22060-5, Dec 2010. ISSN 1091-6490. Disponível em: < http://www.ncbi.nlm.nih.gov/pubmed/21135206 >.

TARPEY, M. M.; FRIDOVICH, I. Methods of detection of vascular reactive species: nitric oxide, superoxide, hydrogen peroxide, and peroxynitrite. Circ Res, v. 89, n. 3, p. 224-36, Aug 2001. ISSN 1524-4571. Disponível em: < http://www.ncbi.nlm.nih.gov/pubmed/11485972 >.

BRYK, R.; GRIFFIN, P.; NATHAN, C. Peroxynitrite reductase activity of bacterial peroxiredoxins. Nature, v. 407, n. 6801, p. 211-215, Sep 2000. ISSN 0028-0836. Disponível em: < <Go to $\mid$ SI $>$ ://WOS:000089241000054 >. 
DUBUISSON, $M$. et al. Human peroxiredoxin 5 is a peroxynitrite reductase. Febs Letters, v. 571, n. 1-3, p. 161-165, Jul 2004. ISSN 0014-5793. Disponível em: < <Go to |SI >://WOS:000223094600028 >.

URSINI, F. et al. DIVERSITY OF GLUTATHIONE PEROXIDASES. Biothiols, Pt B, v. 252, p. 38-53, 1995. ISSN 0076-6879. Disponível em: <<Go to ISI>://WOS:A1995BE08C00005 >.

INOUE, Y. et al. Genetic analysis of glutathione peroxidase in oxidative stress response of Saccharomyces cerevisiae. Journal of Biological Chemistry, v. 274, n. 38, p. 27002-27009, Sep 1999. ISSN 0021-9258. Disponível em: <<Go to ISI>://WOS:000082570700052 >.

BRIGELIUS-FLOHE, R.; MAIORINO, M. Glutathione peroxidases. Biochimica Et Biophysica ActaGeneral Subjects, v. 1830, n. 5, p. 3289-3303, May 2013. ISSN 0304-4165. Disponível em: < $<$ Go to $|S|>$ ://WOS:000317797600011 >.

DELAUNAY, A. et al. A thiol peroxidase is an $\mathrm{H} 2 \mathrm{O} 2$ receptor and redox-transducer in gene activation. Cell, v. 111, n. 4, p. 471-481, Nov 2002. ISSN 0092-8674. Disponível em: < <Go to |SI>://WOS:000179346900001 >.

KIM, I. H.; KIM, K.; RHEE, S. G. INDUCTION OF AN ANTIOXIDANT PROTEIN OF SACCHAROMYCES-CEREVISIAE BY O-2,FE-3+, OR 2-MERCAPTOETHANOL. Proceedings of the National Academy of Sciences of the United States of America, v. 86, n. 16, p. 6018-6022, Aug 1989. ISSN 0027-8424. Disponível em: <<Go to ISI>://WOS:A1989AK85100002 >.

KIM, K. W. et al. THE ISOLATION AND PURIFICATION OF A SPECIFIC PROTECTOR PROTEIN WHICH INHIBITS ENZYME INACTIVATION BY A THIOL/FE(III)/O-2 MIXED-FUNCTION OXIDATION SYSTEM. Journal of Biological Chemistry, v. 263, n. 10, p. 4704-4711, Apr 1988. ISSN 00219258. Disponível em: <<Go to ISI>://WOS:A1988M788600032 >.

KANG, S. W. et al. Mammalian peroxiredoxin isoforms can reduce hydrogen peroxide generated in response to growth factors and tumor necrosis factor-alpha. Journal of Biological Chemistry, v. 273, n. 11, p. 6297-6302, Mar 1998. ISSN 0021-9258. Disponível em: < <Go to $|S|>: / /$ WOS:000072488500049 >.

WONG, C. M. et al. Cooperation of yeast peroxiredoxins Tsa1p and Tsa2p in the cellular defense against oxidative and nitrosative stress. Journal of Biological Chemistry, v. 277, n. 7, p. 5385-5394, Feb 2002. ISSN 0021-9258. Disponível em: $<<G o$ to |S|>://WOS:000173962900107 >.

TANAKA, T.; IZAWA, S.; INOUE, Y. GPX2, encoding a phospholipid hydroperoxide glutathione peroxidase homologue, codes for an atypical 2-Cys peroxiredoxin in Saccharomyces cerevisiae. Journal of Biological Chemistry, v. 280, n. 51, p. 42078-42087, Dec 2005. ISSN 0021-9258. Disponível em: < <Go to ISI >://WOS:000233992700034 >. 
TRUJILLO, M. et al. Pre-steady state kinetic characterization of human peroxiredoxin 5: Taking advantage of Trp84 fluorescence increase upon oxidation. Archives of Biochemistry and Biophysics, v. 467, n. 1, p. 95-106, Nov 2007. ISSN 0003-9861. Disponível em: < <Go to |SI>://WOS:000250764700011 >.

CORDRAY, P. et al. Oxidation of 2-Cys-peroxiredoxins by arachidonic acid peroxide metabolites of lipoxygenases and cyclooxygenase-2. Journal of Biological Chemistry, v. 282, n. 45, p. 32623-32629, Nov 2007. ISSN 0021-9258. Disponível em: < <Go to $|S|>: / /$ WOS:000250625400011 >.

STORZ, G. et al. SPONTANEOUS MUTAGENESIS AND OXIDATIVE DAMAGE TO DNA IN SALMONELLA-TYPHIMURIUM. Proceedings of the National Academy of Sciences of the United States of America, v. 84, n. 24, p. 8917-8921, Dec 1987. ISSN 0027-8424. Disponível em: <<Go to ISI>://WOS:A1987L760100035 >.

WOLFF, S. P.; GARNER, A.; DEAN, R. T. FREE-RADICALS, LIPIDS AND PROTEIN-DEGRADATION. Trends in Biochemical Sciences, v. 11, n. 1, p. 27-31, Jan 1986. ISSN 0968-0004. Disponível em: $<<$ Go to ISI >://WOS:A1986A016300014 >.

RAMANA, K. V.; SRIVASTAVA, S.; SINGHAL, S. S. Lipid Peroxidation Products in Human Health and Disease 2016. Oxidative Medicine and Cellular Longevity, p. 2, 2017. ISSN 1942-0900. Disponível em: < <Go to |SI>://WOS:000397849200001 >.

MANEVICH, Y. et al. Binding of peroxiredoxin 6 to substrate determines differential phospholipid hydroperoxide peroxidase and phospholipase $A(2)$ activities. Archives of Biochemistry and Biophysics, v. 485, n. 2, p. 139-149, May 2009. ISSN 0003-9861. Disponível em: $<<$ Go to $|S|>: / /$ WOS:000265949100007 >.

RHEE, S. G.; CHAE, H. Z.; KIM, K. Peroxiredoxins: A historical overview and speculative preview of novel mechanisms and emerging concepts in cell signaling. Free Radical Biology and Medicine, v. 38, n. 12, p. 1543-1552, Jun 15 2005. ISSN 0891-5849.

CALABRESE, $V$. et al. Nitric oxide in the central nervous system: neuroprotection versus neurotoxicity. Nature Reviews Neuroscience, v. 8, n. 10, p. 766-775, Oct 2007. ISSN 14710048.

MONTEIRO, G. et al. Reduction of 1-Cys peroxiredoxins by ascorbate changes the thiol-specific antioxidant paradigm, revealing another function of vitamin C. Proceedings of the National Academy of Sciences of the United States of America, v. 104, n. 12, p. 4886-4891, Mar 2007. ISSN 0027-8424. Disponível em: <<Go to ISI>://WOS:000245256700024 >.

HALL, A.; KARPLUS, P. A.; POOLE, L. B. Typical 2-Cys peroxiredoxins - structures, mechanisms and functions. Febs Journal, v. 276, n. 9, p. 2469-2477, May 2009. ISSN 1742-464X. Disponível em: $<<$ Go to $|S|>$ ://WOS:000264882700005 >. 
PEDRAJAS, J. R. et al. Glutaredoxin Participates in the Reduction of Peroxides by the Mitochondrial 1-CYS Peroxiredoxin in Saccharomyces cerevisiae. Antioxidants \& Redox Signaling, v. 13 , n. 3, p. 249-258, Aug 2010. ISSN 1523-0864. Disponível em: < <Go to $\mid$ SI $>: / /$ WOS:000279072000001 >.

GREETHAM, D.; GRANT, C. M. Antioxidant Activity of the Yeast Mitochondrial One-Cys Peroxiredoxin Is Dependent on Thioredoxin Reductase and Glutathione In Vivo. Molecular and Cellular Biology, v. 29, n. 11, p. 3229-3240, Jun 2009. ISSN 0270-7306. Disponível em: < <Go to $|S|>: / /$ WOS:000266006500025 >.

PINEYRO, M. D. et al. Tryparedoxin peroxidases from Trypanosoma cruzi: High efficiency in the catalytic elimination of hydrogen peroxide and peroxynitrite. Archives of Biochemistry and Biophysics, v. 507, n. 2, p. 287-295, Mar 2011. ISSN 0003-9861. Disponível em: < <Go to |SI>://WOS:000288058000011 >.

GUERRERO, S. A. et al. His-tagged tryparedoxin peroxidase of Trypanosoma cruzi as a tool for drug screening. Applied Microbiology and Biotechnology, v. 53, n. 4, p. 410-414, Apr 2000. ISSN 0175-7598. Disponível em: <<Go to ISI>://WOS:000086969800008 >.

NOGOCEKE, E. et al. A unique cascade of oxidoreductases catalyses trypanothione-mediated peroxide metabolism in Crithidia fasciculata. Biological Chemistry, v. 378, n. 8, p. 827-836, Aug 1997. ISSN 1431-6730. Disponível em: <<Go to ISI>://WOS:A1997XU29300014 >.

BUDDE, $\mathrm{H}$. et al. Kinetics and redox-sensitive oligomerisation reveal negative subunit cooperativity in tryparedoxin peroxidase of Trypanosoma brucei brucei. Biological Chemistry, v. 384, n. 4, p. 619-633, Apr 2003. ISSN 1431-6730. Disponível em: < <Go to $\mid$ ISI : //WOS:000182158100013 >.

CASTRO, $\mathrm{H}$. et al. Specificity and kinetics of a mitochondrial peroxiredoxin of Leishmania infantum. Free Radical Biology and Medicine, v. 33, n. 11, p. 1563-1574, Dec 2002. ISSN 08915849. Disponível em: <<Go to ISI>://WOS:000179434500015 >.

FLOHE, L. et al. Tryparedoxin peroxidase of Leishmania donovani: Molecular cloning, heterologous expression, specificity, and catalytic mechanism. Archives of Biochemistry and Biophysics, v. 397, n. 2, p. 324-335, Jan 2002. ISSN 0003-9861. Disponível em: < <Go to |SI>://WOS:000173611700028 >.

KONIG, J.; FAIRLAMB, A. H. A comparative study of type I and type II tryparedoxin peroxidases in Leishmania major. Febs Journal, v. 274, n. 21, p. 5643-5658, Nov 2007. ISSN 1742-464X. Disponível em: <<Go to ISI>://WOS:000250297600018 >.

MANTA, B. et al. The peroxidase and peroxynitrite reductase activity of human erythrocyte peroxiredoxin 2. Archives of Biochemistry and Biophysics, v. 484, n. 2, p. 146-154, Apr 2009. ISSN 0003-9861. Disponível em: <<Go to ISI>://WOS:000265705800007 >. 
BAKER, L. M. S. et al. Essential thioredoxin-dependent peroxiredoxin system from Helicobacter pylori: Genetic and kinetic characterization. Journal of Bacteriology, v. 183, n. 6, p. 1961-1973, Mar 2001. ISSN 0021-9193. Disponível em: <<Go to ISI>://WOS:000167261300015 >.

POTAMITOU, A.; HOLMGREN, A.; VLAMIS-GARDIKAS, A. Protein levels of Escherichia coli thioredoxins and glutaredoxins and their relation to null mutants, growth phase, and function. Journal of Biological Chemistry, v. 277, n. 21, p. 18561-18567, May 2002. ISSN 0021-9258. Disponível em: <<Go to ISI>://WOS:000175975800042 >.

JACOBSON, F. S. et al. AN ALKYL HYDROPEROXIDE REDUCTASE FROM SALMONELLATYPHIMURIUM INVOLVED IN THE DEFENSE OF DNA AGAINST OXIDATIVE DAMAGE PURIFICATION AND PROPERTIES. Journal of Biological Chemistry, v. 264, n. 3, p. 1488-1496, Jan 1989. ISSN 0021-9258. Disponível em: <<Go to ISI>://WOS:A1989R890300024 >.

CHAE, H. Z. et al. CLONING AND SEQUENCING OF THIOL-SPECIFIC ANTIOXIDANT FROM MAMMALIAN BRAIN - ALKYL HYDROPEROXIDE REDUCTASE AND THIOL-SPECIFIC ANTIOXIDANT DEFINE A LARGE FAMILY OF ANTIOXIDANT ENZYMES. Proceedings of the National Academy of Sciences of the United States of America, v. 91, n. 15, p. 7017-7021, Jul 1994. ISSN 00278424. Disponível em: <<Go to ISI>://WOS:A1994NY34800056 >.

WONG, C. M.; SIU, K. L.; JIN, D. Y. Peroxiredoxin-null yeast cells are hypersensitive to oxidative stress and are genomically unstable. Journal of Biological Chemistry, v. 279, n. 22, p. 2320723213, May 2004. ISSN 0021-9258. Disponível em: <<Go to ISI>://WOS:000221570900052 >.

DEMASI, A. P. D.; PEREIRA, G. A. G.; NETTO, L. E. S. Cytosolic thioredoxin peroxidase I is essential for the antioxidant defense of yeast with dysfunctional mitochondria. Febs Letters, v. 509, n. 3, p. 430-434, Dec 2001. ISSN 0014-5793. Disponível em: < <Go to |S|>://WOS:000172949600017 >.

Yeast oxidative stress response - Influences of cytosolic thioredoxin peroxidase I and of the mitochondrial functional state. Febs Journal, v. 273, n. 4, p. 805-816, Feb 2006. ISSN 1742-464X. Disponível em: <<Go to |SI ://WOS:000234974600012 >.

MUNHOZ, D. C.; NETTO, L. E. S. Cytosolic thioredoxin peroxidase I and II are important defenses of yeast against organic hydroperoxide insult - Catalases and peroxiredoxins cooperate in the decomposition of $\mathrm{H} 2 \mathrm{O} 2$ by yeast. Journal of Biological Chemistry, v. 279, n. 34, p. 3521935227, Aug 2004. ISSN 0021-9258. Disponível em: <<Go to ISI>://WOS:000223303400012 >.

OGUSUCU, R. et al. Reactions of yeast thioredoxin peroxidases I and II with hydrogen peroxide and peroxynitrite: Rate constants by competitive kinetics. Free Radical Biology and Medicine, v. 42, n. 3, p. 326-334, Feb 2007. ISSN 0891-5849. Disponível em: < <Go to $|S|>: / /$ WOS:000243764500002 >.

PERKINS, A. et al. Peroxiredoxins: guardians against oxidative stress and modulators of peroxide signaling. Trends in Biochemical Sciences, v. 40, n. 8, p. 435-445, Aug 2015. ISSN 0968-0004. Disponível em:<<Go to ISI>://WOS:000358805800004 >. 
HORTA, B. B. et al. Structural and Biochemical Characterization of Peroxiredoxin $Q$ beta from Xylella fastidiosa CATALYTIC MECHANISM AND HIGH REACTIVITY. Journal of Biological Chemistry, v. 285, n. 21, p. 16051-16065, May 2010. ISSN 0021-9258. Disponível em: < <Go to $|S|>: / /$ WOS:000277715900043 >.

CARVALHO, L. A. C. et al. Urate hydroperoxide oxidizes human peroxiredoxin 1 and peroxiredoxin 2. Journal of Biological Chemistry, v. 292, n. 21, p. 8705-8715, May 2017. ISSN 0021-9258. Disponível em: <<Go to ISI>://WOS:000402153900017 >.

OHDATE, T.; KITA, K.; INOUE, Y. Kinetics and redox regulation of Gpx1, an atypical 2-Cys peroxiredoxin, in Saccharomyces cerevisiae. Fems Yeast Research, v. 10, n. 6, p. 787-790, Sep 2010. ISSN 1567-1356. Disponível em: <<Go to ISI>://WOS:000280997400015 >.

FLOHE, L. et al. GLUTATHIONE PEROXIDASE .5. KINETIC MECHANISM. Hoppe-Seylers Zeitschrift Fur Physiologische Chemie, v. 353, n. 6, p. 987-\&, 1972. ISSN 0018-4888. Disponível em: $<<$ Go to ISI $>$ ://WOS:A1972M792300036 >.

BRIVIBA, K. et al. Kinetic study of the reaction of glutathione peroxidase with peroxynitrite. Chemical Research in Toxicology, v. 11, n. 12, p. 1398-1401, Dec 1998. ISSN 0893-228X. Disponível em: <<Go to ISI : //WOS:000077737800002 >.

GUNZLER, W. A. et al. GLUTATHIONE PEROXIDASE .6. REACTION OF GLUTATHIONE PEROXIDASE WITH DIFFERENT HYDROPEROXIDES. Hoppe-Seylers Zeitschrift Fur Physiologische Chemie, v. 353, n. 6, p. 1001-\&, 1972. ISSN 0018-4888. Disponível em: < <Go to ISI>://WOS:A1972M792300037 >.

WINTERBOURN, C. C.; HAMPTON, M. B. Thiol chemistry and specificity in redox signaling. Free Radical Biology and Medicine, v. 45, n. 5, p. 549-561, Sep 2008. ISSN 0891-5849. Disponível em: $<<$ Go to $|S|>: / /$ WOS:000258995200001 >.

SHARAPOV, M. G.; RAVIN, V. K.; NOVOSELOV, V. I. Peroxiredoxins as multifunctional enzymes. Molecular Biology, v. 48, n. 4, p. 520-545, Jul 2014. ISSN 0026-8933. Disponível em: < <Go to $\mid$ SI $>$ ://WOS:000340679900006 >.

MASUMOTO, K. et al. Kinetic study of the reaction of ebselen with peroxynitrite. Febs Letters, v. 398, n. 2-3, p. 179-182, Dec 1996. ISSN 0014-5793. Disponível em: < <Go to $\mid$ SI $>$ ://WOS:A1996VX78100011 >.

SIES, H.; ARTEEL, G. E. Interaction of peroxynitrite with selenoproteins and glutathione peroxidase mimics. Free Radical Biology and Medicine, v. 28, n. 10, p. 1451-1455, May 2000. ISSN 0891-5849. Disponível em: <<Go to ISI>://WOS:000088732700002 >.

SINGH, R. J. et al. The peroxynitrite generator, SIN-1, becomes a nitric oxide donor in the presence of electron acceptors. Archives of Biochemistry and Biophysics, v. 361, n. 2, p. 331339, Jan 1999. ISSN 0003-9861. Disponível em: < <Go to ISI>://WOS:000078139900022 >. 
PACHER, P.; BECKMAN, J. S.; LIAUDET, L. Nitric oxide and peroxynitrite in health and disease. Physiological Reviews, v. 87, n. 1, p. 315-424, Jan 2007. ISSN 0031-9333. Disponível em: < <Go to $|S|>: / /$ WOS:000243594500008 >.

KARPLUS, P. A. A primer on peroxiredoxin biochemistry. Free Radical Biology and Medicine, v. 80 , p. 183-190, Mar 2015. ISSN 0891-5849. Disponível em: < <Go to |SI>://WOS:000351485000021 >.

COX, A. G.; WINTERBOURN, C. C.; HAMPTON, M. B. Mitochondrial peroxiredoxin involvement in antioxidant defence and redox signalling. Biochemical Journal, v. 425, p. 313-325, Jan 2010. ISSN 0264-6021. Disponível em: <<Go to ISI>://WOS:000273772300003 >.

LOW, F. M. et al. Peroxiredoxin 2 functions as a noncatalytic scavenger of low-level hydrogen peroxide in the erythrocyte. Blood, v. 109, n. 6, p. 2611-2617, Mar 2007. ISSN 0006-4971. Disponível em: <<Go to |S|>://WOS:000245004700054 >.

BENFEITAS, R. et al. Hydrogen peroxide metabolism and sensing in human erythrocytes: A validated kinetic model and reappraisal of the role of peroxiredoxin II. Free Radical Biology and Medicine, v. 74, p. 35-49, Sep 2014. ISSN 0891-5849. Disponível em: < <Go to $|S|>: / /$ WOS:000341274100004 >.

ZIELONKA, J. et al. Boronate Probes as Diagnostic Tools for Real Time Monitoring of Peroxynitrite and Hydroperoxides. Chem Res Toxicol, Jun 2012. ISSN 1520-5010. Disponível em: < http://www.ncbi.nlm.nih.gov/pubmed/22731669 $>$.

SIKORA, A. et al. Direct oxidation of boronates by peroxynitrite: Mechanism and implications in fluorescence imaging of peroxynitrite. Free Radical Biology and Medicine, v. 47, n. 10, p. 1401-1407, Nov 15 2009. ISSN 0891-5849. Disponível em: < <Go to |S|>://WOS:000271934400010 >.

YU, F. et al. A fluorescent probe directly detect peroxynitrite based on boronate oxidation and its applications for fluorescence imaging in living cells. Analyst, v. 137, n. 16, p. 3740-3749, 2012 2012. ISSN 0003-2654. Disponível em: <<Go to ISI>://WOS:000306483000021 >.

ZIELONKA, J. et al. Global profiling of reactive oxygen and nitrogen species in biological systems: high-throughput real-time analyses. J Biol Chem, v. 287, n. 5, p. 2984-95, Jan 2012. ISSN 1083-351X. Disponível em: < http://www.ncbi.nlm.nih.gov/pubmed/22139901 >.

Boronate Probes as Diagnostic Tools for Real Time Monitoring of Peroxynitrite and Hydroperoxides. Chemical Research in Toxicology, v. 25, n. 9, p. 1793-1799, Sep 2012. ISSN 0893-228X. Disponível em: <<Go to |SI>://WOS:000308777100001 >.

KEITH, W. G.; POWELL, R. E. KINETICS OF DECOMPOSITION OF PEROXYNITROUS ACID. Journal of the Chemical Society a -Inorganic Physical Theoretical, n. 1, p. 90-\&, 1969. Disponível em: $<<$ Go to ISI ://WOS:A1969C390200020 >. 
FOMENKO, D. E. et al. Thiol peroxidases mediate specific genome-wide regulation of gene expression in response to hydrogen peroxide. Proceedings of the National Academy of Sciences of the United States of America, v. 108, n. 7, p. 2729-2734, Feb 2011. ISSN 00278424. Disponível em: <<Go to ISI $>/ / / W O S: 000287377000024>$.

WINZELER, E. A. et al. Functional characterization of the S-cerevisiae genome by gene deletion and parallel analysis. Science, v. 285, n. 5429, p. 901-906, Aug 1999. ISSN 0036-8075. Disponível em: <<Go to IS|>://WOS:000081860900053 >.

KAYA, A. et al. Thiol Peroxidase Deficiency Leads to Increased Mutational Load and Decreased Fitness in Saccharomyces cerevisiae. Genetics, v. 198, n. 3, p. 905-+, Nov 2014. ISSN 00166731. Disponível em: <<Go to ISI>://WOS:000344373300009 >.

AUSUBEL, F. M. E. A. Short protocols in molecular biology: a compendium of methods from current protocols in molecular biology. 5th. 2002 $\mathrm{N}$-center dot donors. Nitric Oxide-Biology and Chemistry, v. 21, n. 1, p. 69-75, Aug 2009. ISSN 1089-8603. Disponível em:<<Go to |S|>://WOS:000268430300009 >.

HASSAN, H. M. EXACERBATION OF SUPEROXIDE RADICAL FORMATION BY PARAQUAT. Methods in Enzymology, v. 105, p. 523-532, 1984. ISSN 0076-6879. Disponível em: < <Go to ISI>://WOS:A1984AAB8100070 >.

HOGG, N. et al. PRODUCTION OF HYDROXYL RADICALS FROM THE SIMULTANEOUS GENERATION OF SUPEROXIDE AND NITRIC-OXIDE. Biochemical Journal, v. 281, p. 419-424, Jan 1992. ISSN 0264-6021. Disponível em: <<Go to ISI>://WOS:A1992HB61500020 >. Redox Metabolism in Respiring Cells. Cell Metabolism, v. 14, n. 3, p. 415-427, Sep 2011. ISSN 1550-4131. Disponível em: <<Go to ISI>://WOS:000295660200015 >.

ESPINOSA-DIEZ, C. et al. Antioxidant responses and cellular adjustments to oxidative stress. Redox Biology, v. 6, p. 183-197, Dec 2015. ISSN 2213-2317. Disponível em: < <Go to |SI>://WOS:000367338700018 >. respiration via key mitochondrial proteins. Proceedings of the National Academy of Sciences of the United States of America, v. 112, n. 34, p. 10685-10690, Aug 2015. ISSN 0027-8424. Disponível em: <<Go to ISI ://WOS:000360005600051 >. mediated by the Ccp1 sensor protein. Free Radical Biology and Medicine, v. 85, p. 138-147, Aug 2015. ISSN 0891-5849. Disponível em: <<Go to ISI>://WOS:000358198000013 >. 
SCHNEPER, L.; DUVEL, K.; BROACH, J. R. Sense and sensibility: nutritional response and signal integration in yeast. Current Opinion in Microbiology, v. 7, n. 6, p. 624-630, Dec 2004. ISSN 1369-5274. Disponível em: <<Go to ISI>://WOS:000225782400010 >.

JAMIESON, D. J. Oxidative stress responses of the yeast Saccharomyces cerevisiae. Yeast, v. 14, n. 16, p. 1511-1527, Dec 1998. ISSN 0749-503X. Disponível em: < <Go to |SI>://WOS:000077792400005 >. 207, Apr 1999. ISSN 1369-5274. Disponível em: <<Go to ISI>://WOS:000079526800015 >. HYDROGEN-PEROXIDE AND MENADIONE. Journal of Bacteriology, v. 174, n. 20, p. 6678-6681, Oct 1992. ISSN 0021-9193. Disponível em: <<Go to ISI>://WOS:A1992JT53000044 >. 760, 1983. ISSN 0066-4154. Disponível em: <<Go to ISI>://WOS:A1983QY55400024 >.

MONTEIRO, G. et al. Glutathione and thioredoxin peroxidases mediate susceptibility of yeast mitochondria to Ca2+-induced damage. Archives of Biochemistry and Biophysics, v. 425, n. 1, p. 14-24, May 2004. ISSN 0003-9861. Disponível em: < <Go to ISI>://WOS:000221003100002 $>$. thiol peroxidase II. Journal of Biological Chemistry, v. 277, n. 14, p. 12109-12117, Apr 2002. ISSN 0021-9258. Disponível em: <<Go to ISI>://WOS:000174846400067 >. protein-cysteine residues: from quantification to kinetics. Free Radical Biology and Medicine, v. 50, n. 9, p. 1032-1038, May 2011. ISSN 0891-5849. Disponível em: < <Go to $\mid$ ISI>://WOS:000289664500003 >. 
